Revue des patrimoines

\title{
Les colonies de vacances en France, quelle architecture?
}

\section{Bernard Toulier}

\section{(2) OpenEdition \\ Journals}

Édition électronique

URL : http://journals.openedition.org/insitu/4088

DOI : $10.4000 /$ insitu.4088

ISSN : 1630-7305

Éditeur

Ministère de la culture

\section{Référence électronique}

Bernard Toulier, « Les colonies de vacances en France, quelle architecture ? », In Situ [En ligne],

9 | 2008, mis en ligne le 05 septembre 2013, consulté le 19 avril 2019. URL : http://

journals.openedition.org/insitu/4088; DOI : 10.4000/insitu.4088

Ce document a été généré automatiquement le 19 avril 2019.

\section{cc) $(1) \odot$}

In Situ Revues des patrimoines est mis à disposition selon les termes de la licence Creative Commons Attribution - Pas d'Utilisation Commerciale - Pas de Modification 4.0 International. 


\title{
Les colonies de vacances en France, quelle architecture?
}

\author{
Bernard Toulier
}

1 Au début du XXe siècle, le séjour en colonie de vacances est reconnu pour son action d'hygiène préventive et ses vertus pédagogiques pour les enfants ${ }^{1}$. Elle est la « première ligne de défense contre la tuberculose ", "véritable croisade de paix et de rédemption ", « œuvre patriotique et humanitaire ... de salut public et d'intérêt général », « remède au dépérissement de la race», "meilleure arme de guerre contre l'accroissement du prolétariat dégénéré $»^{2}$. Éloigné des miasmes de la ville industrielle, l'enfant découvre les bienfaits de l'air, de l'eau et du soleil, par un séjour de trois à quatre semaines sur le littoral, à la campagne ou à la montagne, encadré par les nouveaux espaces socialisés de la colonie. L'objectif est « d'éloigner pour un temps les jeunes écoliers de l'air peu sain de nos agglomérations et de développer chez eux le goût de la nature par le spectacle changeant que celle-ci offre chaque jour à leurs yeux émerveillés » (Municipalité de Montreuil-sur-Seine, 1919) (fig. ${ }^{\circ} \mathbf{1}$ ). 


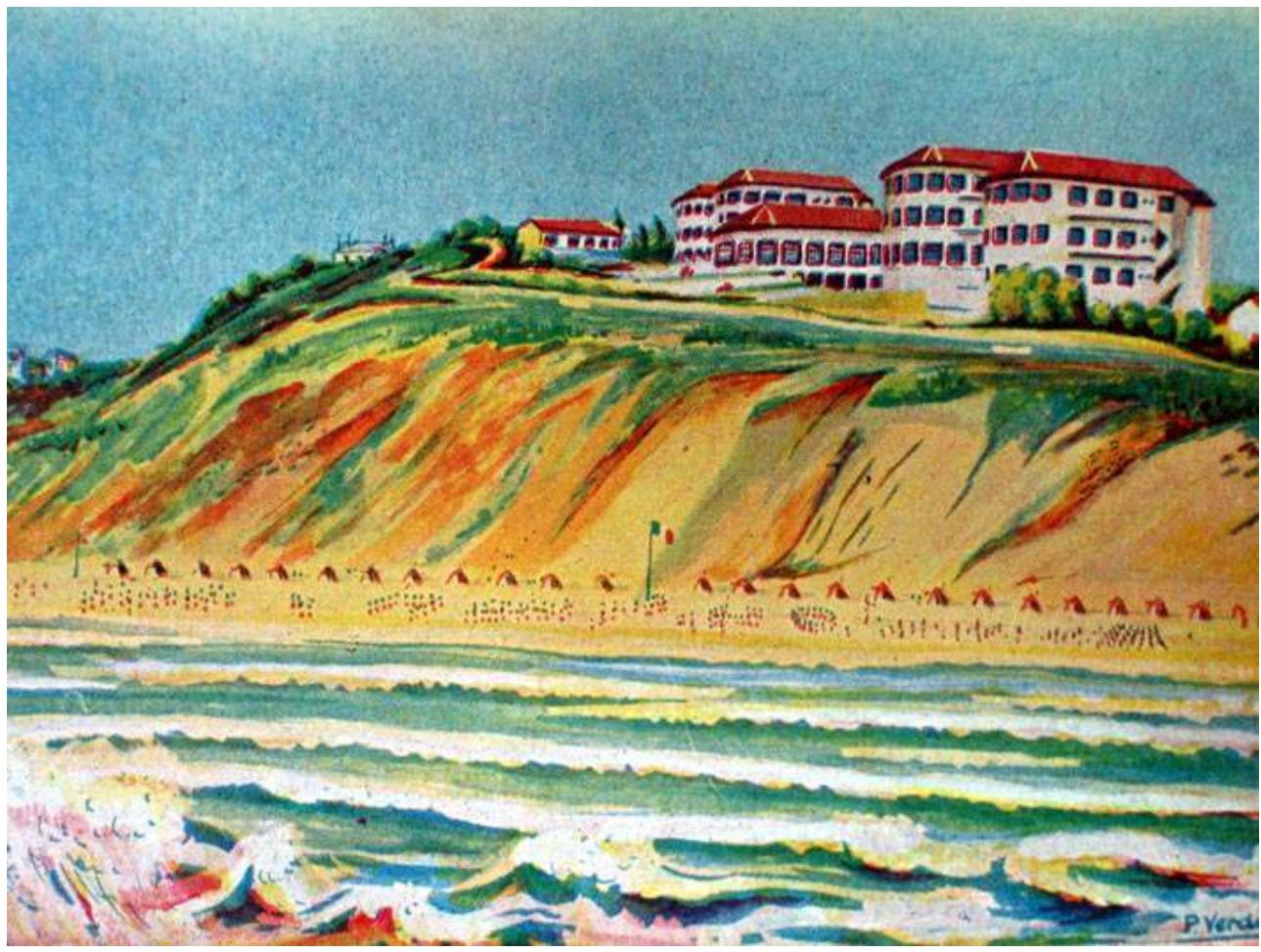

Biarritz (Pyrénées-Atlantiques). Côte des Basques, colonie de vacances du département de la Dordogne

Carte postale, coll. B. Toulier (c) B. Toulier

2 Si l'histoire institutionnelle des colonies de vacances a fait l'objet de quelques synthèses magistrales ${ }^{3}$, celle des bâtiments chargés d'accueillir les colons est loin de susciter un pareil engouement en France ${ }^{4}$. Quelles sont les caractéristiques de ces «maisons» de communautés enfantines, hors la ville et proches de la nature qui abritent ces activités hygiéniques et pédagogiques? Le caractère éphémère de ces activités éducatives, liées aux collectivités et aux associations à caractère pédagogique ou religieux, aux syndicats et aux entreprises, et le faible investissement de l'État ont-ils laissé émerger quelques architectures, incité les maîtres d'ouvrage, promoteurs et animateurs à réemployer des édifices, plutôt qu'à construire des bâtiments plus adaptés à ce nouveau programme de loisirs, sanitaire puis éducatif? Quel est l'impact des théories pédagogiques sur les normes et règlements de construction ou la mise en conformité pour les autorisations d'ouverture délivrées par l'administration? L'étude des sources et des bâtiments nous renseigne-t-elle sur les pratiques et les modes de vie de ces espaces de villégiature temporaire à l'usage des enfants?

3 Il n'existe pas d'inventaire qualitatif de ces bâtiments 5 . Les premières statistiques nationales sont lancées par le ministère de la Santé Publique en $1925^{6}$ et ce n'est qu'en 1937 que la déclaration préalable pour l'ouverture d'un établissement devient obligatoire. Ces déclarations d'ouverture ne sont enregistrées annuellement que dans les années 1960. À partir de 1973, les recensements des centres départementaux du ministère de la Jeunesse et des Sports amalgament les colonies de vacances avec les «centres de vacances ", qui offrent une définition «élargie " 7 . En 1994, 10429 " centres de vacances " sont « recensés ». Encore faut-il bien distinguer l'activité de loisir du site d'implantation, 
qui lui-même peut accueillir de nombreux "séjours en centre de vacances". Les statistiques de fréquentation des colonies de vacances nous donnent quelques évaluations approximatives, qui peuvent être divergentes selon les sources utilisées, selon les comptages par «effectifs» ou par «nombre de journées de vacances»: de quelques centaines d'enfants dans les années 1880, le nombre des colons passe à plus de 20000 en 1905, à près de 100000 en 1913 pour quadrupler en 1936. De 1936 à 1948, ce chiffre double pour atteindre 880000 colons. Le pic des fréquentations semble atteint vers 1964 pour culminer à 978000 colons (hors camps de vacances ${ }^{8}$, séjours de petites vacances et séjours à l'étranger) et diminuer à partir des années 1970, pour arriver, en 2002, à un effectif d'environ 850000 enfants hébergés dans les bâtiments en dur des " centres de vacances » et 250000 abrités dans les camps fixes ou itinérants. Enfin, si à la veille de la Première Guerre mondiale, le nombre d'édifices abritant des colonies de vacances pouvait atteindre le chiffre de 500, il a été multiplié par vingt moins d'un siècle plus tard.

\section{7-1914 : une œuvre d'hygiène préventive}

\section{De la colonie pénitentiaire à la colonie pour écoliers en vacances}

L'histoire des colonies de vacances commence traditionnellement avec le pasteur suisse, Wilhelm Bion. En 1876, pour restaurer la santé des enfants pauvres de son quartier de Zurich, il les envoie à la campagne, et dirige lui-même la « colonie de vacances ", secondé par une dizaine d'instituteurs et d'institutrices. Ces Ferienkolonien (colonies d'écoliers en vacances) reçoivent un accueil favorable en Suisse et l'idée essaime dans toute l'Europe : Allemagne, Angleterre, Danemark en premier lieu, aux États-Unis et peu de temps après, en France.

5 Cette origine mythique de la " colonie » pour enfants " en vacances »", revendiquée par de nombreux contemporains et reprise généralement par les historiens, cache sans doute d'autres racines ou origines. La colonie est un lieu de transplantation, volontaire ou forcée, de personnes, à titre temporaire (pour le temps des vacances par exemple) ou définitif, hors de leur « patrie » d'origine.

La colonie pénitentiaire pour enfants avait été instituée avant la colonie de "vacances » pour pallier les effets nocifs de la révolution industrielle urbaine sur leur santé et leur moralité. La colonie pour enfants, comme l'asile, est un moyen de lutte contre la délinquance infantile. La colonie pénitentiaire agricole ${ }^{10}$ est un "établissement de bienfaisance destiné à recevoir des orphelins pauvres, des enfants coupables acquittés pour avoir agi sans discernement, que l'on emploie au défrichement des terres incultes $»^{11}$ - Ce type de colonie s'établit en réaction contre les progrès de l'industrie, jugés moralement néfastes en prônant un retour à la terre susceptible de redresser les jeunes détenus. De 1838 à 1850, une cinquantaine de colonies agricoles sont fondées en France et en Algérie $^{12}$. La loi du 5 août 1850 sur l'éducation et le patronage des jeunes détenus vient consacrer la théorie éducative de Charles Lucas et l'expérience des colonies agricoles. Les garçons mineurs détenus sont conduits dans une colonie pénitentiaire pour y être élevés en commun, sous une discipline sévère et effectuer des travaux agricoles. Des colonies maritimes et industrielles ${ }^{13}$ sont ensuite mises en place ainsi que des établissements pénitenciers pour les filles mineures, jusqu’à présent « rééduquées » dans des colonies pénitentiaires privées dirigées par de grandes congrégations religieuses (Congrégation du Bon-Pasteur, Notre-Dame de Charité du Refuge, Sœurs des prisons). 
7 Au titre des établissements de bienfaisance, on trouve aussi au milieu du XIXe siècle le mot de «colonie» employé comme synonyme d'«asile» pour enfants, associé à un programme d'hospice ${ }^{14}$. Le glissement du terme vers un caractère curatif est donc naturel. Il faudrait réviser cette histoire des origines et prendre en compte les premières expérimentations de colonies pour enfants. Les sociétés de charité protestantes sont à l'origine des premiers établissements pour enfants valétudinaires en bord de mer. En 1847, Coraly Hinsch fonde à Sète une maison destinée aux protestants pauvres de l'Hérault pour la pratique des bains de mer. Après une première installation dans un des entrepôts du port, les pensionnaires s'installent pour la saison estivale dans une villa aménagée, dénommée bientôt la "maison Krüger ", du nom de son propriétaire. Cette « maison Krüger » serait-elle une des premières colonies du bord de mer ${ }^{15}$ ?

\section{Un programme double : l'hôpital marin/sanatorium}

8 La colonie de vacances est associée à l'hôpital marin : sanatorium destiné aux enfants scrofuleux, anémiques et rachitiques ouvert toute l'année et fonctionnant comme colonie de vacances durant la saison d'été. Le sanatorium du Moulleau dans la baie d'Arcachon en Gironde (ouvert dès 1882), celui de Pen-Bron face au port du Croisic en Loire-Atlantique (1887), de Cap-Breton dans les Landes (1889) fonctionnent selon ce modèle. En 1888, le comité protestant genevois convoie un premier contingent d'enfants valétudinaires au Lazaret de Sète. L'année suivante, ils se rendent à l'asile Dollfus à Cannes, installé depuis 1886 dans l'ancien hôtel de lord Brougham qui sera bientôt acquis par le comité genevois. L'établissement, ouvert d'octobre à juin suit le rythme saisonnier des stations d'hiver de la Riviera méditerranéenne, contrairement à ceux situés sur la façade atlantique, ouverts durant la saison estivale. De 1898 à 1903, la Caisse des écoles de Saint-Mandé dans la région parisienne envoie les enfants au sanatorium Parmentier, dans une station balnéaire de la Manche à Berck-sur-Mer dans le Pas-de-Calais ; à partir de 1904, seules les filles sont hébergées au sanatorium Parmentier ; les garçons sont accueillis au sanatorium Bouville et, de 1911 à 1913, ils sont envoyés au sanatorium de Zuydcoote dans le Nord. Il sera longtemps difficile de distinguer la colonie de vacances temporaire de l'établissement permanent à caractère hospitalier (préventorium) ou pédagogique (école de plein air $)^{16}$.

9 Quelle que soit l'origine connue ou revendiquée, l'institution des colonies de vacances n'est reconnue que dans les années 1880 avec le $4^{\mathrm{e}}$ Congrès international d'hygiène et de démographie de Genève tenu en $1882^{17}$.. En 1888, le premier Congrès des colonies de vacances de Zurich, marque la reconnaissance officielle des colonies de vacances et amorce le début de leur autonomie face au monde médical.

On remarquera que ces « colonies de vacances " se mettent en place en France en même temps que les grandes lois scolaires de la Troisième République. La création de la Fédération nationale des colonies de vacances et cuvres de grand air, et le premier Congrès national des colonies de vacances de Bordeaux de 1906 mettent un terme à cette première phase de l'histoire des colonies de vacances, et particulièrement de celles associées aux hôpitaux marins ${ }^{18}$. Les colonies de vacances, centrées sur l'hygiène préventive et la fonction pédagogique deviennent « indépendantes » et peu à peu autonomes par rapport aux établissements « curatifs » spécialisés. L'objet de la colonie est, selon l'inspecteur des écoles Edmond Cottinet, «d'offrir une cure d'air aidée par l'exercice naturel en pleine campagne, par la propreté, la bonne nourriture, la gaieté ». La première génération des 
établissements climatologiques mixtes, associant le curatif et le préventif, l'hôpital et la colonie de vacances est définitivement éteinte avec l'avènement des préventoriums à partir des années 1920, aboutissement de la spécialisation des installations sanitaires.

\section{Les colonies religieuses ou privées}

11 Les premières colonies sont organisées par des particuliers (médecins, pasteurs, prêtres, instituteurs), des institutions de bienfaisance, des comités ou des associations privées, municipales ou scolaires créés à cet effet. En France, le pasteur Lorriaux, de Clichy en Seine-Saint-Denis, organise dès 1881 une colonie de vacances sous le nom de l'Oeuvre des Trois semaines ${ }^{19}$. Les réseaux confessionnels, en particulier protestants, et les réseaux philanthropiques se mobilisent pour récolter des fonds. L'Oeuvre de la Chaussée du Maine, également d'obédience protestante, fondée en 1871 par Mme Élise de Préssenssé, étend ses activités aux colonies de vacances avec l'Oeuvre des colonies de vacances ${ }^{20}$. En 1893, le pasteur Louis Comte suscite la création de l'Oeuvre des enfants à la montagne au profit des enfants de la région stéphanoise puis de la région lyonnaise qu'il envoie dans des villages d'altitude du plateau du Vivarais. À partir de 1904, le pasteur Comte envoie les colons en bord de mer, au château du Grau-du-Roi (Gard), étonnant bâtiment de style italo-flamand construit par l'architecte Henri Leehnardt pour lui-même quelques années auparavant ${ }^{21}$ (fig. $\mathbf{n}^{\circ}$ 2). La confession juive développe elle aussi son réseau. En 1899, l'Oeuvre israélite des séjours à la campagne réutilise la ferme de La Poste, aux Bézards dans le Loiret, qui avait été utilisée précédemment pour le même usage par l'ÆEuvre de la Chaussée du Maine.

Figure 2

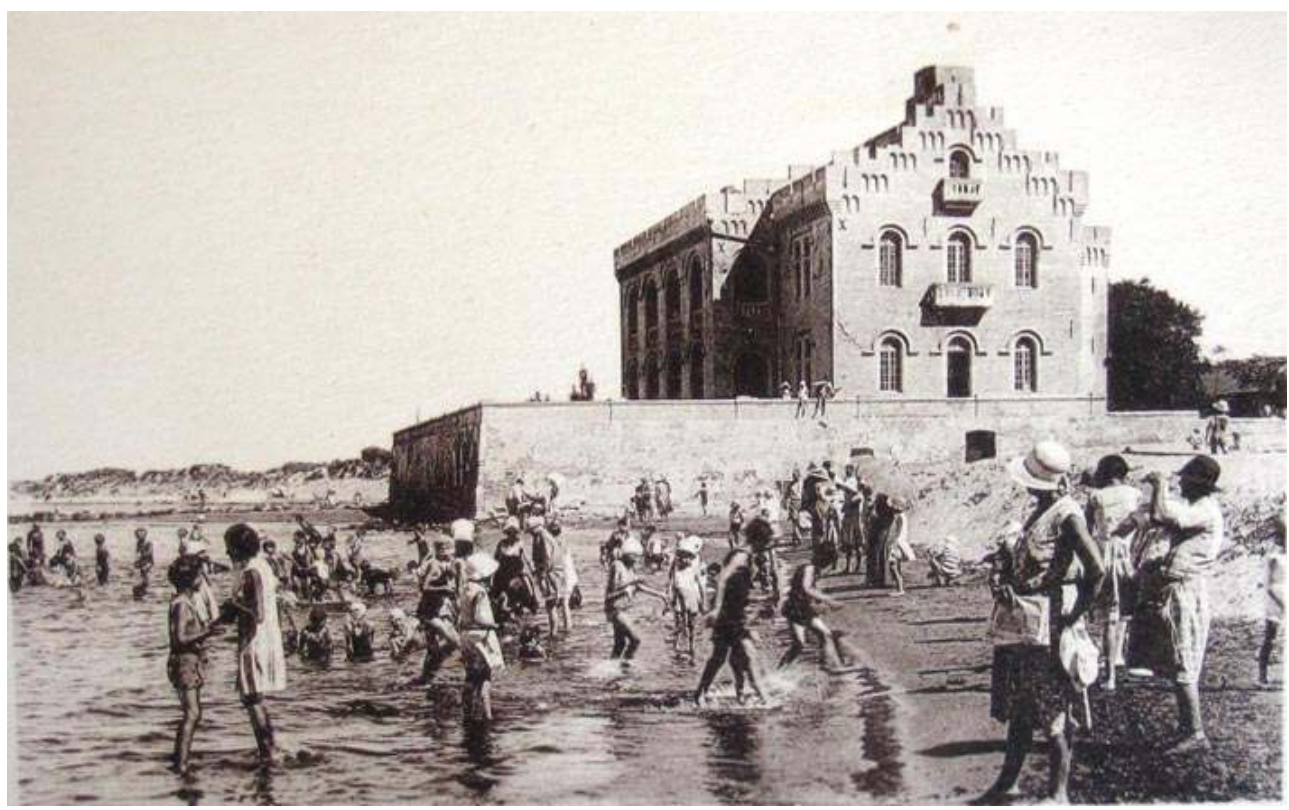

Le Grau-du-Roi (Gard). Établissement protestant de colonie de vacances Carte postale, coll. B. Toulier (c) B. Toulier

Les colonies catholiques apparaissent aussi dans les années 1890. La colonie se situe dans le prolongement $\mathrm{du}$ patronage paroissial. À la différence des protestants, la préoccupation n'est pas tant de fortifier le corps et prendre le bon air mais plus d'éduquer le corps et l'esprit dans un environnement sain, comme un antidote à 
l'enseignement laïc. En 1897, l'abbé Pitray, responsable du patronage de Saint-Sulpice à Paris, crée dans un ancien chalet la fameuse colonie Édouard, près d'Arcachon en Gironde, pour les enfants faibles et maladifs. La conférence de Saint-Vincent-de-Paul organise de nombreuses colonies à la mer ou à la campagne dans des bâtiments prêtés par des institutions religieuses ou le clergé local.

En 1905, les trois quarts des colonies recensées sont d'origine privée. À Paris et dans les environs, on compte 42 œuvres responsables de 68 colonies dont bénéficient 7250 enfants. Les œuvres parisiennes qui organisent plus de cinq colonies sont, outre l'oeuvre des Trois semaines (7) et l'Oeuvre des colonies de vacances (6), l'Oeuvre fraternelle des Enfants de France (8), l'Oeuvre mutuelle des colonies de vacances (8), et les Oeuvres des comités de patronage des paroisses (12). En 1907, l'Union parisienne des colonies de vacances fédère 49 « œuvres éducatives » organisatrices de colonies ${ }^{22}$. En province, les colonies de vacances privées les plus nombreuses se situent à Lyon dans le Rhône (12) et à Saint-Étienne dans la Loire ${ }^{23}$ (13).

\section{Les colonies scolaires}

Le milieu scolaire est lui aussi sollicité : les Caisses des écoles parisiennes sont en première ligne ${ }^{24}$. Edmond Cottinet, administrateur de la Caisse des écoles du IXe arrondissement de Paris, fonde en 1883 la première colonie scolaire à Luxeuil en HauteMarne $^{25}$. Le choix du lieu est déterminé par l'altitude, supérieure à celle de Paris, et par la distance, raisonnable, de la capitale. Les colonies scolaires logent dans les écoles ou les pensionnats existants ou construisent des bâtiments spécifiques. Ces colonies municipales sont les premières à utiliser des structures à grande capacité d'accueil. En 1894, un vaste bâtiment de deux étages abrite les 111 enfants de la colonie du XIe arrondissement de Paris à Mandres-sur-Vair dans les Vosges, tandis que 150 enfants peuvent être reçus dans la colonie scolaire lyonnaise du Serverin dans l'Isère. Le conseil municipal de Paris apporte un large appui financier à l'établissement de ces colonies. En 1889, il vote en leur faveur une subvention de $45000 \mathrm{~F}$, portée à $200000 \mathrm{~F}$ en 1902 et à $223000 \mathrm{~F}$ en 1910. Grâce à ces fonds, la Caisse des écoles du Xe arrondissement fonde en 1898 une colonie pour 40 enfants à Chatillon-sur-Seine en Côte d'Or.

Durant les vingt-cinq premières années d'existence des colonies, le nombre moyen de colons par site serait estimé à 225 colons par an, soit trois séjours pour 70 enfants environ ou deux de 150 enfants $^{26}$. En 1905, les 32 colonies des écoles municipales représentent $43 \%$ des colons parisiens envoyés « aux champs, à la mer ou à la montagne ». À cette date, sur l'ensemble de la France, le mouvement des colonies scolaires ou municipales représente seulement $27 \%$ du nombre des colonies recensées pour $40 \%$ des départs de colons $^{27}$. Les colonies municipales drainent en moyenne un nombre d'enfants plus important que les colonies privées ou fondées par des œuvres. Ces colonies municipales ne touchent que les grandes villes comme Amiens, Roanne, Roubaix, Bordeaux (8), Marseille (5), Dijon, Lille (5) et Lyon (2).

À partir de 1893, des fonds du Conseil général du département de la Seine sont affectés aux colonies de vacances ${ }^{28}$. Dans les années 1890 , les pouvoirs publics s'investissent davantage dans la lutte contre la tuberculose ; la colonie de vacances est considérée alors comme un traitement préventif complémentaire. Des établissements hospitaliers comme Pen-Bron en Loire-Atlantique, Cap-Breton dans les Landes, Saint-Pol-sur-Mer dans le Nord et ensuite Arcachon en Gironde, sont ouverts toute l'année et accueillent durant 
l'été une colonie de vacances. À Pen-Bron, la colonie est installée à l'écart dans l'ancienne sardinerie qui avait été utilisée comme premier bâtiment du sanatorium. Jusqu'en 1914, la charité publique reste la principale ressource financière. À l'exception des premières colonies organisées par les municipalités, la participation publique reste faible mais la contribution des familles est souvent nulle. Pour les colonies confessionnelles, le recours au financement privé est quasi exclusif.

\section{Le choix des lieux de séjour}

Les conclusions des premières expériences de colonies de vacances portant sur le choix du lieu de séjour sont données par le docteur Varrentrapp, conseiller sanitaire à Francfort en 1882. «Il ne faut pas qu'il soit trop près de la ville, car les visites des parents seraient trop fréquentes, ni trop loin à cause des frais de transport. L'endroit ne doit pas être visité d'ordinaire ou habité par les touristes et les étrangers et autant que possible il doit être à proximité des forêts. Il doit offrir de la sécurité au point de vue des accidents et une bonne nourriture, en particulier de la viande fraîche et du lait pur. La maison d'habitation sera dans une position salubre avec des chambres claires, grandes et gaies. On veillera à ce que les chambres à coucher ou dortoirs aient en minimum une capacité de 10 mètres cubes par enfant. Il est bon que le maître ait une chambre indépendante d'où il puisse surveiller les enfants pendant la nuit et il est nécessaire de s'assurer d'une grande salle pour réunir les enfants en cas de mauvais temps... $»^{29}$.

18 Les ecclésiastiques, pasteurs ou prêtres au sacerdoce itinérant, exercent une grande influence sur le choix du lieu de séjour. Le pasteur suisse Bion choisit en 1876 le village rural d'Appenzell où il avait exercé avant d'être nommé dans un quartier pauvre de Zurich. En 1912, l'abbé Galpin, prêtre d'origine savoyarde envoyé dans la banlieue ouvrière parisienne d'Ivry, choisit naturellement son pays natal pour envoyer les enfants à « La Belle-Étoile ».

Une des premières cartes de répartition des colonies de vacances est établie par les docteurs L. Landouzy et G. Sersiron pour le Congrès de la tuberculose de 1905. Cette première carte peut être comparée à celle issue des travaux plus contemporains de ReyHerme (1954) sur les colonies recensées jusque 1906. Les petits parisiens partent d'abord à peu de distance de la capitale, à la campagne dans le Loiret ou ensuite sur les bords de la Manche à partir de 1889, le long de la côte Normande et de la côte d'Opale. Sur la côte Atlantique, les bordelais ne se déplacent pas au-delà d'Arcachon et de Royan et s'interdisent le sud de la France. Les lieux choisis, à proximité d'une gare, recoupent en partie ceux de la villégiature périurbaine et surtout des bords de mer, en s'adaptant au flux migratoire facilité par les chemins de fer et les offres de billets de groupe à prix réduits. Les colonies provinciales sont plus dispersées sur le territoire, avec un regroupement dans le Lyonnais à proximité de Saint-Étienne et de Lyon autour de l'axe rhodanien, entre Mâcon et Montélimar.

\section{Types d'hébergements et de bâtiments}

Sur place, la colonie utilise diverses formules d'hébergement : le placement familial ou l'hébergement collectif dans des bâtiments réutilisés ou vacants, ou encore la construction neuve. 
21 Les premières années, le placement familial est la norme. En 1900, sur 52 colonies de vacances répertoriées, on distingue 19 colonies de vacances et 32 « colonies rurales des écoles » qui réunissent 8216 enfants $^{30}$. À Reims, les écoliers désignés comme les plus chétifs par les instituteurs sont placés par la Caisse des écoles de la ville dans une de ces colonies rurales. Ils sont répartis individuellement ou par deux, selon leur sexe, chez des «nourriciers", paysans des villages environnants, ayant souvent des enfants d'âge semblable ${ }^{31}$. Ce système, largement utilisé par les œuvres privées perdure entre les deux guerres. Pour le Val-de-Marne, il ne devient minoritaire qu'à partir des années 1930 mais sera encore en usage jusqu'en $1939^{32}$.

Les premières colonies en placement collectif ont lieu dans des maisons prêtées par des particuliers ou des "pensions libres ", vacantes durant l'été. Les réseaux confessionnels possèdent de nombreux locaux religieux ou scolaires, susceptibles d'héberger des colonies. Ils sont aussi en liaison avec de généreux donateurs susceptibles de mettre leurs propriétés gracieusement à disposition. Le placement en "demi-colonies » plus tard dénommé "centre aéré ", est un placement à la journée sans hébergement, à la périphérie des grandes villes, dans des espaces verts et aérés.

\section{La transformation d'anciens bâtiments en colonies}

En fonction de l'évolution de la demande et des besoins, les associations louent, à titre onéreux ou gracieux, ou achètent des édifices proches de la mer, de la montagne, ou à la campagne et les transforment pour l'accueil temporaire des enfants. Plusieurs colonies de vacances des paroisses parisiennes s'installent dès le début du $\mathrm{XX}^{\mathrm{e}}$ siècle dans l'Ile de Noirmoutier en Vendée ${ }^{33}$ : avant 1913, les colons de la paroisse Saint-Jean de Montmartre sont accueillis au Bois de La Chaise dans la Villa Jeanne-d'Arc, propriété de leur curé, le chanoine Sobeaux. Saint-Pierre-de-Chaillot s'établit en 1912 dans une maison de la Grande-Rue et, en 1919, la colonie du Vieux-Crabe de la paroisse Saint-François-de-Salles est hébergée dans deux maisons de la ville de Noirmoutier. Le milieu balnéaire est très prisé des organisateurs, particulièrement les villas normandes du bord de mer, proches de Paris. À Tracy-sur-Mer dans le Calvados, la villa Les Bergeries, édifiée durant le dernier quart du XIX ${ }^{\mathrm{e}}$ siècle dans le quartier de La Brèche, change d'affectation au début du XX ${ }^{\mathrm{e}}$ siècle pour devenir une colonie dénommée « Villa Saint-Joseph $»^{34}$.

Des exploitations agricoles peuvent se recycler en bâtiments de colonies de vacances. La ferme du château de Syam dans le Jura, édifiée vers 1822-1830 pour l'industriel métallurgiste Emmanuel Jobez par l'architecte Champonnois l'aîné, est transformée en 1901 par l'architecte Schacre pour abriter une colonie. Malgré ces remaniements, la ferme, de plan en $\mathrm{U}$, conserve toujours son style néo-palladien contemporain de celui du château ${ }^{35}$. D’anciens sanatoriums sont aussi réaffectés comme colonies : en 1894, l'ancien sanatorium de Ver-sur-Mer dans le Calvados est racheté par l'Euvre des Trois semaines.

\section{Les premières constructions : de la villa de villégiature au pavillon hospitalier}

Le nombre de constructions neuves créées ex-nihilo dès les origines jusqu'à 1906 peut être évalué, d'après Rey-Herme à moins d'une cinquantaine. Le programme architectural n'est pas défini et les maîtres d'œuvre puisent leur inspiration dans la villa de villégiature ou le pavillon hospitalier. 

pour 45 à 50 jeunes filles. Cette colonie de vacances est considérée comme une «maison modèle ». En 1896, l'architecte de l'assistance publique Paul-Louis Renaud édifie dans le quartier dit de la Réserve-Péreire, à Saint-Germain-en-Laye dans les Yvelines, une "Villa Scolaire » à usage de colonie de vacances/sanatorium pour la caisse des écoles du VIIe arrondissement de Paris. Saint-Germain-en-Laye, réputé comme la « Montagne du BonAir », est une station climatique et un lieu de villégiature apprécié, à proximité de Paris. Dès le début du XIX ${ }^{e}$ siècle, on y envoie les petits parisiens en nourrice. Ouverte à proximité de la forêt, la "Villa Scolaire» permet aux enfants de santé déficiente, orphelins ou appartenant à des familles nombreuses, de faire une cure de bon air durant trois semaines, accompagnés de leurs enseignants. D'une capacité d'une vingtaine de lits, elle est construite à l'imitation des nombreux pavillons et villas de villégiature, avec des moellons de meulière apparents et des encadrements en brique. Comme les villas, elle porte fièrement sur sa façade un décor en céramique, avec les armoiries de la ville de Paris surmontées de la date de construction 1896 et de l'appellation « VILLA SCOLAIRE DU VIIe ARRONDISSEMENT $»^{36}$.

Figure 3

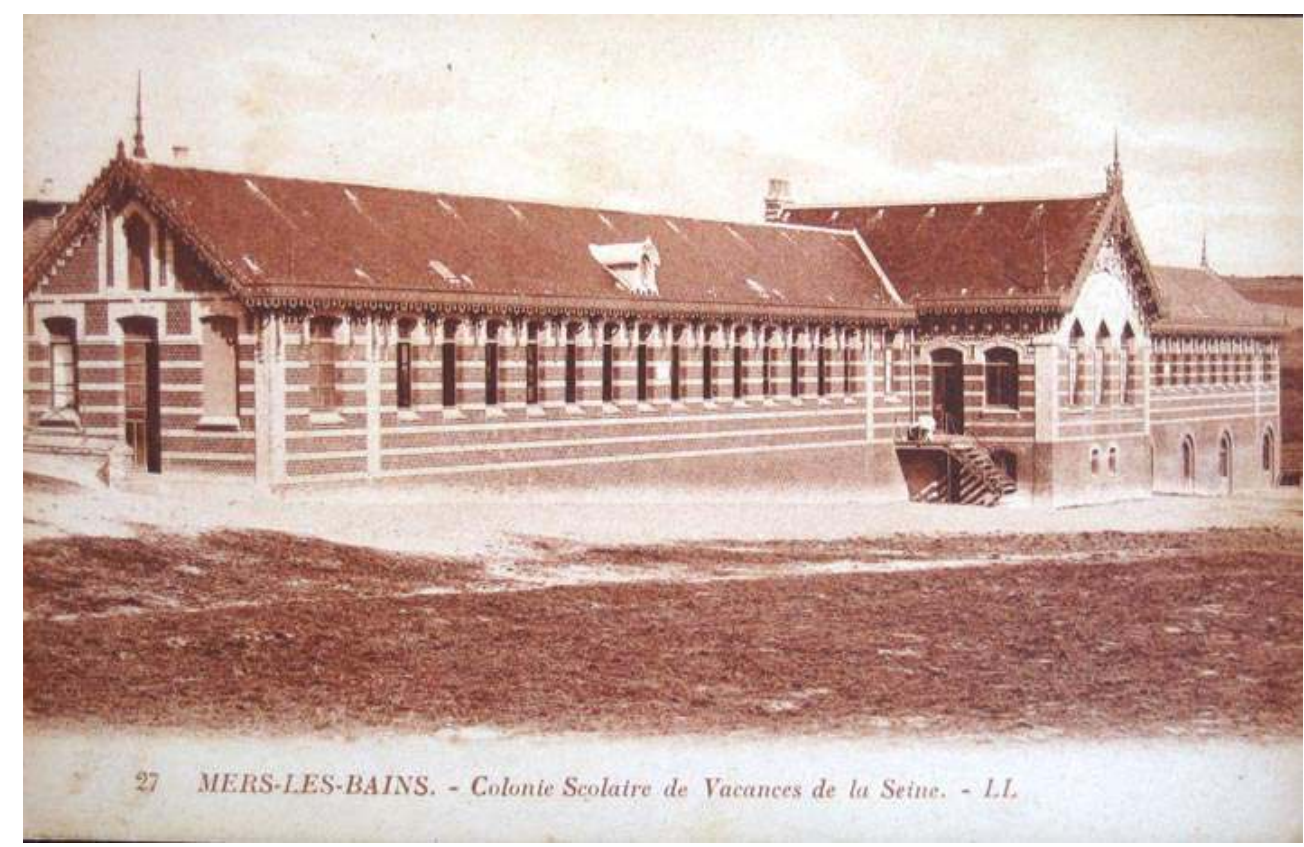

Mers-les-Bains (Somme). Colonie scolaire du département de La Seine

Carte postale, coll. B. Toulier (c) B. Toulier

De 1898 à 1902, l'architecte amiénois Fernand Ratier édifie pour le département de la Seine une colonie scolaire dans la station balnéaire de Mers-les-Bains dans la Somme sur un terrain appartenant à l'orphelinat Prévost. Le bâtiment, accroché à la falaise et orienté est-ouest est perpendiculaire à la Manche. Il s'étend sur plus de 70 mètres sur un seul niveau en dénivelé (fig. $\mathbf{n}^{\circ} \mathbf{3}$ ). Il se compose d'un pavillon central à usage de cuisine et de réfectoire, encadré par deux ailes de dortoirs largement éclairés par de hautes baies. Chaque dortoir a une capacité de trente lits, l'un pour les filles et l'autre pour les garçons. Chaque dortoir est complété par trois chambres de surveillants, deux chambres d'isolement, une lingerie, et des latrines. À l'extrémité des ailes, on trouve d'une part le 
logement du gardien et de l'autre, celui du directeur. La décoration polychrome joue sur une alternance de briques rouges et de briques émaillées blanches (fig. $\left.\mathbf{n}^{\circ} \mathbf{4}\right)$.

Figure 4

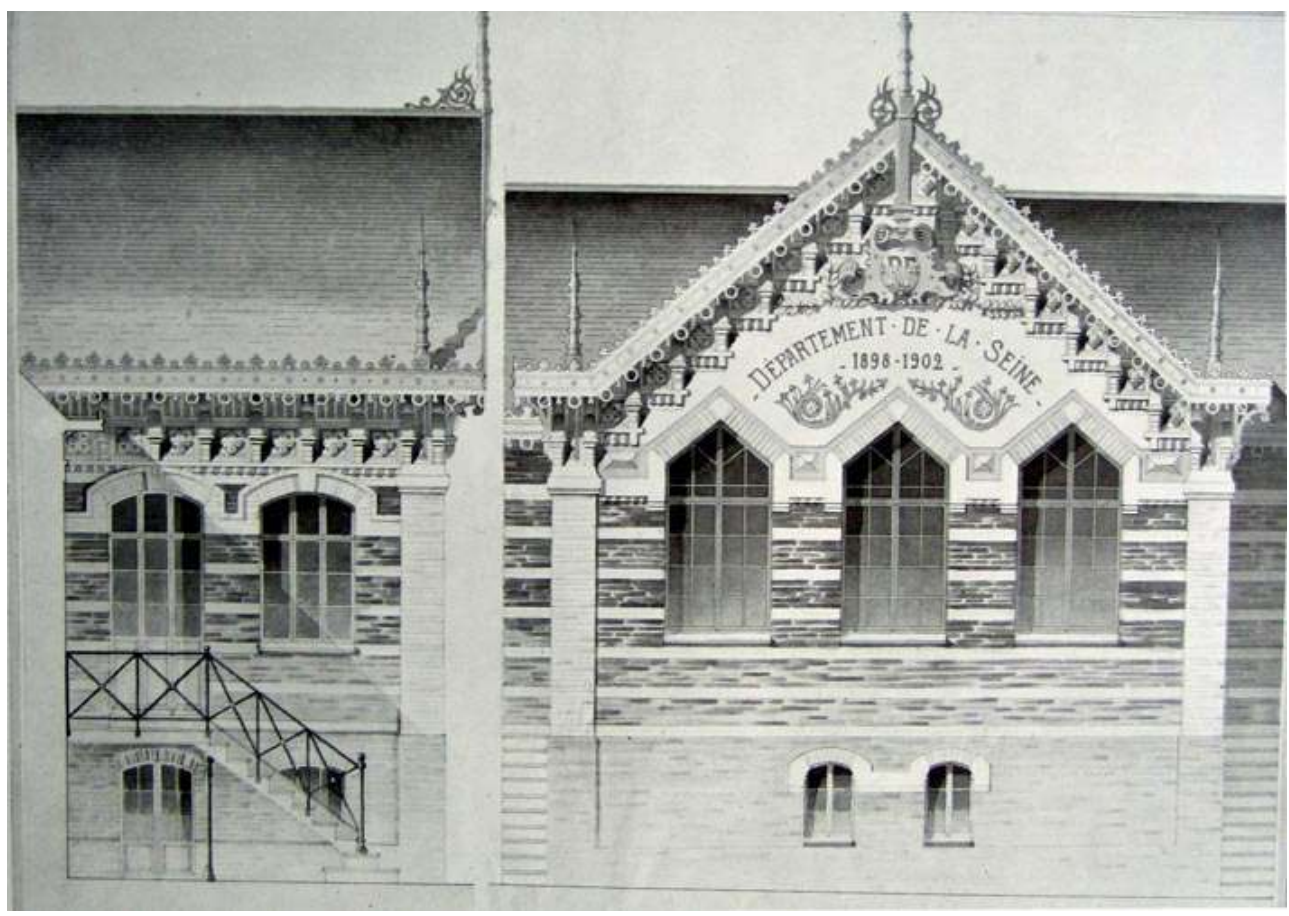

Mers-les-Bains (Somme). Colonie scolaire, détails des élévations de l'avant-corps central

Extrait de LA CONSTRUCTION MODERNE, 1906-1907, pl. 30

Tout le décor est reporté sur le fronton-pignon du pavillon central. Les pas de moineau à la flamande s'inspirent des constructions du nord de la France, et le décor des lambrequins des bordures de rives et de la zinguerie du faîtage, surmontant la signature du maître d'ouvrage, évoque le style du « chalet-balnéaire ». Cette colonie-orphelinat est occupée en dehors des périodes scolaires par les enfants de l'orphelinat Prévost et, pendant les vacances et à tour de rôle, par les élèves des divers arrondissements de Paris et ceux des institutions humanitaires du département de la Seine ${ }^{37}$.

L'établissement le plus colossal est édifié le long de la plage de Zuydcoote, entre Dunkerque et la frontière belge, lors du transfert de celui de Saint-Pol-sur-Mer, menacé de destruction par l'extension du port de Dunkerque. Le chantier est mené de 1904 à 1910 par les architectes Alexandre Maistrasse et Charles Berger qui appliquent le modèle de l'établissement pavillonnaire comme dans leur précédente construction de l'hôpital Trousseau à Paris. L'établissement est entièrement clôturé et se donne des allures de caserne. Il s'inscrit dans un quadrilatère long de 500 mètres, donnant sur la mer, avec une profondeur de près de 300 mètres. Les différents pavillons de style néo-flamand ont une capacité de 1600 lits, garantissant la mixité des fonctions: 6 à 700 pour la cure sanatoriale des enfants et 900 réservés pour les colonies de vacances durant la saison estivale $^{38}$ (fig. $\mathbf{n}^{\circ}$ ). 


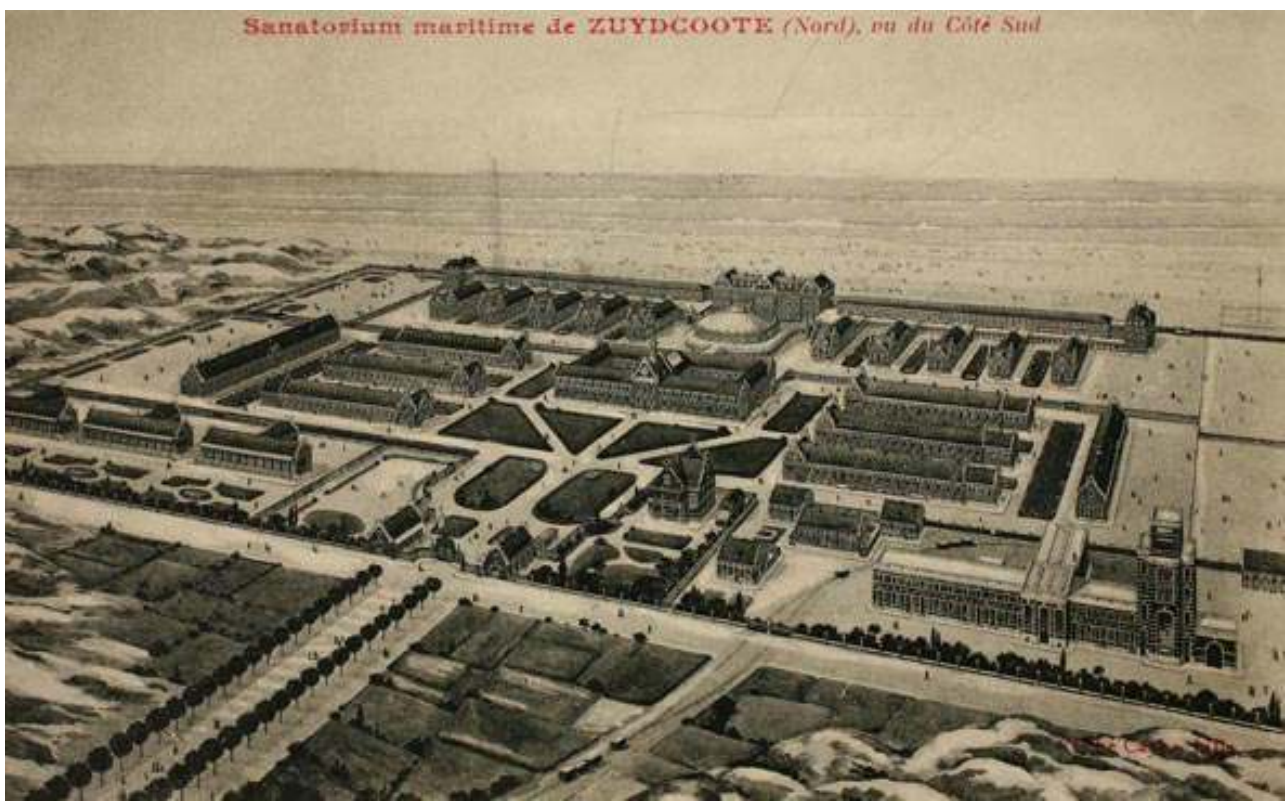

Zuydcoote (Nord). Sanatorium/colonie de vacances, vue à vol d'oiseau

Carte postale, coll. B. Toulier (c) B. Toulier

\section{8-1945 : de la prévention au sport}

Pendant cette période, outre les organismes de bienfaisance, de nouveaux acteurs apparaissent tels que les syndicats, les mutualités, les unions départementales des mutilés, les coopératives ouvrières ou les sociétés sportives. Les associations « régionalistes", notamment à Paris, développent des «colonies d'originaires». Les "Savoyards", les « Normands", les «Bretons », les «Pupilles des Pyrénées » envoient leurs enfants au « pays ».

Entre 1920 et 1930, les colonies scolaires se «municipalisent ». Les mairies socialistes et communistes des banlieues rouges placent la colonie de vacances au cœur de leurs programmes d'actions municipales. À Ivry-sur-Seine par exemple, deux mois après l'élection du maire communiste en 1925, la municipalité remplace la colonie républicaine des Petits Ivryens à la Campagne par l'Oeuvre des vacances populaires enfantines (OVPE). En 1929, cette nouvelle institution achète sur la Côte atlantique, près de Royan, Les Mathes, une vieille métairie avec un grand potager au centre d'un domaine de 13 hectares boisé de pins, situé à 5 kilomètres de la mer.

Les années 1930 marquent un tournant dans l'histoire des colonies. En 1931, se tient à Genève la Conférence internationale des colonies de vacances et œuvres de grand air. En France, le ministère de la Santé créé en 1930 accentue à partir de 1937 la politique de reconnaissance et de développement des colonies de vacances. La circulaire du 17 avril 1937 relative à l'agrément des préventoriums privés classe les établissements de prévention en cinq catégories : $1^{\circ}$ les colonies et camps de vacances ${ }^{39} ; 2^{\circ}$ les écoles de plein air $; 3^{\circ}$ les maisons de repos et de convalescence pour enfants; $4^{\circ}$ les maisons spécialisées pour certaines catégories infantiles; $5^{\circ}$ les préventoriums et aériums. Quelques jours plus tard, la décision de l'État de renouveler sa « contribution financière 
aux dépenses de premier établissement des colonies scolaires ", dont l'origine remonte à 1920, entraîne de nombreuses constructions nouvelles. Parallèlement, après la crise de 1929, le recours au financement privé, notamment les Caisses d'Épargne, est de plus en plus important.

Les instructions relatives à l'organisation et au fonctionnement des colonies et camps de vacances subventionnés par l'État du 18 mai 1937, publiées par le ministère de tutelle de la santé publique précise l'« organisation matérielle» de la colonie, qui est peu contraignante ${ }^{40}$. L'État, ne subventionnant pas directement la construction des bâtiments, mais les " placements d'enfants » n'édicte pas de règle précise, à l'exception des dortoirs. "La colonie sera éloignée de toute grosse agglomération urbaine ou industrielle, tout en étant située près d'une grande voie d'accès. Elle sera bien exposée, à l'abri du soleil, des vents, et à proximité d'ombrages ${ }^{41}$... L'immeuble comprendra des pièces distinctes pour le dortoir, le réfectoire, la salle de réunion et de récréation ». Le camp de vacances, présent dans ce texte officiel, est défini très brièvement comme un équipement composé de baraques ou de simples tentes en toile.

\section{Le temps des reconversions à l'économie}

Les cas de réemplois sont majoritaires: forts et casernes, écoles et châteaux ou établissements religieux se reconvertissent en colonies. Le cas d'Ivry-sur-Seine est particulièrement représentatif de ces nombreux réemplois d'édifices, facilités par le réseau de relations confessionnelles. L'abbé Joseph Galpin, curé d'Ivry-sur-Seine, remplace la villa savoyarde de "La Belle Étoile », à Mercury-Gemilly en Savoie, occupée de 1912 à 1932, par deux autres demeures prêtées par des âmes charitables. Le couvent des Sœurs de Saint-Vincent-de-Paul de Saint-Flour dans le Cantal accueille les filles tandis que les garçons sont hébergés au château de Sauveboeuf en Dordogne, propriété de la famille Oberkampf ${ }^{42}$. 


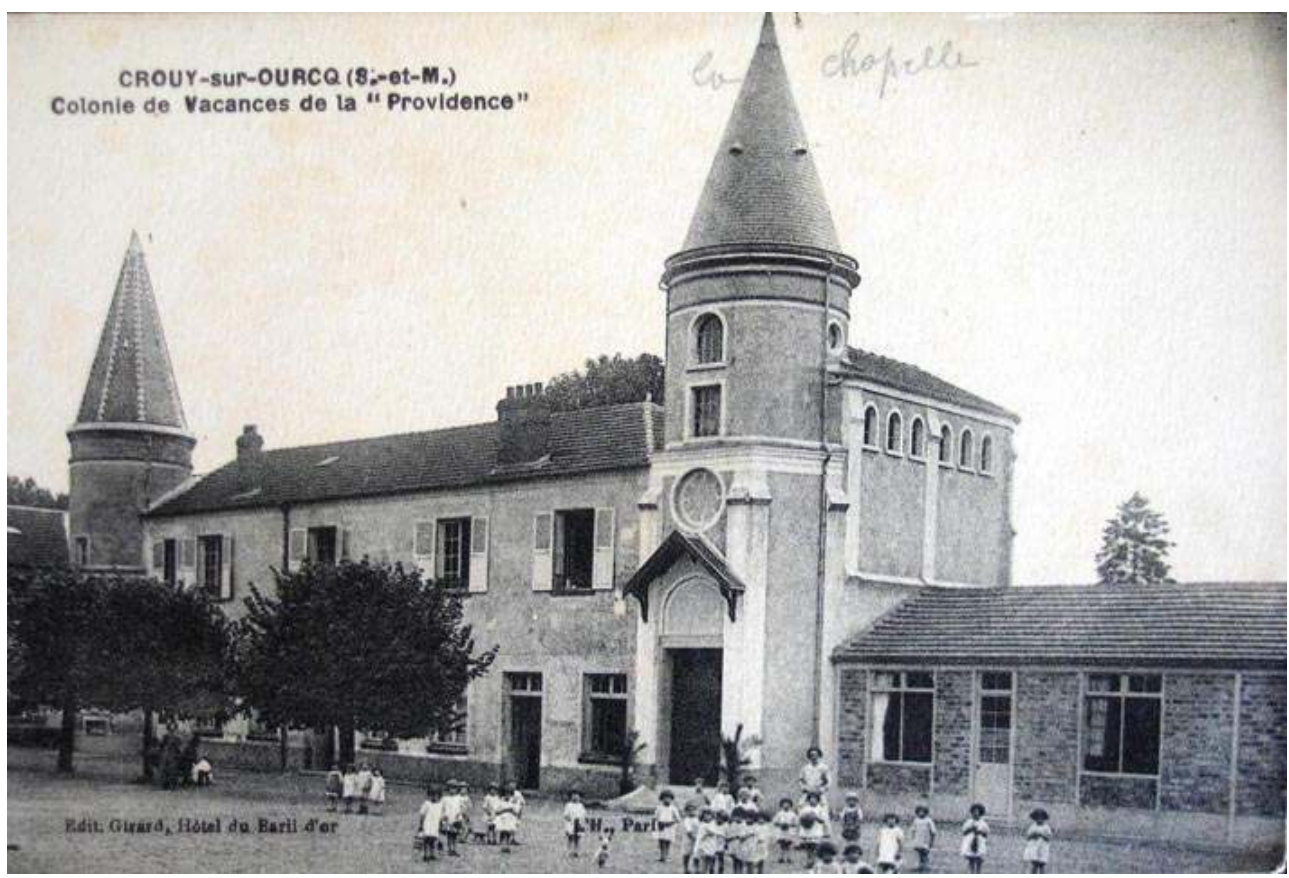

Crouy-sur-Ourcq (Seine-et-Marne). Colonie de vacances La Providence

Carte postale, coll. B. Toulier (c) B. Toulier

Les exemples de réemploi de châteaux sont nombreux et souvent bien visibles ${ }^{43}$. Les châteaux peuvent être achetés mais aussi «mis à disposition " par des ecclésiastiques comme à Linas, près de Montlhéry dans l'Essonne. Après la Première Guerre mondiale, Mlle Jeanne-Marie de Crayon-Latour met sa demeure à la disposition des sœurs de SaintVincent-de-Paul pour servir de maison de repos et de colonie de vacances, sous le nom de Pavillon Sainte-Marie ${ }^{44}$. On rencontre un cas semblable à Fort-Louis dans le Bas-Rhin. Le château, construit en 1835, est légué un siècle plus tard à l'évêché de Strasbourg qui y installe une " cure d'air » et une colonie de vacances ${ }^{45}$. Les châteaux sont très prisés des œuvres catholiques. Ils y construisent souvent une chapelle de vastes dimensions placée sur le retour du logis, avec le clocher en forme de tour d'angle. À Crouy-sur-Ourcq en Seine-et-Marne, le clocher/tour de la chapelle de la colonie de La Providence répond à la tour d'angle symétrique du château (fig. $\mathbf{n}^{\circ}$ 6). À L'Age d'Étagnac en Charente, l'imposant clocher d'angle néo-roman poitevin flanqué de ses lourds contreforts ne laisse aucun doute sur l'appartenance religieuse de l'établissement (fig. $n^{\circ} 7$ ). 


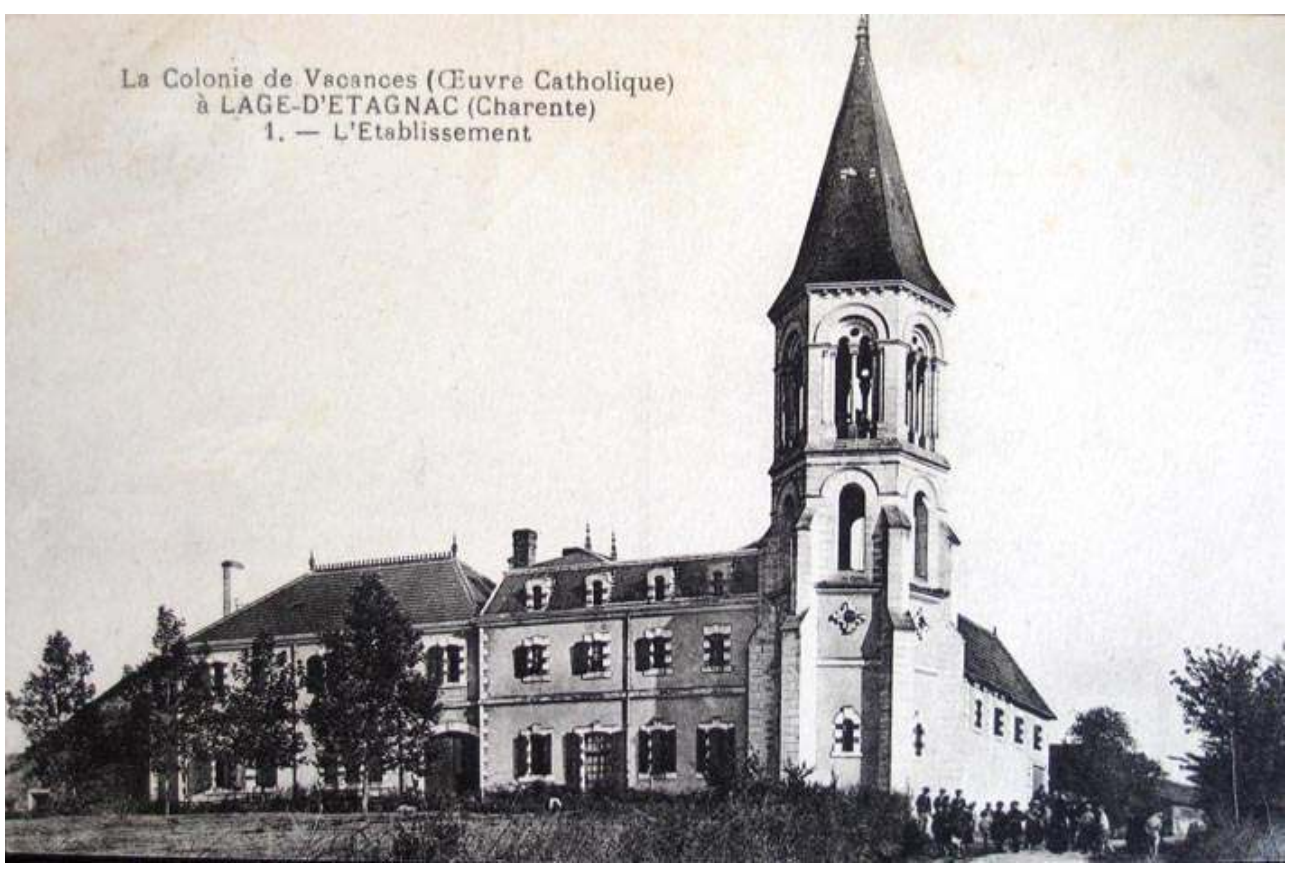

Lage d'Étagnac (Charente). Colonie de vacances catholique

Carte postale, coll. B. Toulier ( $)$ B. Toulier

Les châteaux et villas en bord de mer sont aussi très appréciés par les municipalités. À Saint-Georges-d'oléron en Charente-Maritime, le château du Mesnil, puis domaine Marchys, élevé dans la seconde moitié du XIX ${ }^{e}$ siècle, est vendu en 1937 à la ville de Brivela-Gaillarde en Corrèze pour ses colonies ${ }^{46}$. Dans le Val-de-Marne, la colonie de SaintMaur-des-Fossés s'installe à La Baule (Loire-Atlantique) (1929) et celle d'Arcueil à Villerssur-Mer (Calvados) (1934). Parmi les nombreux réemplois de villas de bord de mer, on notera par exemple sur la Côte de Granit rose, la maison de villégiature dite de Ker-Woel à Trébeurden (Côtes-d'Armor).

Certains hôtels de voyageurs en bord de mer sont aussi convoités pour leur capacité à être reconvertis en colonies, comme dans les Côtes-d'Armor, l'Hôtel des Grèves à Plangouenoual ou l'hôtel d'Angleterre à Trébeurden, édifié vers 1913 et rénové en 1924. Certaines « reconversions » sont plus périlleuses. À Perros-Guirec dans les Côtes-d'Armor, la maison dite Le Hédraou, construite pour un notable au milieu du XIX ${ }^{e}$ siècle, devient un casino entre 1890 et 1904 avant d'être utilisée comme colonie.

De 1925 à 1928, la colonie d'Ivry-sur-Seine dans le Val-de-Marne s'abrite dans les anciens forts militaires déclassés de Saint-Vaast-la-Hougue sur la Mer du Nord, de l'Ile d'Oléron et de l'Ile de Ré en Charente-Maritime ${ }^{47}$. En Bretagne, à la Pointe de Bag-Lann sur la commune de Sarzeau dans le Morbihan, l'ancienne caserne des douaniers dite Fort du Becland, construite vers 1860 et rachetée par les Frères de Picpus à la fin du XIX ${ }^{e}$ siècle, a longtemps servi de maison de colonie de vacances ${ }^{48}$.

Les enfants de réfugiés sont souvent logés dans des colonies installées dans des bâtiments recyclés. Dès 1933, des colonies de vacances sont établies dans les Vosges pour accueillir les enfants des Juifs immigrés d'Europe de l'Est ${ }^{49}$. À partir de l'été 1942, quand les enfants juifs sont arrêtés sur l'ensemble du territoire français, des filières de sauvetage d'enfants sont mises en place: ils sont cachés sous de fausses identités dans des institutions 
religieuses ou dans des colonies. En juin 1943, le pasteur Jean Josselin rassemble de jeunes enfants juifs parisiens et organise une colonie de vacances au château de Cappy à Verberie (Oise). La colonie devient un lieu de refuge permanent pour échapper à la déportation, jusqu'à la Libération ${ }^{50}$. À Izieu dans l'Ain, «la colonie d'enfants réfugiés de l'Hérault » réutilise une maison isolée avec sa grange ${ }^{51}$.

Malgré l'inadéquation de ces édifices à une destination temporaire à l'usage de colonie et les problèmes liés aux frais d'entretien de bâtiments inoccupés les trois quarts de l'année, la formule du réemploi a rencontré un grand succès. Pour Corinne Hubert, ce choix est «l'occasion pour certains de réaliser des affaires immobilières juteuses, pour d'autres de prendre une revanche sociale, en se réappropriant l'instrument de loisirs des classes possédantes.... Il nous semble surtout que dans le contexte de la crise des années 1930, les municipalités et les caisses des écoles hésitent à s'endetter et optent pour l'achat, plutôt que pour la construction, coûteuse, de propriétés immédiatement utilisables après quelques aménagements " $^{52}$. L'achat d'un bâtiment permettait souvent de réaménager à peu de frais et d'occuper tout de suite les lieux, puis suivant les possibilités financières, d'envisager des travaux plus importants de construction. En 1931, le premier contingent des apprentis du Réseau de l'État, dont la colonie est fondée par Raoul Dautry, emménage dans le château de la Meilleraie en Vendée. L'année suivante, sous la direction de l'architecte Henri Pacon, les communs sont transformés en dortoirs et de nouveaux locaux sont peu à peu construits pour abriter les autres services de la colonie ${ }^{53}$. Dans les années 1930, les baraquements de bois du «camp de vacances» des apprentis de la Compagnie de chemin de fer du Paris-Orléans de Quiberon dans le Morbihan sont remplacés par des bâtiments en dur élevés autour de la cour fermée du terrain de jeux (fig. $n^{\circ}$ 8).

Figure 8

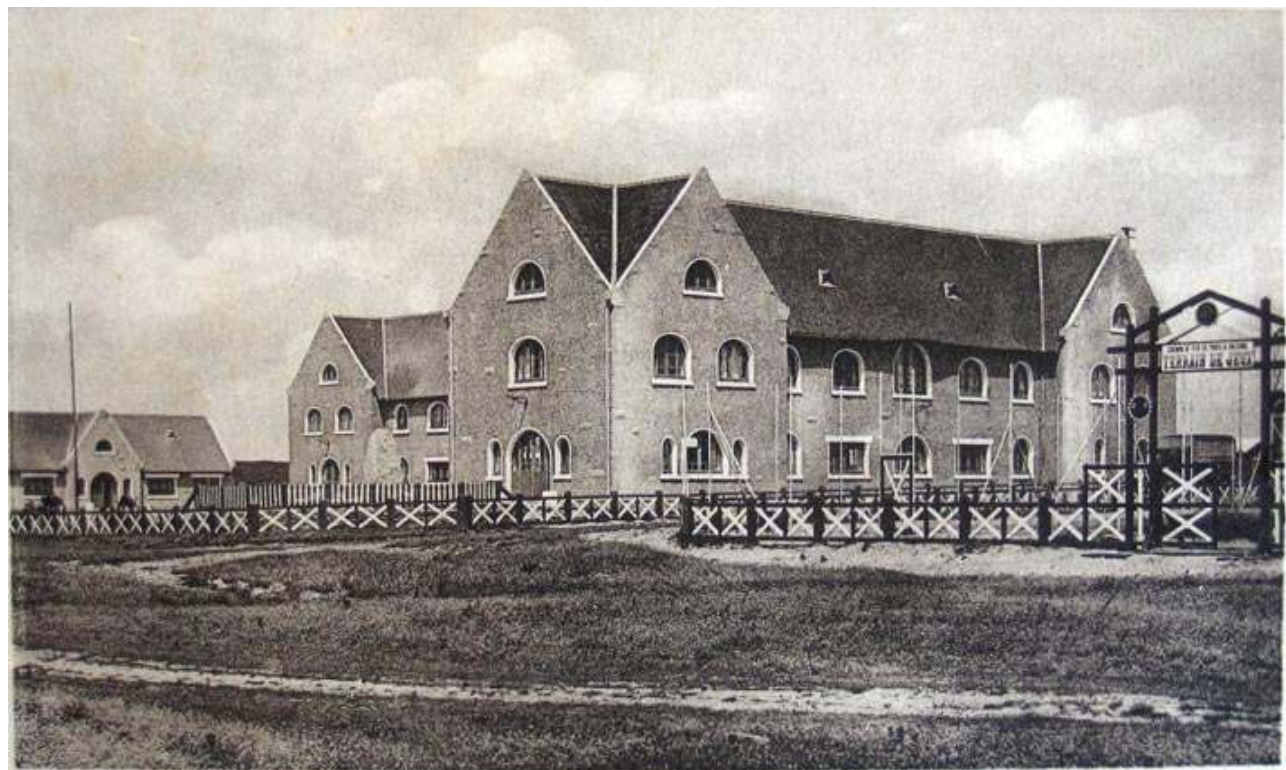

Quiberon (Morbihan). Colonie de vacances de la Compagnie de chemin de fer du Paris-Orléans Carte postale, coll. B. Toulier (c) B. Toulier

Les réemplois de bâtiments nécessitent parfois d'importants travaux d'aménagement et d'agrandissement. Ces extensions, élevées à proximité des anciens bâtiments (ex. château 
des Goëlands à Saint-Guénolé sur la commune de Penmarc'h dans le Finistère ; château de Chantereine à Criel-sur-Mer en Seine-Maritime ou en remplacement des dépendances (ex. Les Mathes en Charente-Maritime), dans les espaces des domaines agricoles ou les parcs des châteaux, peuvent être assimilés à des constructions ex-nihilo.

\section{Un établissement médical préventif : les vertus du plein air, de la lumière et du soleil}

Après la Première guerre mondiale, le ministère des Régions libérées soutient l'effort de reconstruction des colonies de vacances. Il crée la colonie de Camiers dans le Pas-deCalais, sur le littoral de la Manche, à l'usage des enfants sinistrés qui occupent, de 1920 à 1925, un hôpital militaire britannique désaffecté. Une description de 1924 mentionne que 6000 enfants sont logés dans 300 baraques réparties en quatre quartiers de 1500 enfants. Chaque quartier possède 20 dortoirs, 3 réfectoires, 1 cuisine, 1 infirmerie, 1 salle de consultation médicale, des lavabos, des bains-douches et des water-closets ${ }^{54}$. Cette colonie exceptionnelle et unique est sans lendemain, bien que le recours aux baraques de bois soient une solution de fortune qui perdurera jusqu'aux années 1950.

À partir des années 1930, les constructions neuves se multiplient, ouvertes sur le bon air et laissant largement pénétrer la lumière. Vers 1920-1930, dans l'Ile de Noirmoutier en Vendée, la colonie de Saint-Oustrille, établie à proximité de la grande plage de Luzéronde, est construite à la manière d'une grande maison régionaliste, avec un toit à pentes dissymétriques et des façades revêtues d'enduit rustique ${ }^{55}$. Sur la Côte de Granit Rose dans les Côtes d'Armor, l'architecte parisien Paul Gélis bâtit une colonie de vacances (1930-1932) pour sa cousine Hilda Gélis-Didot. L'établissement est nommé Fondation May Lockwood, en souvenir de sa mère décédée avant d'avoir pu réaliser ce projet destiné à la convalescence des enfants parisiens et de la banlieue. Le bâtiment oscille entre le style régionaliste d'une maison, suggérée par la façade-pignon de l'avant-corps central, et le bâtiment scolaire moderne, entouré d'un préau couvert d'un appentis qui court le long des façades ${ }^{56}$.

Vers 1928-1929, l'association L'Enfance coopérative ${ }^{57}$ crée la colonie La Maison-Heureuse installée à Saint-Georges d'Oléron en Charente-Maritime dans les anciens bâtiments militaires abandonnés de Boyardville. Les assises d'une partie des bâtiments sont reprises et de nouvelles constructions s'élèvent dans l'espace central. Malgré le bâtiment d'accueil en forme de maison de villégiature avec ses toits débordants et la présence des pans de bois, du moulin à vent au-dessus des cuisines et du petit clocheton surmontant l'horloge, ce petit hameau aux bâtiments alignés et symétriques ressemble plus à un casernement qu'à un village d'enfants (fig. $\mathbf{n}^{\circ}$ 9). Le projet, confié à L. Clément-Camus ${ }^{58}$, s'inscrit dans l'expérience des écoles de plein air ; il peut recevoir 400 enfants. Cet architecte parisien dessine un projet régionaliste issu du vocabulaire de la villégiature, avec colombages et pergola, et un toit en croupe débordant sur l'avant-corps central, repris sur les ailes symétriques de la façade principale ${ }^{59}$. L'ensemble a été construit par des sociétés coopératives. La décoration est due au dessinateur André Hellé dont les décors du réfectoire et des dortoirs peints sur des bois découpés représentent les fables de $\mathrm{La}$ Fontaine, les contes d'Andersen ou des chansons anciennes (fig. $\mathbf{n}^{\circ} \mathbf{1 0}$ ). 


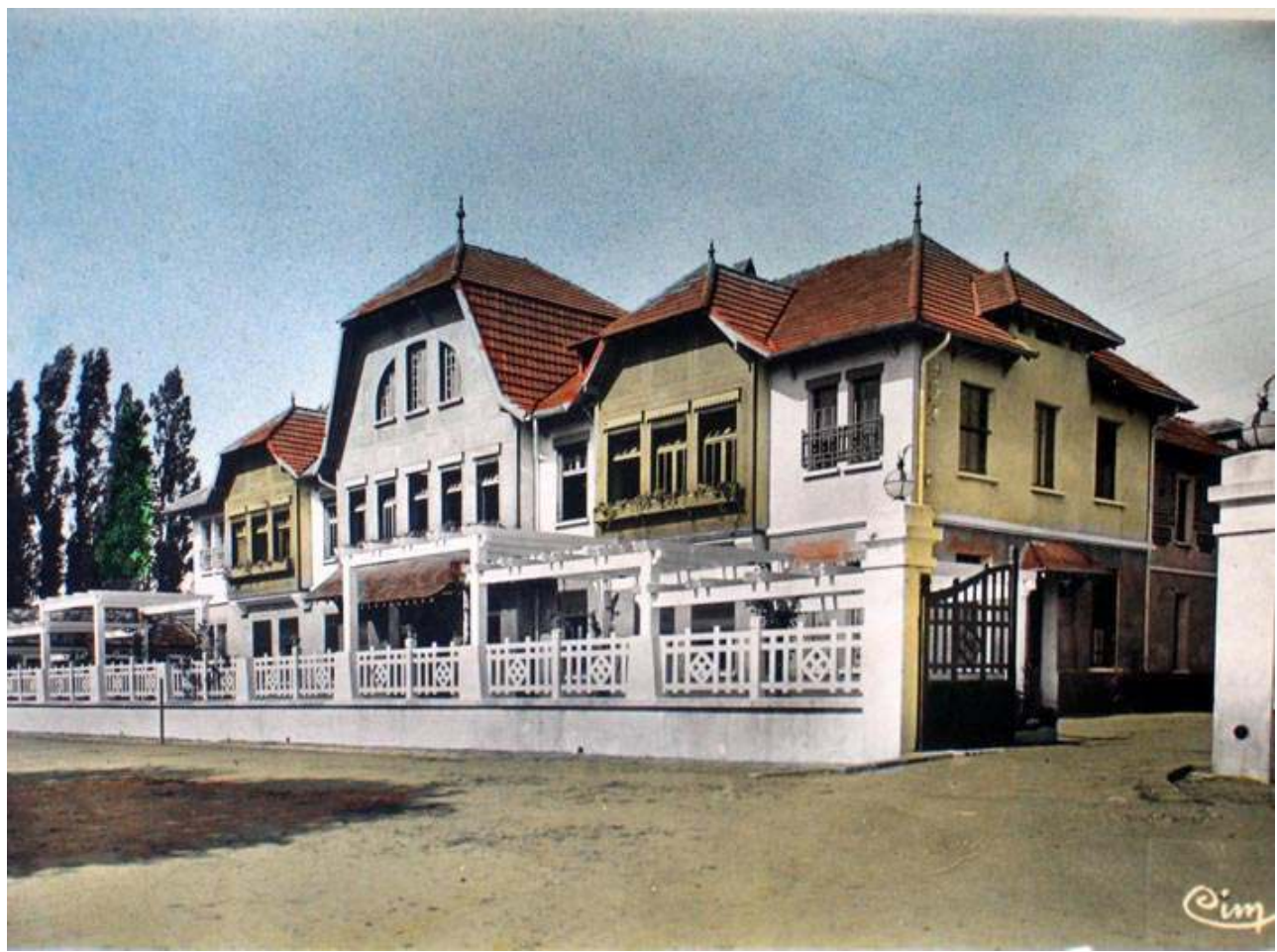

Ile d'Oléron, Boyardville (Charente-Maritime). Colonie de vacances La Maison heureuse, vue générale Carte postale, coll. B. Toulier (c) B. Toulier

Figure 10

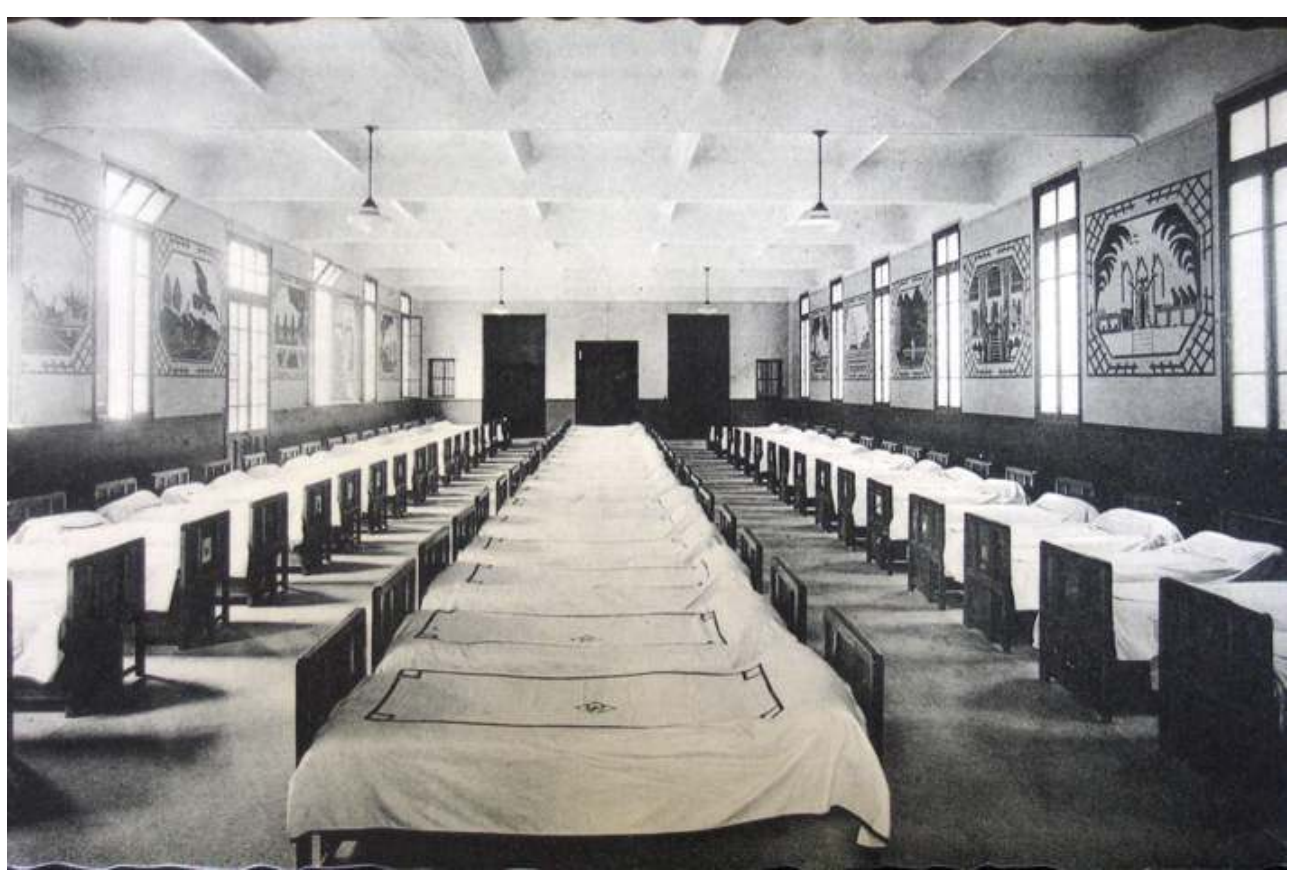

Ile d'Oléron, Boyardville (Charente-Maritime). Colonie de vacances La Maison heureuse, dortoir Carte postale, coll. B. Toulier (c) B. Toulier 
Les motifs peints de la salle des fêtes évoquent le thème du travail: usine, école, vendange, moisson, cueillette, semailles, labours et le bâtiment. Le mobilier et l'ameublement, depuis les céramiques du hall d'accueil pour les parents jusqu'au-dessus de lit des dortoirs sont conçus par Francis Jourdain ${ }^{60}$. Les lavabos des sanitaires (fig. $\mathbf{n}$ -11), les salles de bains à la romaine en granito de marbre et parois en faïence et le système des douches avec cloisons en verre cathédrale (fig. $\left.\mathbf{n}^{\circ} \mathbf{1 2}\right)$ sont particulièrement innovants.

Figure 11

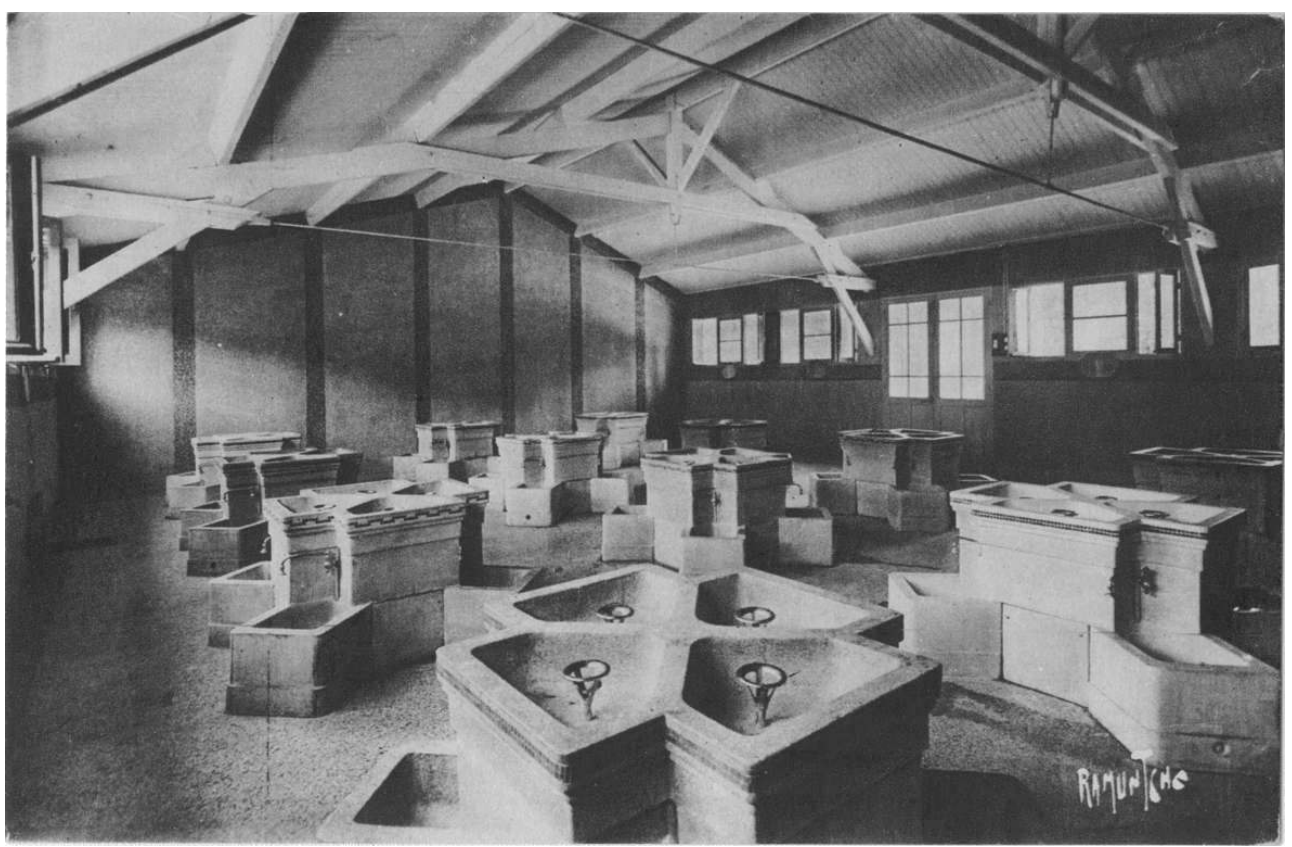

Ile d'Oléron, Boyardville (Charente-Maritime). Colonie de vacances La Maison heureuse, détail des sanitaires et lavabos

Carte postale, coll. B. Toulier ( $)$ B. Toulier 
Figure 12

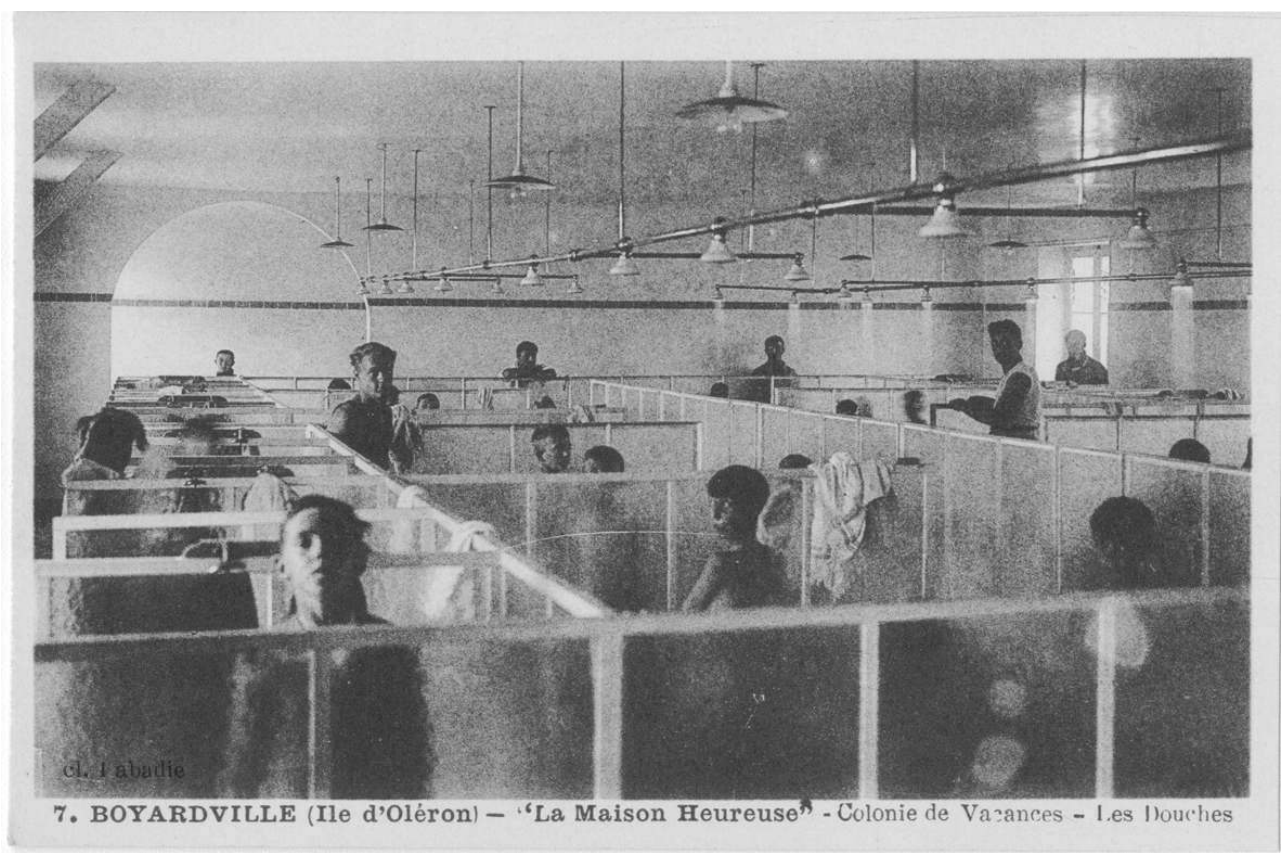

Ile d'Oléron, Boyardville (Charente-Maritime). Colonie de vacances La Maison heureuse, détail des douches

Carte postale, coll. B. Toulier (c) B. Toulier

On retrouve les mêmes principes constructifs et les mêmes procédés décoratifs dans la colonie dite de La Maison-Joyeuse à Gérardmer dans les Vosges (fig. $\mathbf{n}^{\circ} \mathbf{1 3}$ ), propriété de la même association et œuvre des mêmes auteurs.

\section{Figure 13}

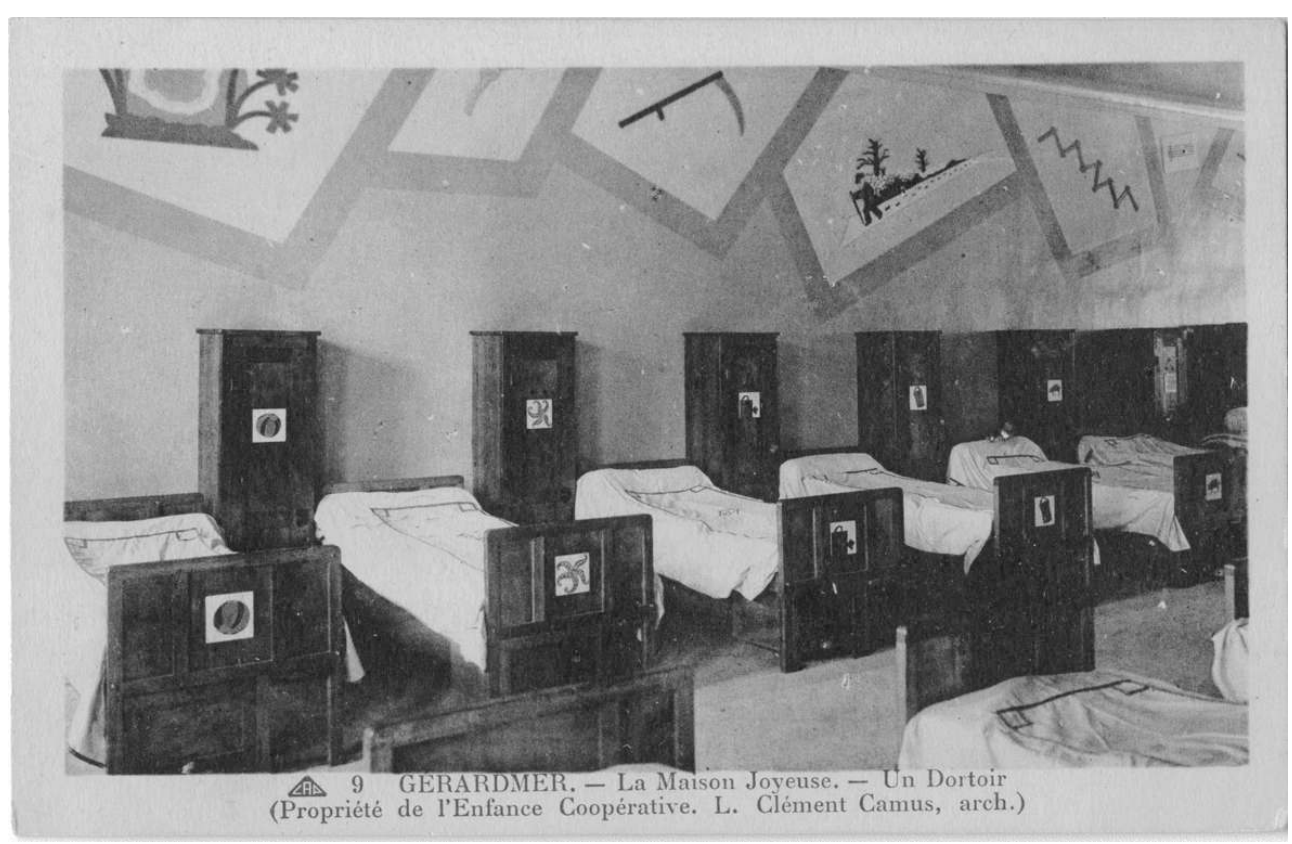

Gérardmer (Vosges). Colonie de vacances La Maison Joyeuse, dortoir Carte postale, coll. B. Toulier (c) B. Toulier 
Dortoirs et réfectoires sont décorés de peintures murales, peintes à fresque ou au pochoir, ou encore de toiles marouflées évoquant des contes pour enfants, des histoires à but moral ou religieux, tirés de la Bible ou à défaut d'images pieuses ou d'affiches publicitaires (notamment des chemins de fer), parfois soulignées par des maximes ou des slogans. Comme en Suisse, en Belgique et surtout en Allemagne, ce procédé en usage dans tous les milieux éducatifs, déjà utilisé dès le début $\mathrm{du} \mathrm{XX}^{\mathrm{e}}$ siècle, se répand largement entre les deux guerres pour se poursuivre jusque dans les années $1970^{61}$.

À l'instar des bâtiments scolaires et hospitaliers, les colonies bénéficient d'une ventilation par un système d'ouverture des baies particulier pour l'aération et le passage de la lumière tout en assurant une mise en sécurité des enfants. Le nouveau dortoir de la colonie de vacances de Beauvais et de sa région, élevé à Cayeux-sur-Mer dans la Somme au cours des années 1930, est doté d'un système de vasistas appliqué sur les impostes des fenêtres côté rue et sur le mur opposé, sous le faîtage, donnant une ventilation haute ouverte à la brise marine. On retrouve ces impostes à vasistas à la colonie de vacances de la préfecture de police d'Ormoy dans l'Yonne, construite dans les années 1920.

Avec ses immenses baies vitrées sur deux niveaux, la colonie de Saint-Ouen à Jullouville dans la Manche, construite sur ossature en béton armé avec un toit en terrasse, est directement inspirée des modèles d'établissements hospitaliers héliothérapiques (fig. $\mathbf{n}$ - 14). Les préaux couverts sont percés de grandes baies vitrées à petits carreaux à ouverture horizontale à guillotine, munies de systèmes de sécurité comme au Clos familial de Langrune-sur-Mer dans le Calvados.

Figure 14

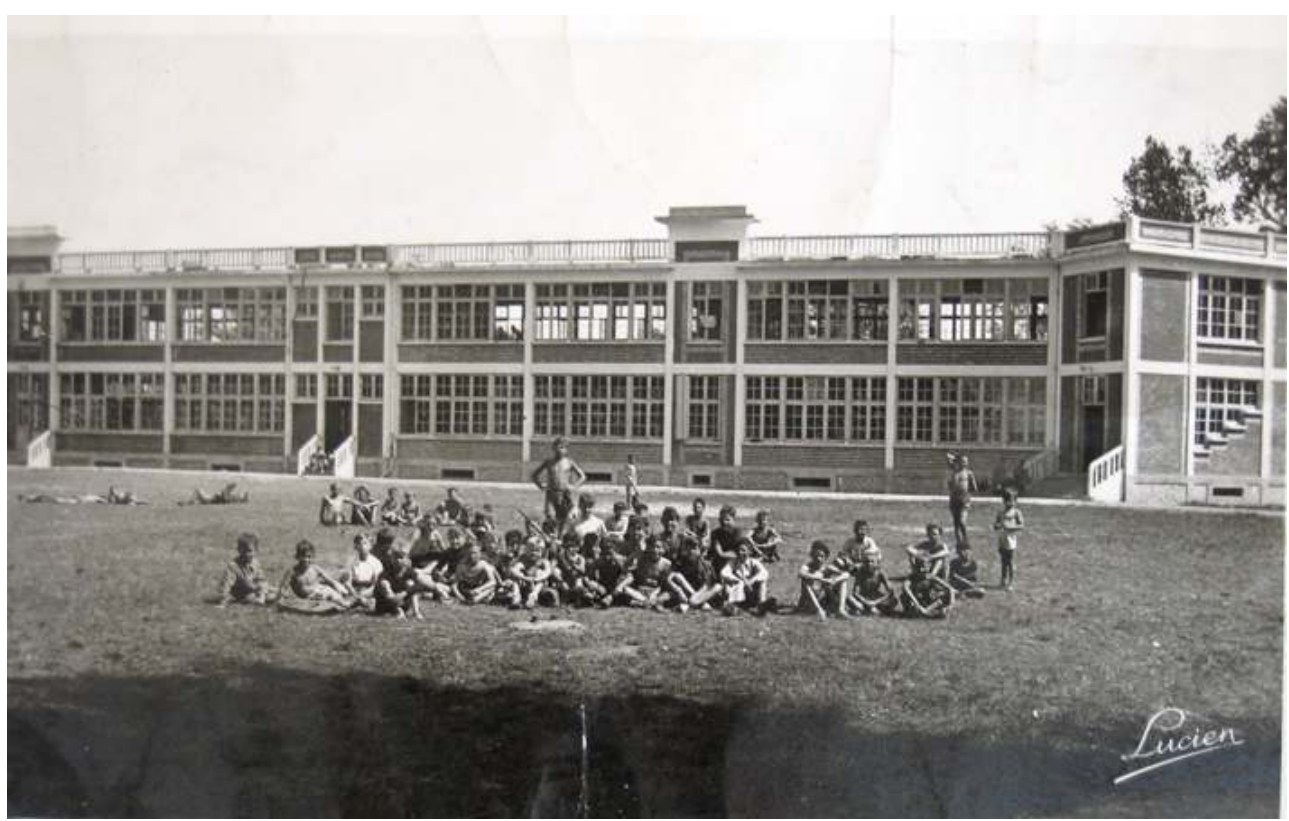

Jullouville (Manche). Colonie de vacances de Saint-Ouen, aile gauche

Carte postale, coll. B. Toulier (c) B. Toulier

De 1933 à 1937, les Sœurs de la Charité d'Angers édifient à La Guérinière en Vendée la colonie Notre-Dame de Bon-Secours, sur les plans de l'architecte angevin Couillaud. L'imposant corps de bâtiment principal, à plan en $U$ avec deux ailes en retour, s'élève sur deux étages. Construit en béton armé et couronné par un vaste toit en terrasse, il adopte 
un style moderne avec ses façades sobres, peintes en blanc, originellement animées par des balcons d'angle et des oriels et par de larges bandeaux colorés ${ }^{62}$.

\section{Écoles de plein air et colonies}

51 En 1922, le premier Congrès international des écoles de plein air, tenu à Paris, officialise et définit l'école de plein air comme « un établissement d'éducation situé hors des villes, dans de bonnes conditions d'exposition et, pour le moment, réservé aux enfants non tuberculeux, mais ayant besoin d'un régime scolaire et hygiénique spécial sous un contrôle médical »63. La même année, une commission présidée par le docteur Dequidt et Mme Gevin Cassal, inspecteurs généraux de l'administration, visite 500 colonies pour constater que ces idées nouvelles sur l'aération et l'hygiène ne sont pas encore mises en œuvre dans les colonies de vacances. En 1923, ils publient leur rapport qui a pour but "d'établir quelques règles techniques et administratives susceptibles de guider le Ministère de l'Hygiène dans un domaine où la nécessité d'une doctrine s'est si impérieusement fait sentir $~_{64}$. Ils prônent une implantation éloignée des agglomérations «dans un terrain pittoresque, abrité des vents et légèrement en pente; il convient d'éviter le vent, le brouillard et le soleil excessif ».

\section{Figure 15}

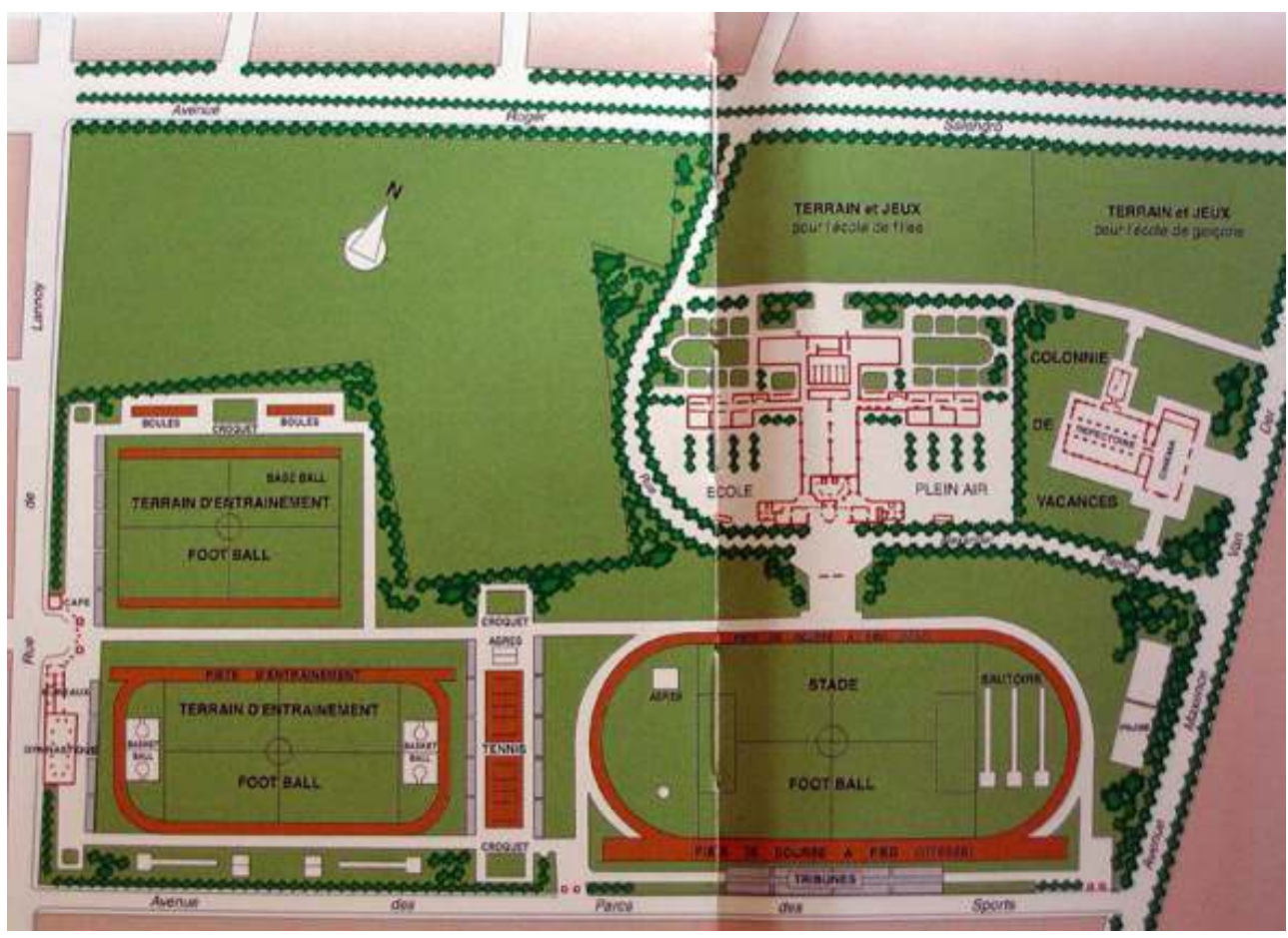

Roubaix (Nord). École de plein air/colonie de vacances

Extrait de Roubaix, UNE VILLE NéE DE L'INDUSTRIE. Direction régionale des affaires culturelles, Service régional de l'inventaire (coll. Itinéraires du patrimoine, $n^{\circ}$ 205), 2000, p. 58-59

Après plusieurs expériences, les premières architectures correspondant à ce nouveau programme d'écoles de plein air apparaissent ${ }^{65}$. L'école du Pont-Rouge à Roubaix dans le Nord (1922-1931), élevée par l'architecte Jacques Greber est une des premières grandes réalisations de ce type d'édifice scolaire, convertible en colonie de vacances «juxtaurbaines ». Située à l'extrémité de Roubaix, vers Lys-les-Lannoy, elle combine les 
avantages de l'école-préventorium et de la colonie de vacances (fig. $\mathbf{n}^{\circ} \mathbf{1 5}$ ). Un dispositif de cloisons et de fermetures mobiles permet la transformation des classes en dortoir pour l'internat pendant la période des vacances. La colonie, aujourd'hui détruite comprenait un réfectoire pour 2000 enfants, flanqué d'une salle de cinéma d'une capacité de 300 places ${ }^{66}$.

écoles de plein air/colonies de vacances se répandent largement dans les années 1930 ${ }^{67}$, comme celle d'Andernos en Gironde, élevée dans un style régionaliste landais. Les différents bâtiments de ces écoles de plein air/colonies sont généralement construits sur le principe des "classes-pavillons », élevées de plain-pied et sans étage et abritent chacun salles de classe, dortoirs, réfectoire, sanitaires, infirmerie et cabinet médical, reliées par des galeries couvertes, et ouvertes sur des zones d'activités de plein air, selon des principes assez comparables aux préventoriums.

D'autres écoles de plein air/colonies, plus nombreuses que les créations ex-nihilo, sont aménagées dans des châteaux. L'« école normande de plein air » du château d'Ouezy, à Cesny-aux-Vignes dans le Calvados, dépendant de l'œuvre des colonies scolaires parisiennes, "ouverte toute l'année aux enfants chétifs, convalescents, anémiés ou nerveux ", accueille une colonie de vacances en dehors des périodes scolaires ${ }^{68}$. La caisse des écoles du XVIII ${ }^{\mathrm{e}}$ arrondissement de Paris réutilise aussi d'anciens bâtiments dédiés à la colonie scolaire pour installer son école de plein air/colonie de vacances à Luzancy en Seine-et-Marne.

\section{Des cités nouvelles pour l'enfance et les loisirs : la prédominance du bâtiment unique multifonctionnel}

Les loisirs s'intensifient et de nouvelles structures destinées aux jeunes se mettent en place. Le 27 août 1930, la première auberge de jeunesse, L'Épi d'Or, est inaugurée à l'initiative de Marc Sangnier à Bierville dans l'Essonne. Le changement de tutelle administrative des colonies de vacances, du ministère de la Santé au sous-secrétariat d'État aux loisirs et aux sports, dépendant de l'Éducation nationale, est significatif. Les vertus médicales préventives de la colonie vont officiellement laisser peu à peu la priorité aux loisirs collectifs éducatifs, pédagogiques et sportifs.

En 1936, le premier sous-secrétariat d'État aux loisirs et aux sports, placé sous la direction de Léo Lagrange, organise notamment le tourisme populaire et donne une nouvelle dynamique aux colonies de vacances et associations qui s'y consacrent. L'administration renforce la réglementation sur les installations nécessaires à l'établissement des colonies par le décret-loi du 17 juin 1938 et celui du 30 octobre 1935 (circulaire du 26 octobre 1937) concernant le règlement sanitaire départemental type. L'article 89 du règlement sanitaire stipule que «l'habitation collective, même temporaire dans les installations, camps, et d'une manière générale en tous lieux ou en tous locaux destinés aux vacances, au repos, aux sports, à la vie saine, loin des agglomérations, ne sera permise que si lesdites installations ont été autorisées par le Préfet, sur le vu d'un rapport favorable établi par l'inspecteur départemental d'hygiène, après une enquête sur place qui portera sur les conditions d'emplacement, d'installations, de logement ou de campement, de ravitaillement, d'approvisionnement en eau potable, d'évacuation des eaux et matières usées, etc. ... ». 
En 1938, le ministre de l'Éducation nationale, Jean Zay, inaugure aux Sables-d'Olonne en Vendée les nouveaux bâtiments de la colonie de vacances construite pour l'Oeuvre universitaire des enfants du Loiret en vacances. Le long bâtiment, construit en béton, présente une façade classique de bâtiment public, encadrée par deux avant-corps latéraux et marquée par un avant-corps central surmonté d'un fronton, deux larges bandeaux de baies éclairant les deux niveaux ${ }^{69}$. Il regroupe sous un même toit toutes les fonctions de la colonie.

\section{Les colonies, au centre du projet d'aménagement du littoral landais}

En 1936, le Groupement régional d'urbanisme des lacs landais et du Bas-Adour regroupe l'ensemble des communes littorales du département. Son objectif est d'apporter « réconfort et regain de santé aux déshérités des rues sans verdure et soleil » (Alfred Éluère $)^{70}$. Ce plan régional d'urbanisme projette sur la côte landaise l'implantation et la redéfinition des colonies de vacances et d'autres équipements de loisirs : auberges de la jeunesse, campings, écoles de plein air, camps thermaux sanitaires, etc., en liaison avec les infrastructures touristiques. Une fondation des «Parcs landais pour la jeunesse française » doit aménager des « cités nouvelles pour l'enfance et les loisirs » à SeignosseHossegor, Seignosse-Plage, Ondres-Plage et Tarnos-Plage dans les Landes ${ }^{71}$. Chaque parc s'étend sur une centaine d'hectares et comprend de nombreuses colonies. Le projet est stoppé par la Seconde Guerre mondiale.

Figure 16

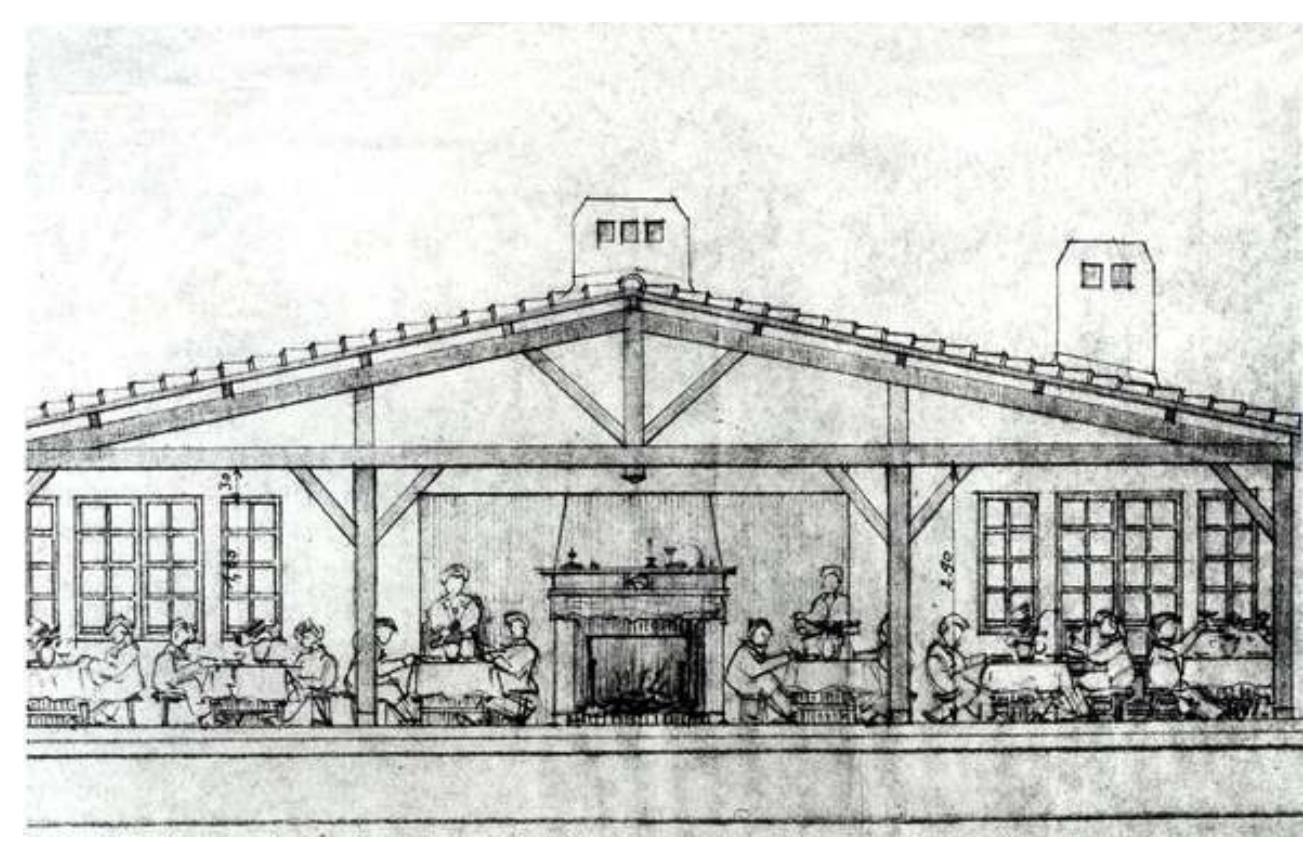

Hossegor (Landes). Parc de Seignosse, colonie de vacances Henri-Sellier. Projet réalisé de l'architecte Marcel Le Gal

Extrait : Dossier du service de l'Inventaire général du patrimoine culturel, Région Aquitaine, Claude Laroche

La colonie Henri-Sellier dans le parc de Seignosse-Hossegor, est un des rares témoins de ce vaste projet. En 1937-1938, l'architecte daxois Marcel Le Gal projette à proximité d'une ancienne ferme acquise par le Foyer des Cités-Jardins du Grand-Paris à Hossegor un 
nouveau bâtiment à usage de dortoirs et de cuisine/réfectoire. Il reprend dans un style régionaliste la typologie de la ferme basco-landaise, en rez-de-chaussée et en pan de bois, avec un réfectoire ouvert directement sur la forêt de pins du parc de Seignosse ${ }^{72}$ (fig. $\mathbf{n}$ -16).

Le projet (non réalisé) de l'architecte Pierre Forestier, pour le parc de Ondres-Plage conçu en opposition avec la colonie régionaliste Henri-Sellier, s'affirme dans un parti moderne et innovant. Il groupe ici les satellites des "groupes d'habitations pour enfants" (dortoirs) autour des services centraux et les dispersent dans le parc. Chacun des satellites conserve son autonomie et son caractère particulier, en fonction de l'âge des enfants. Les bâtiments sont bas, dominés par la forêt de pins, orientés selon l'ensoleillement: vers l'est pour les dortoirs, le sud pour les préaux, les salles de jeux circulaires étant ouvertes sur tous les côtés. Auteur de plusieurs bâtiments hospitaliers et de santé, Pierre Forestier applique ici les principes utilisés pour les hôpitaux et les écoles de plein air et se réfère aux modèles italiens de colonies de vacances héliothérapiques à pavillons ${ }^{73}$ (fig. $\mathbf{n}^{\circ} \mathbf{1 7}$ ).

Figure 17

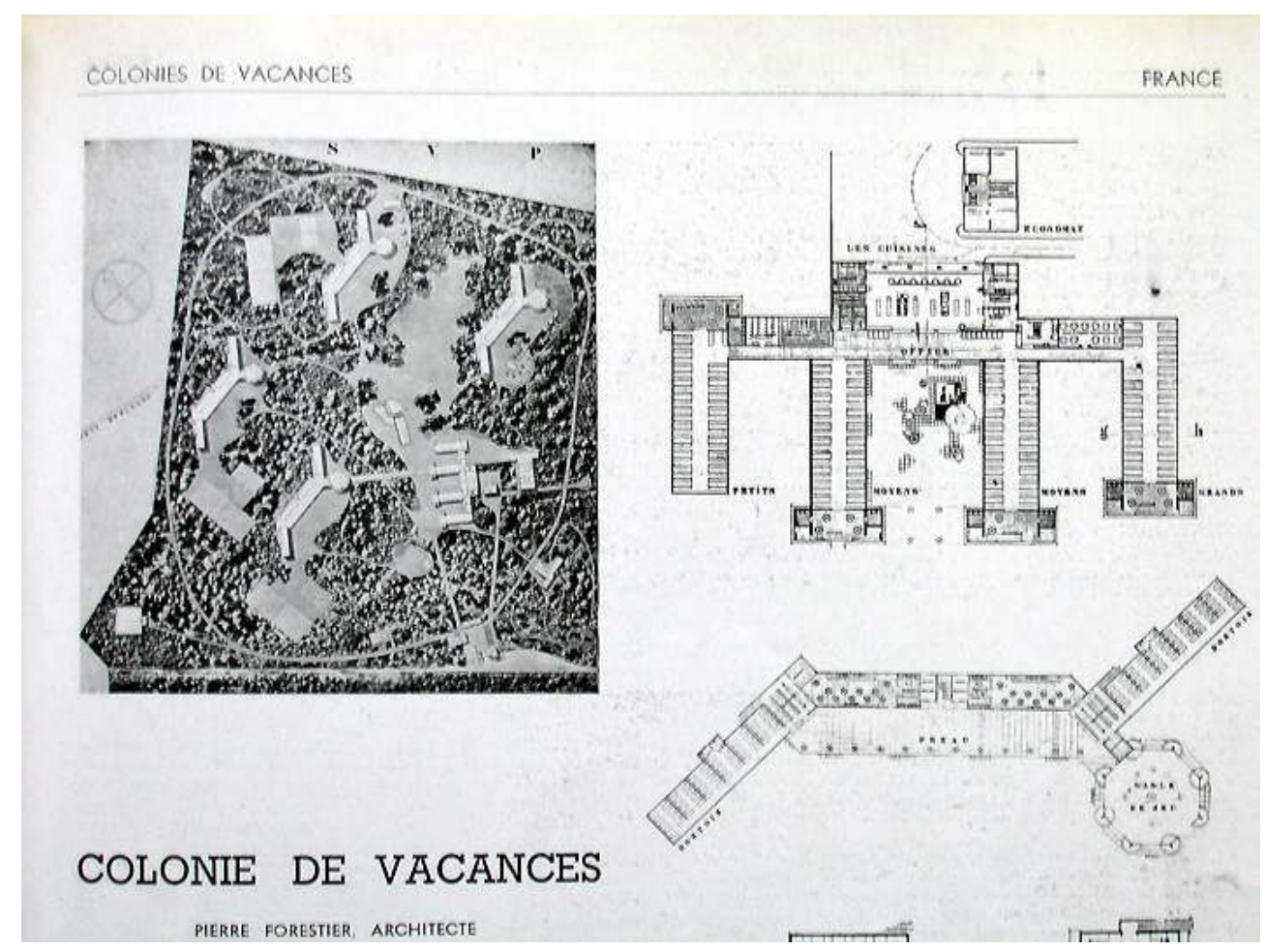

Ondres-Plage (Landes). Colonie de vacances, projet non réalisé par l'architecte Pierre Forestier Extrait de ARCHITECTURE d'AUJOURD'HUI, nº 7, juillet 1939, p. 19 


\section{6-1964 : l'apogée de la colonie de vacances éducative}

\section{L'élaboration d'une doctrine étatique : plans-modèles, instructions et règlements}

61 Dans l'état actuel de la recherche, il semble que le boom des colonies de vacances se soit produit après la Seconde Guerre mondiale, accompagnant la reprise de l'après-guerre et se poursuivant avec le développement de la natalité à partir de 1952 pour arriver à son apogée durant la décennie des années 1960. Le chiffre des colons aurait été multiplié par trois de 1945 à 1948, pour atteindre près du million d'enfants sortis des villes en 1948. Dès la fin de la guerre et jusqu'à la crise du pétrole, l'État joue un rôle central dans la construction et le fonctionnement des colonies. L'aide de l'État atteint son point culminant et représente, en 1946, plus de $45 \%$ du prix de journée. Après la guerre, les comités d'entreprise comme ceux des grandes industries, des banques ou des services publics multiplient les implantations de colonies. Par l'intermédiaire des Caisses pour les actions sociales en faveur du personnel, ils acquièrent et gèrent les domaines des nombreuses colonies.

$62 \mathrm{Au}$ lendemain de la guerre, les « camps et colonies de vacances » sont administrés par le 4e bureau de la direction générale de la jeunesse et des sports du secrétariat d'état à l'enseignement technique à la jeunesse et aux sports. Entrent dans le domaine de ces colonies de vacances les «établissements destinés à recevoir pendant les intersessions scolaires des enfants sains, c'est-à-dire dont les coefficients anthropométriques, la morphologie et l'état clinique sont conformes à la normale, enfants de 6 à 14 ans, justiciables d'un séjour au grand air $^{74}$. Elles se distinguent: a. Des sanatoria, aeria, preventoria, établissements qui accueillent des enfants malades pour un placement de longue durée $; b$. Des colonies thermo-climatiques et des colonies sanitaires temporaires qui reçoivent des enfants physiquement déficients ... $»^{75}$. En 1963, la définition de la colonie de vacances donnée par l'administration s'inspire de celle de 1949 en étant plus succincte sur la nature du séjour et plus explicite sur le personnel d'encadrement et les conditions réglementaires à remplir. "Les colonies de vacances sont l'œuvre d'institutions qui, sous la direction d'un personnel qualifié, accueillent des enfants sains de 6 à 14 ans pour un séjour temporaire en internant dans des établissements réunissant des conditions réglementaires de sécurité, d'hygiène et d'éducation $»^{76}$.

Dans les années 1950, les statistiques des services de l'État classent les centres de vacances accueillant les mineurs de 4 à 18 ans en 6 catégories : colonie maternelle, colonie de vacances, centre de vacances collectives d'adolescents, auberge de jeunesse, gîte d'étape et camp permanent. D'après le dépouillement des statistiques du Finistère pour l'année 1967, 85 à $90 \%$ des établissements recensés restent toujours des édifices « réemployés » pour cet usage, soit des écoles (60\%), soit des habitations individuelles ou collectives comme des châteaux, manoirs, villas, fermes ou des maisons familiales et des hôtels et même quelques bâtiments industriels $(20-25 \%)^{77}$. 


\section{Le choix de l'implantation : l'attrait de la montagne}

64 En 1937, la répartition des colonies entre la montagne (31\%), la plaine (31\%) et la mer (38\%) était à peu près équivalente, avec une légère préférence originelle pour le littoral. Dix ans plus tard, les prescriptions officielles préconisent, d'après une étude menée sur la région parisienne, d'inverser la tendance et de mettre résolument l'accent sur la montagne, lieu recommandé par le corps médical pour $60 \%$ des enfants. L'attrait pour la montagne était déjà largement amorcé avant la guerre parmi le corps médical, relayé par les architectes qui multiplient ces nouveaux programmes ${ }^{78}$.

Le climat montagneux méditerranéen est recommandé pour son niveau d'insolation et son plus faible taux de précipitation en été ${ }^{79}$. Parmi les autres facteurs à considérer dans l'implantation d'une colonie, on relève particulièrement dans les instructions de 1949 : le calme et la mise à l'abri des pollutions, un degré hygrométrique peu élevé, des zones bien dégagées pour favoriser l'aérothérapie, la recherche du voisinage des forêts pour l'ombrage et la coupure des vents, le sol perméable pour l'organisation des jeux, une altitude située entre 600 et $1500 \mathrm{~m}$. pour atténuer le choc climatique, l'alimentation en eau et le ravitaillement (surtout en lait), des communications aisées, un dépaysement favorisé par le voyage mais sans de trop longs trajets, un cadre pittoresque avec des pôles d'attraction (cours d'eau, plan d'eau, forêt au voisinage, rochers, dénivellation, ravins etc.), et l'éloignement des plages dangereuses ainsi que des gros bourgs et des petites villes de province ${ }^{80}$.

\section{9 : Instructions et règlements}

Ces «Instructions » éditées en 1949 viennent compléter l'arrêté signé le 14 avril de la même année sur l'installation et l'aménagement des colonies de vacances et fixent l'essentiel de la doctrine pour quelques décennies. Les principes d'aménagement recommandés reprennent en partie les réflexions pédagogiques déjà avancées avant la guerre et sont clairement définis : effectif restreint des groupes d'enfants ne dépassant pas 45 à 50 enfants, pouvant être doublé avec répartition par groupe d'âge homogène (6-11 ans, 11-14 ans) ; concentration des services communs (administration, infirmerie, cuisine et réfectoire); traitement des locaux séparés (dortoirs, ateliers) en unités par équipes autonomes et restreintes de 10-15 enfants ; caractère " ascétique » des locaux, en contact étroit avec la nature, sans luxe inutile; vaste terrain d'un hectare et demi pour les jeux, avec éventuellement un potager (fig. $\mathbf{n}^{\circ} \mathbf{1 8}$ ). La colonie était considérée comme une œuvre temporaire et évolutive, susceptible d'ajouts et de perfectionnements, il est donc recommandé de construire "en léger", sauf pour les ouvrages exposés à des conditions climatiques sévères. 


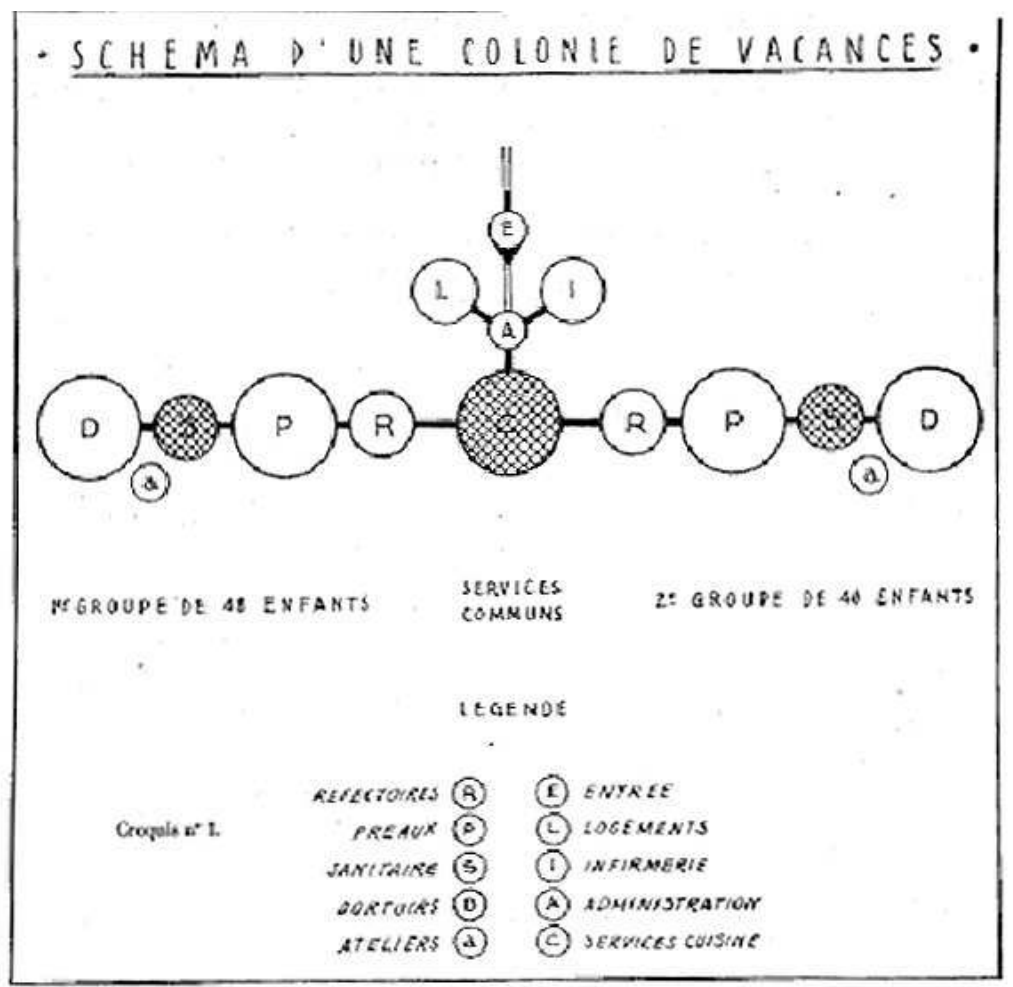

Schéma-type d'une colonie de vacances

Extrait de Instructions et aménagement des colonies de vacances..., 1949, p. 18

Le plan-modèle type d'une colonie double composée de huit équipes de douze enfants répond à une composition symétrique (avec une proposition de variante dissymétrique). L'entrée est encadrée par deux pavillons : l'un est destiné aux chambres du personnel et au gardien chargé pendant toute l'année de la conservation du matériel et du jardinage en vue de l'approvisionnement en légumes, l'autre est consacré à l'infirmerie-lingerie où sont stockés les vêtements des enfants et leurs bagages. Le bâtiment de l'administration fait face à l'entrée, avec la cuisine-buanderie qui communique avec les quatre salles à manger de chacune 24 enfants, séparées de celle de l'encadrement. Les deux préaux communiquent de part et d'autre avec les réfectoires; largement ouverts au sud, ils peuvent être fermés les jours de pluie et servir de salles de réunion ou d'ateliers. Les sanitaires (salle de douche, salle des lavabos et batterie de water-closets) sont placés dans le prolongement des préaux et directement accessibles des quatre bâtiments des dortoirs perpendiculaires, disposés en parallèle. Chaque dortoir est composé de deux pièces pour douze enfants chacune, séparées par une petite cabine de surveillance. Les aires de jeux et les petits ateliers font face aux dortoirs. Pour les dortoirs, les hauts plafonds de plus de 2,60 $\mathrm{m}$ de haut, très fréquents encore dans les constructions de la première moitié du $\mathrm{XX}^{\mathrm{e}}$ siècle, sont prohibés au profit d'une plus grande surface par enfant d'au moins quatre mètres carrés ${ }^{81}$. Les têtes des jeunes colons doivent être à l'abri des refroidissements : elles sont adossées à un mur ou protégées par des cloisons basses, signe d'un désir d'individualisation de l'espace consacré à chaque colon $^{82}$. Pour éviter la surchauffe des dortoirs durant l'été, on adopte les principes de l'architecture climatique : il est préconisé d'assurer une ventilation des combles par des évidements ménagés dans leurs parties basses et des cheminées de ventilation en faîtage. 
Une attention particulière est apportée aux « détails » des installations, significatifs des préoccupations pédagogiques partagées notamment avec les associations. Pour la « salle des lavabos » qui est utilisée le matin et avant l'accès aux réfectoires, il est recommandé d'installer un lavabo central en forme d'auge métallique ou mieux, en granito car la faïence est chère. La canalisation placée au-dessus de l'auge comporte 12 ajutages, ce qui permet en quatre services de procéder à la toilette d'un dortoir de 48 enfants. Les objets de toilette sont disposés à demeure dans un casier qui court sur le pourtour de la salle; une tringle est fixée en dessous des casiers pour le séchage des serviettes. On remarque que les prescriptions d'hygiène demeurent sommaires avec un seul lavabo collectif ...

\section{Les colonies des comités d'entreprises}

\section{Figure 19}

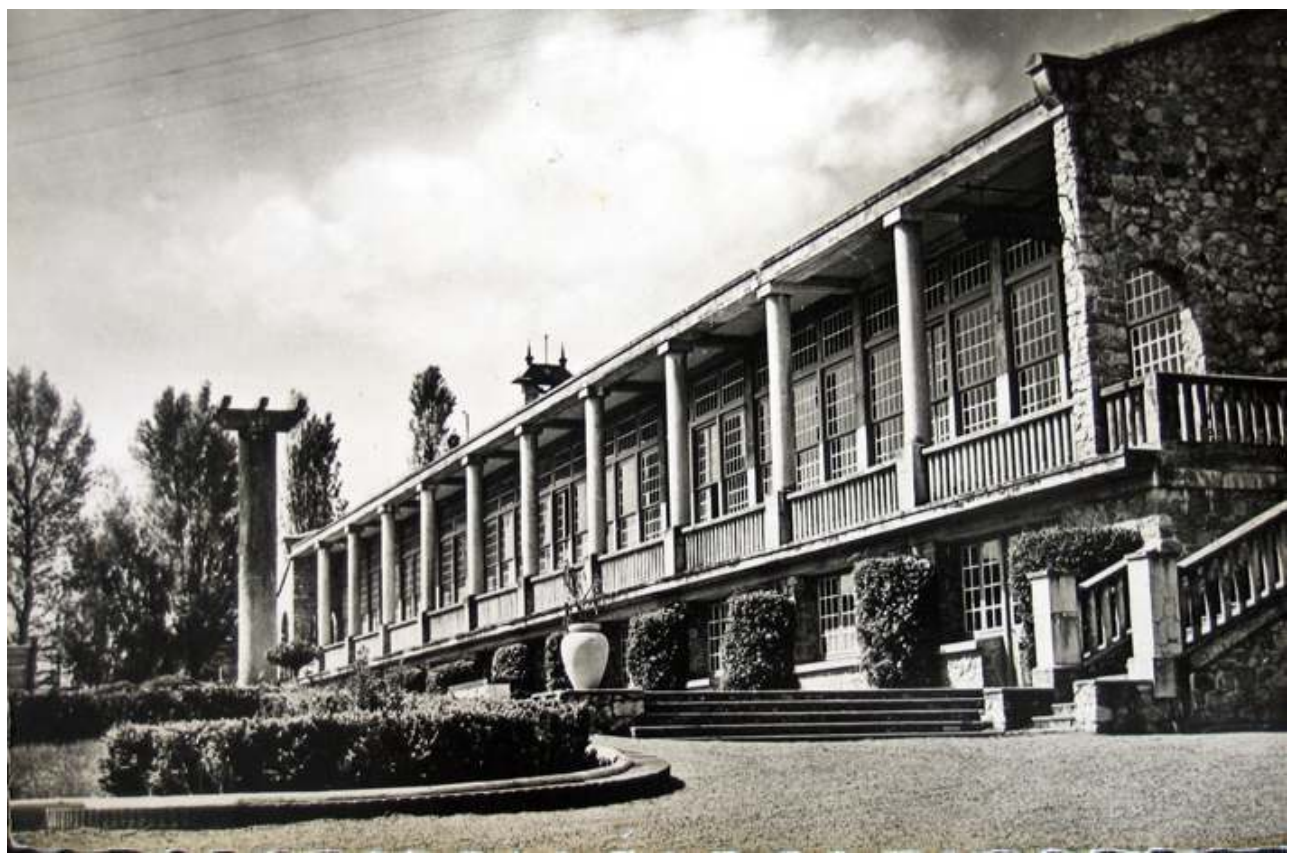

Montdidier (Somme). Colonie de vacances des Trois Doms, Société nationale des chemins de fer français (SNCF)

Carte postale, coll. B. Toulier (c) B. Toulier 


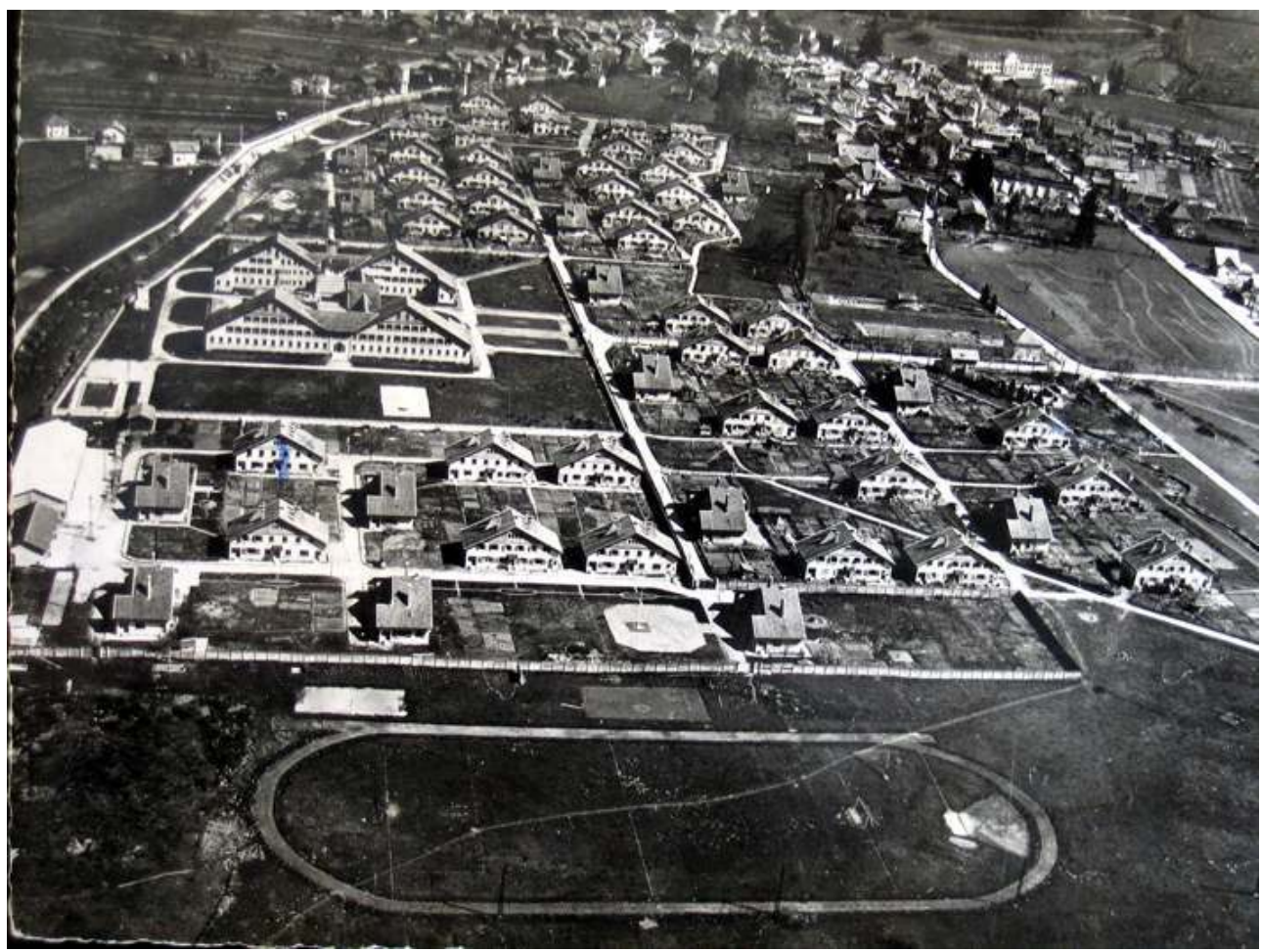

Pontcharra-sur-Bréda (Isère). Cité de la Viscamine, colonie de vacances des Houillères de la Loire Carte postale, coll. B. Toulier (c) B. Toulier

69 Tous les comités d'entreprises publiques comme Électricité et Gaz de France (EGF) ${ }^{83}$, la Société nationale des chemins de fer (SNCF) ${ }^{84}$ (fig. $\left.\mathbf{n}^{\circ} \mathbf{1 9}\right)$, les compagnies des Houillères ${ }^{85}$ (fig. $\mathbf{n}^{\circ} \mathbf{2 0}$ ) ou les Postes, télégraphe et téléphone (PTT) et les grandes entreprises industrielles (particulièrement dans les secteurs à la pointe du social dans les secteurs de l'automobile ${ }^{86}$ ou de la mécanique, de la métallurgie ou de la chimie, de l'aéronautique ou des hydrocarbures $\left.{ }^{87}, \ldots\right)$ continuent à investir massivement dans les centres de loisirs à destination des enfants ou des adultes. Les organisations sociales représentatives du monde rural suivent également le mouvement. La Fédération de la Mutualité agricole de l'Eure, par exemple acquiert en bord de mer à Cabourg (Calvados), un luxueux manoir néo-normand, Sweet-Home (fig. $\mathbf{n}^{\circ}$ 21). 


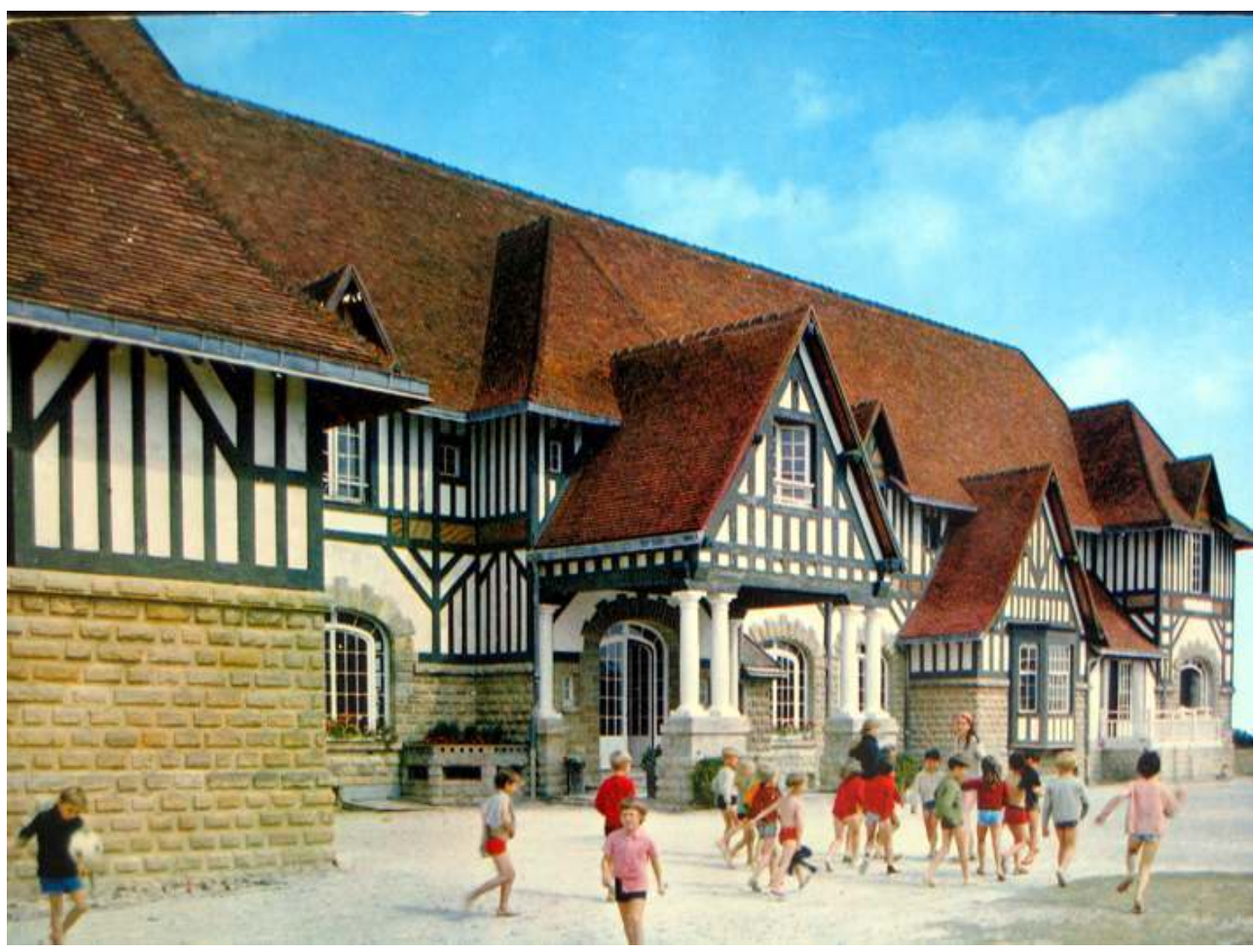

Cabourg (Calvados). Colonie de vacances Sweet-Home de la Fédération de la Mutualité agricole de l'Eure

Carte postale, coll. B. Toulier (c) B. Toulier

À titre d'exemple, dans les années 1950-1960, un colon du Loiret et sa sœur, enfants d'un agent d'Électricité et Gaz de France (EGF) ont ainsi séjourné alternativement durant leur adolescence dans des bâtiments en dur ou sous toile et voyagé ainsi aux quatre coins de la France pendant leurs vacances d'été. Outre la filature recyclée de Willer-sur-Thur dans le Haut-Rhin ${ }^{88}$, ils ont fréquenté d'anciennes cités ouvrières créées pour la construction de centrales ou de barrages comme Gèdre dans les Hautes-Pyrénées et Champs-surTarentaine dans le Cantal. Les colons orléanais ont été hébergés dans des colonies installées dans les châteaux de Gonneville à Blainville-sur-Mer dans la Manche, de Serbonnes dans l'Yonne, celui du domaine de Sibron à Signes dans le Var. Ils ont goûté aux charmes des vacances sous la tente dans les stations balnéaires de Grière-Plage à la Tranche-sur-Mer en Vendée, de Quimiac-Plage autour du château de Tréambert en LoireAtlantique, au camp de Maison-Blanche à Kérity dans les Côtes-d'Armor (fig. $\mathbf{n}^{\circ} \mathbf{2 2}^{2}$ et en Alsace à « Maison-Blanche » sur la commune d'Hohrob dans le Haut-Rhin. 


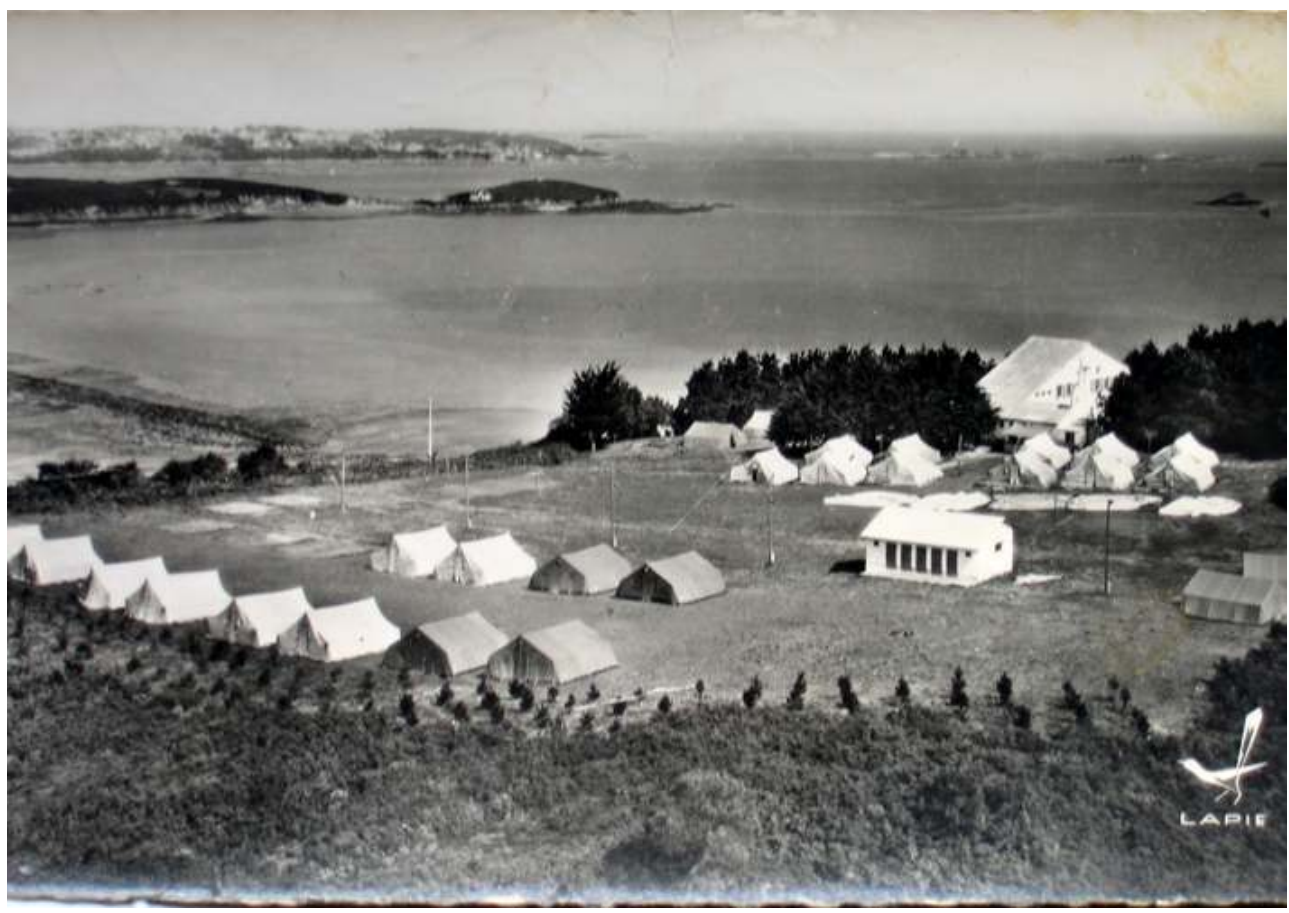

Kérity (Côtes-d'Armor). Camp de vacances de Maison Blanche de la Caisse centrale d'activités sociales (CCAS) du personnel des industries électrique et gazière

Carte postale, coll. B. Toulier (c) B. Toulier

71 Toujours d'après les cartes postales envoyées par nos colons, il semble qu'ils aient séjourné dans les bâtiments en dur spécialement construits pour une colonie à Trébeurden dans les Côtes-d'Armor, aux Rives à Saint-Jean-d'Hérans en Isère et à Campan dans les Hautes-Pyrénées ${ }^{89}$. Ce comité d'entreprise possède ou a l'usage de plusieurs centaines de centres de vacances. L'échantillonnage aléatoire constitué par les types de séjour de ces deux enfants durant près d'une décennie est assez significatif du patrimoine des colonies et centres pour enfants d'EGF : $33 \%$ de camps sous tente, $25 \%$ de bâtiments en dur construits à l'usage de colonie, $42 \%$ de bâtiments réemployés. Il faudrait multiplier de tels sondages et considérer que le capital des centres de vacances de ce comité d'entreprise est sans doute très largement au-dessus de la moyenne nationale.

\section{Le recyclage continue, malgré les interventions de l'État}

Dans les années 1950, l'État encourage les constructions nouvelles, jugées par lui plus économiques que les réemplois de bâtiments. Cependant, l'État ne réussira jamais à enrayer cette tendance dominante : la vogue d'achat des châteaux, notamment ceux du XIXe siècle, avec leurs nombreuses pièces, communs et dépendances, se poursuit (fig. $\mathbf{n}$ - 23). Les parcs et les grands jardins de ces grandes demeures sont très recherchés. Ils sont propices à de vastes emplacements de jeux et permettent l'établissement en dur des nouveaux bâtiments de la colonie. Ainsi par exemple, l'Association des amis de l'Enfance Saint-Laurent achète en 1947 le château de Hochberg, édifié en 1866 sur la commune de Wingen-sur-Moder (Bas-Rhin) ${ }^{90}$. 
Figure 23

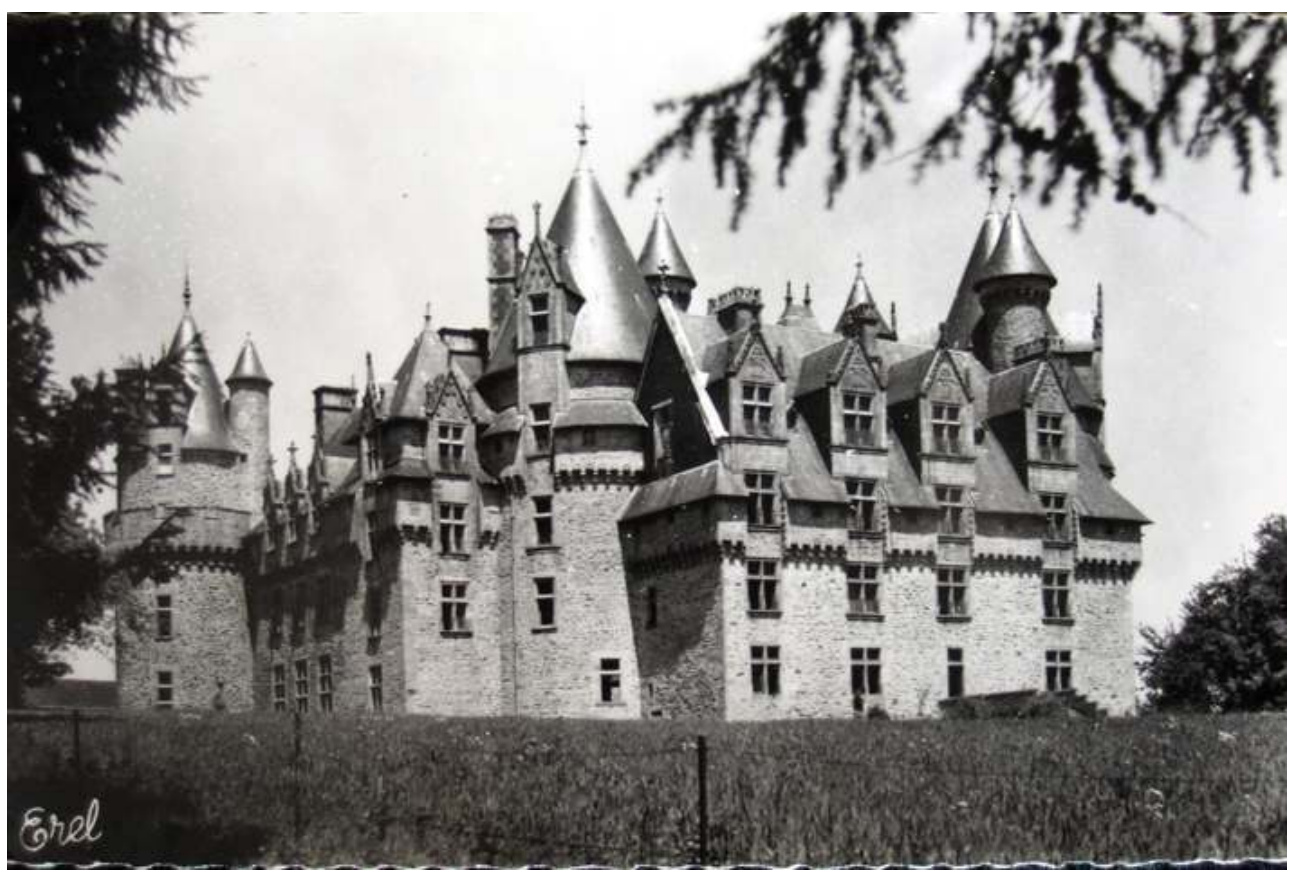

Lambertie (Haute-Vienne). Château, colonie de vacances de la Société française des pétroles (BP)

Carte postale, coll. B. Toulier (c) B. Toulier

Le « château, la maison bourgeoise, n'étaient faits que pour un petit nombre d'estivants et quelques domestiques. Les installations sanitaires, la distribution de l'eau, sont dans presque tous les cas, absolument insuffisantes; il en est de même aussi de la cuisine. Les chambres de l'habitation principale se prêtent mal à l'organisation de dortoirs. Il n'y a pas toujours de pièces assez grandes pour les salles de réunion. Il semble qu'on puisse poser en règle générale que le château ne peut guère servir lui-même que pour loger les services généraux, le personnel de ces services, abriter la cuisine, et permettre, à la rigueur, d'organiser réfectoire et salles de jeux. Dans cette hypothèse, il faudrait que les communs puissent apporter la solution au logement des enfants, sinon il faut compléter par les bâtiments légers, préconisés pour les colonies de vacances, à construire de toutes pièces ${ }^{91}$. Cette préconisation des services de l'État ne fait qu'entériner un usage fréquent depuis plusieurs décennies et prôné dans la présentation d'un modèle de colonie de vacances présenté en 1947 à Paris pour l'Exposition de l'habitation et de l'urbanisme. Le projet théorique d'Alfred Brauner, François Peatrik et Françoise Riesel-Brauner intègre le château et ses communs, convertis en centre administratif, placés au centre d'un "projet théorique d'un centre de vacances pour jeunes (1 000 personnes)». Le projet prévoit dans le parc une zone de logements permanents, une zone de campeurs libres et une zone de plein air ${ }^{92}$ (fig. $\mathbf{n}^{\circ} \mathbf{2 4}$ ). 


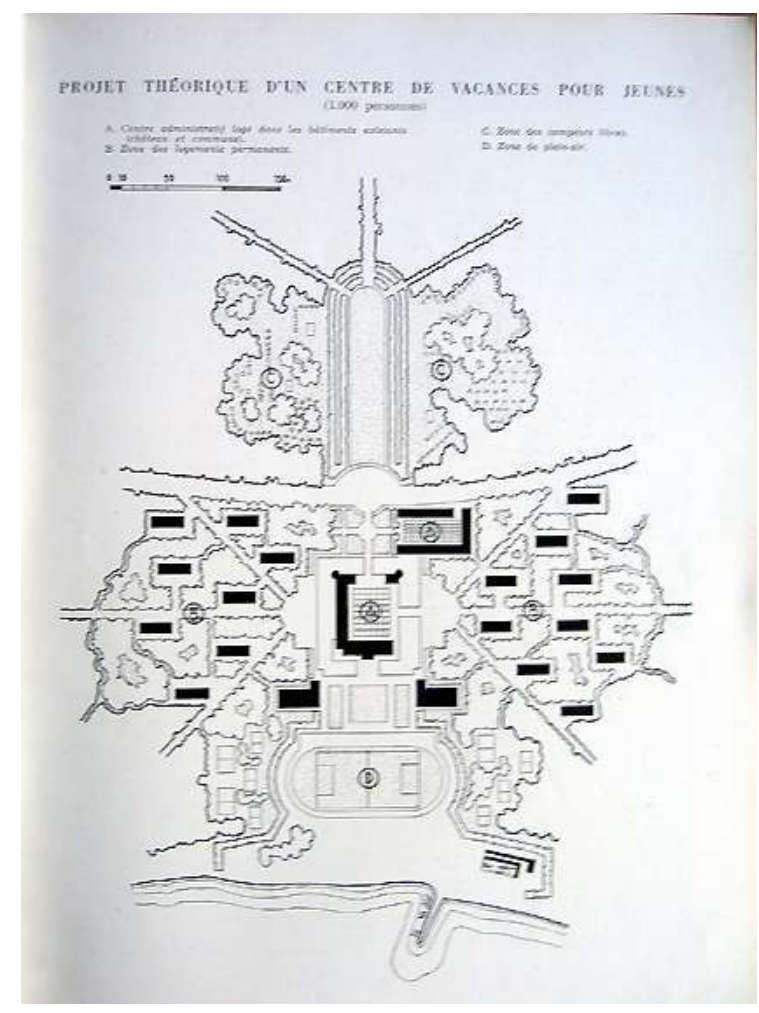

Projet théorique d'un centre de vacances pour jeunes (1000 personnes) par François Peatrick et Alfred Brauner

Extrait de L'ARCHITECTURE FRANÇAISE, $n^{\circ}$ 89-90, 1949, p. 13

En 1950, l'architecte A. Porte édifie dans le parc de l'ancienne villa Engelfred au Lavandou dans le Var les bâtiments d'une colonie, dans le goût provençal pour les villes de Montélimar et de Romans en gardant le bâtiment du château et ses annexes. Il reprend les principes exposés en 1947. Les trois bâtiments de dortoirs, avec sanitaires intégrés sont en rez-de-chaussée et les lits sont regroupés dans des box deux par deux, séparés par des cloisons basses, comme dans les Instructions ministérielles éditées l'année précédente ${ }^{93}$. Le préau circulaire et ouvert, selon un modèle déjà en usage dans les années 1930, est traité sous une forme de fabrique en béton sous forme de rotonde, couverte d'un dôme ${ }^{94}$.

Le château, reconverti, peut garder l'essentiel de son décor. Au château de Saint-Julien à Siccieu-Saint-Julien-et-Carisieu dans l'Isère, dans les années 1960, les travaux nécessaires à l'installation d'une colonie conservent l'essentiel du château et de ses aménagements de $1836^{95}$. Cependant, les châteaux doivent répondre aux règlements de sécurité et multiplier les issues de secours. Les nombreux escaliers de sécurité en fer sont un des signes du réemploi pour ces bâtiments à étage comme au château de La Luzière à la FertéSaint-Aubin dans la Sologne du Loiret, propriété de la ville de Bezons dans le Val d'Oise. Les galeries en bois et les escaliers extérieurs de l'ancien château Fourcade, à Guchen dans les Hautes-Pyrénées sont protégés par une ferme de charpente débordante, dans le style de ce château-chalet, ont été aménagés au moment de sa transformation en colonie ${ }^{96}$ . Ce concept de colonie-château perdure jusque dans les années 1960-1970 et bien audelà : il devient un des archétypes de la colonie à la française. 
76 Les villas et maisons de villégiature installées en bord de mer, à la campagne ou à la montagne sont aussi très demandées. Sur le littoral, dans les années 1950, la Villa Le Clos dans les Côtes-d'Armor, de style régionaliste, est aménagée en colonie dans les années $1950^{97}$. À la campagne, la ville d'Aulnay-sous-Bois acquiert une maison de villégiature d'un industriel à Villers-Cotterets dans l'Aisne ${ }^{98}$. La ville d'Hyères jette son dévolu sur une des « Barcelonnettes » dans la vallée de l'Ubaye, la Villa Les Charmettes à Jausiers dans les Alpes-de-Haute-Provence ${ }^{99}$. Les hôtels sont toujours aussi prisés. Vers 1960, André Joppé achète à Trébeurden dans les Côtes-d'Armor l'hôtel Printania élevé vers 1930-1931 face à la mer, pour y établir un centre nautique qui deviendra par la suite colonie puis centre de vacances ${ }^{100}$. L'ancien hôtel du Soleil-Levant, devant la petite plage de Saint-Trojan-lesBains en Charente-Maritime est transformé et agrandi pour une colonie.

Les ensembles fortifiés déclassés, sont très attractifs par leur position le long du littoral. La batterie des Saumonards à Saint-Georges-d'Oléron en Charente-Maritime est occupée par une colonie. Situées souvent dans des sites pittoresques, les friches de petites industries, avec leurs annexes, attirent également les repreneurs. Vers 1955-1960, certains ateliers de l'usine de produits chimiques de Banassac en Lozère sont recyclés pour les usages d'une colonie ${ }^{101}$. Dans le Jura, en 1951, la Caisse mutuelle d'action sociale du personnel d'Électricité et Gaz de France transforme la minoterie dite moulin de La Platière à Thoirette ${ }^{102}$. Dans ce département, à Saint-Lupicin, l'ancienne " tournerie » sur buis pour les pipes est cédée en 1954 aux associations dijonnaises de l'Étoile de Jouvence et Les Jouvencelles ${ }^{103}$. La lunetterie de Longchaumois et son logement patronal, racheté par la ville de Saint-Claude sont restaurés et transformés en colonie ${ }^{104}$.

\section{Le réaménagement des écoles rurales}

78 Le ministère de l'Éducation nationale, dont dépend le bureau des colonies de vacances, n'est cependant pas hostile à l'adaptation d'un établissement scolaire, situé à la campagne, ou à la double destination d'école/colonie issue de colonies transformées destinées à l'accueil permanent d'enfants ou d'écoles réutilisées en été avec un minimum d'investissement. Les «Instructions » de 1949 préconisent l'adaptation de petites écoles rurales. Les classes sont transformées en dortoirs et réfectoire, mais il faut construire à part sur un terrain contigu un bâtiment annexe pour la cuisine-buanderie, les sanitaires, les services et le dépôt des meubles de l'école.

79 L'administration propose aussi une autre variante du plan-type de la colonie avec une partie en dur pour les services, préaux et sanitaires pouvant provenir d'un bâtiment réemployé et une autre partie sous tentes pour les dortoirs (tente pour 6 à 8 enfants avec plancher de caillebotis et lits), réfectoires et ateliers. On retrouve cette formule dans certains établissements d'enseignement, comme l'École nationale de perfectionnement de Crotenay dans le Jura qui accueille à partir des années 1960, dans un cadre moderne des colonies de vacances. L'hébergement est assuré sous des tentes pour six enfants et le bâtiment en dur abrite le réfectoire, les services administratifs et les annexes (fig. $\mathbf{n}^{\circ} \mathbf{2 5}$ ). 


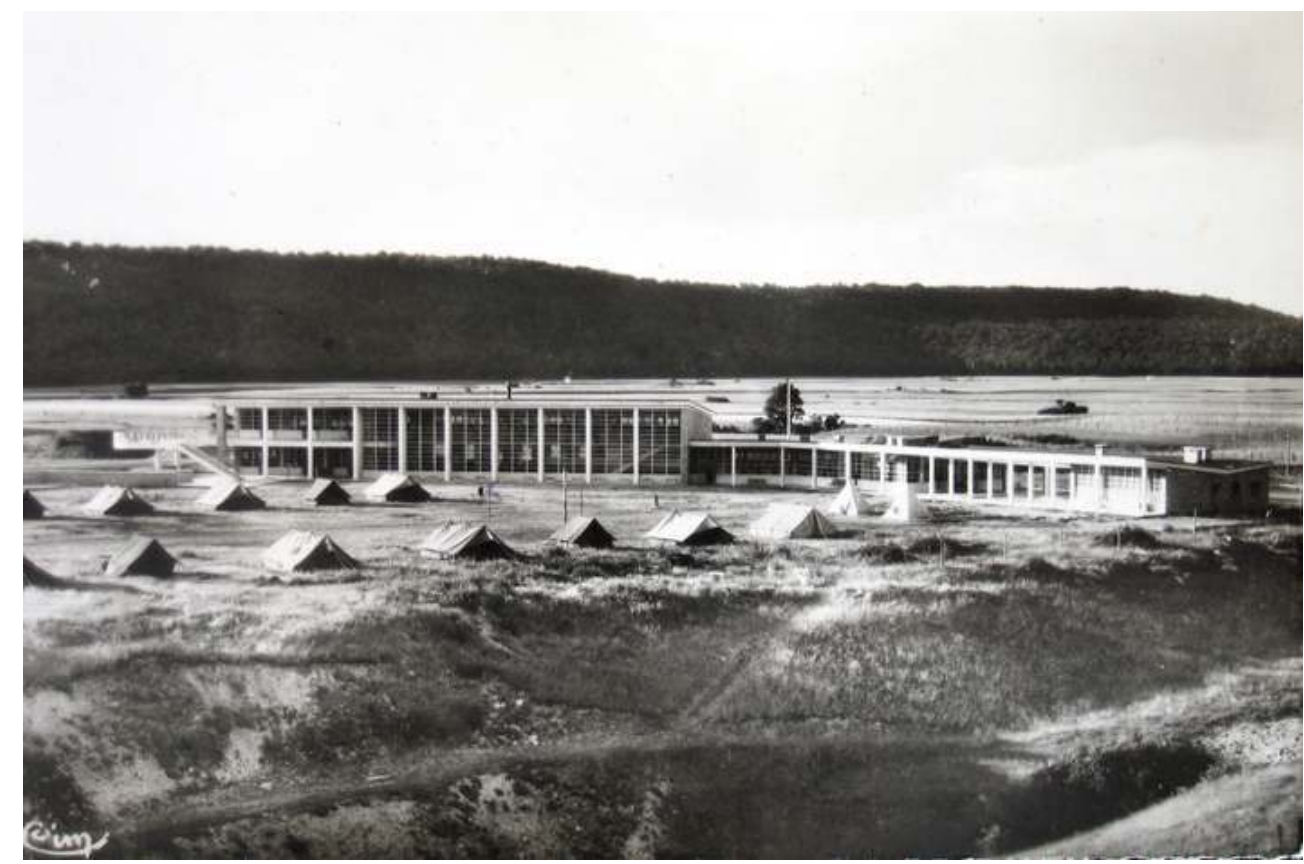

Crotenay (Jura). Colonie de vacances des écoles nationales de perfectionnement

Carte postale, coll. B. Toulier (c) B. Toulier

\section{Le village d'enfants sur un modèle pavillonnaire}

chambrées, pour briser l'ambiance des grands dortoirs construits en dur ou de petites tentes de 6 à 8 colons. En 1947, l'architecte François Peatrik propose à l'Exposition de l'habitation et de l'urbanisme de Paris des pavillons, simples ou doubles, par équipe de douze enfants ${ }^{105}$. Le bâtiment administratif de ce village est dénommé «Mairie». La « cité » est administrée par le conseil municipal, formé par les délégués des pavillons. La conception d'une "Cité des jeunes", ou d'une "République des jeunes» qui s'autoadministre dans un apprentissage à la décision collective est née dans les années $1930^{106}$. Elle a perduré après la guerre avec des variantes selon diverses pratiques pédagogiques empruntées à l'apprentissage d'une communauté religieuse et/ou républicaine. Les enfants sont regroupés par classe d'âge dans des bâtiments ou des tentes, par petites équipes en classes d'âge homogène dirigées par des chefs choisis parmi les enfants. Cette conception pédagogique s'adapte plus facilement au système architectural composé de pavillons ou de tentes, réaffirme l'idée d'un bâtiment « centralisé » et nécessite un lieu de rassemblement de tous les enfants autour d'un grand mât utilisé pour hisser un drapeau, à la manière militaire.

\section{L'architecture moderne au service d'un nouveau programme}

81 Les constructions inspirées de l'architecture néo-régionaliste, courantes avant-guerre laissent la place aux courants issus de l'architecture moderne. En 1947-1950, André Lurçat édifie «La Journée aérée » à Mériel (95) pour la ville de Saint-Denis avec laquelle il avait construit de nombreux programmes de logements sociaux ${ }^{107}$. La construction de la 
"colonie-école de plein air " est conçue dès 1945 pour une population enfantine de protection de l'enfance qui loge dans des immeubles insalubres. Située en bordure de la forêt de l'Isle-Adam, sur un éperon bien exposé dominant la campagne, la colonie est réalisée en deux tranches dans un espace boisé de trois hectares. La première comporte divers services généraux, un préau couvert et un réfectoire pour 200 enfants et fonctionne dès le début le jeudi et le dimanche pour la détente des enfants. L'ensemble des bâtiments, reliés par un portique aux baies largement ouvertes, présente une composition symétrique en $U$, donnant sur le plateau de rassemblement. La seconde tranche comprend un bâtiment isolé et séparé des autres par une aire de jeux, abritant les classes avec dortoirs et infirmerie pour un hébergement temporaire. La pénurie des matériaux impose à l'architecte l'emploi des moellons apparents et du béton pour les infrastructures et un réseau de cadres en bois boulonné pour les parties hautes. L'ensemble de ces bâtiments d'un seul niveau, largement ouverts sur la forêt et couverts d'un toit en terrasse est conçu selon un classicisme rationnel ${ }^{108}$.

Au début des années 1950, l'intervention des architectes Raymond Lopez et Raymond Gravereaux à la colonie de vacances de Saint-Servan en Ille-et-Vilaine est plus limitée ${ }^{109}$. Ils édifient pour l'Association paritaire d'Action sociale deux bâtiments-dortoirs parallèles, pour la colonie de La Barronie, établie dans la malouinière de La Barronie. Chacun des deux bâtiments abrite en rez-de-chaussée un dortoir pour 48 enfants, une chambre de surveillant et un bloc sanitaire, selon la réglementation en vigueur. À l'exception des pignons en pierre, tout est en bois : poteaux et charpente soutenant un toit en avancée couvert en aluminium ainsi que les fenêtres et impostes en bois verni, avec les volets peints en blanc.

Figure 26

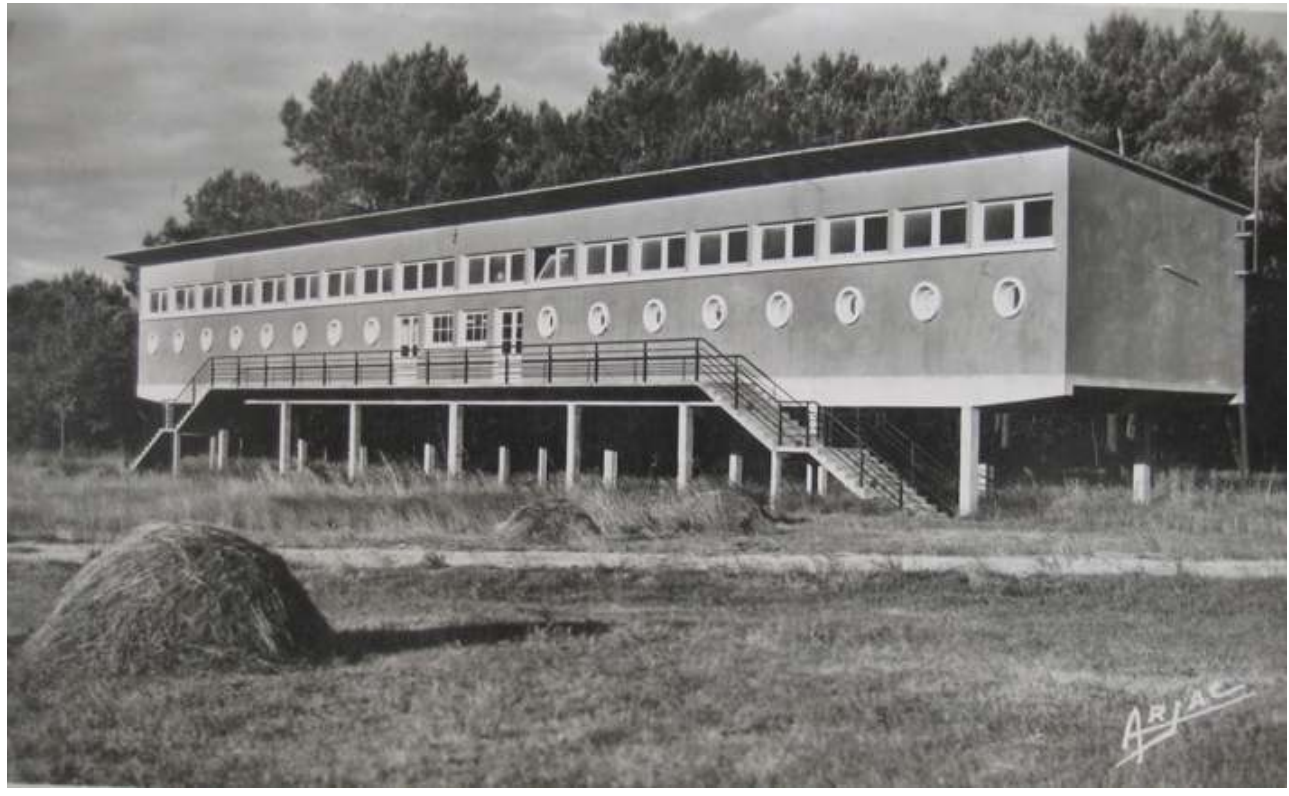

Ile d'Oléron (Charente-Maritime). Colonie de vacances du département de la Corrèze, dortoir Carte postale, coll. B. Toulier (C) B. Toulier

En 1950, à Oléron en Charente-Maritime, le département de la Corrèze élève une colonie sur pilotis à La Martière, selon les principes de l'architecture moderne : le registre des ouvertures du rez-de-chaussée surélevé est composé d'une série de baies circulaires, de 
style paquebot donnant sur le réfectoire, surmontées au registre supérieur d'un bandeau en continu de fenêtres à vasistas éclairant le dortoir ${ }^{110}$ (fig. $\mathbf{n}^{\circ} \mathbf{2 6}$ ).

\section{5-2007 : nouveaux centres de vacances et reconversions}

\section{4-1965, évolution de la doctrine et de la réglementation} liberté ». Ces principes « régissent le plan d'ensemble qui met en place les événements et en établit les relations. Les événements du plan d'ensemble sont les lieux de vie. Leur implantation et leur proximité doivent animer la vie collective tout en permettant une vie individuelle. Trop d'éloignement entre le logement, les salles à manger et les lieux d'activité, conduirait, sous prétexte de la recherche du calme, à rompre un rythme de vie qui est le lien le plus sûr entre l'enfant et la collectivité. Il apparaît dès lors que le logement ne réclame pas un éloignement géographique, première réaction contre notre vie urbaine, mais plutôt une orientation des façades des chambres sur un espace ouvert et calme, d'échelle réduite favorisant le réveil individualisé. Les salles à manger, recherchées à proximité du logement, mais ouvertes sur des orientations différentes, faciliteront les relations. Les lieux d'activité se greffent, à leur tour, sur ce premier noyau et se caractérisent par une plus grande liberté d'implantation, compte tenu de leur diversité. Leur situation dans le plan d'ensemble sera fonction des activités elles-mêmes ; jeux bruyants ou jeux calmes. Les services généraux sont à rejeter du noyau central et à implanter en périphérie du plan, tout en respectant les relations fonctionnelles indispensables " (fig. $\mathbf{n}^{\circ} \mathbf{2 7}$ ). Ce premier principe d'organisation entre vie individuelle et vie collective est doublé d'un second, basé sur l'articulation entre les bâtiments et leur environnement. Les réflexions pédagogiques menées notamment par les associations prônent notamment une plus grande autonomie laissée aux individus tout en favorisant leur apprentissage par la vie collective. 


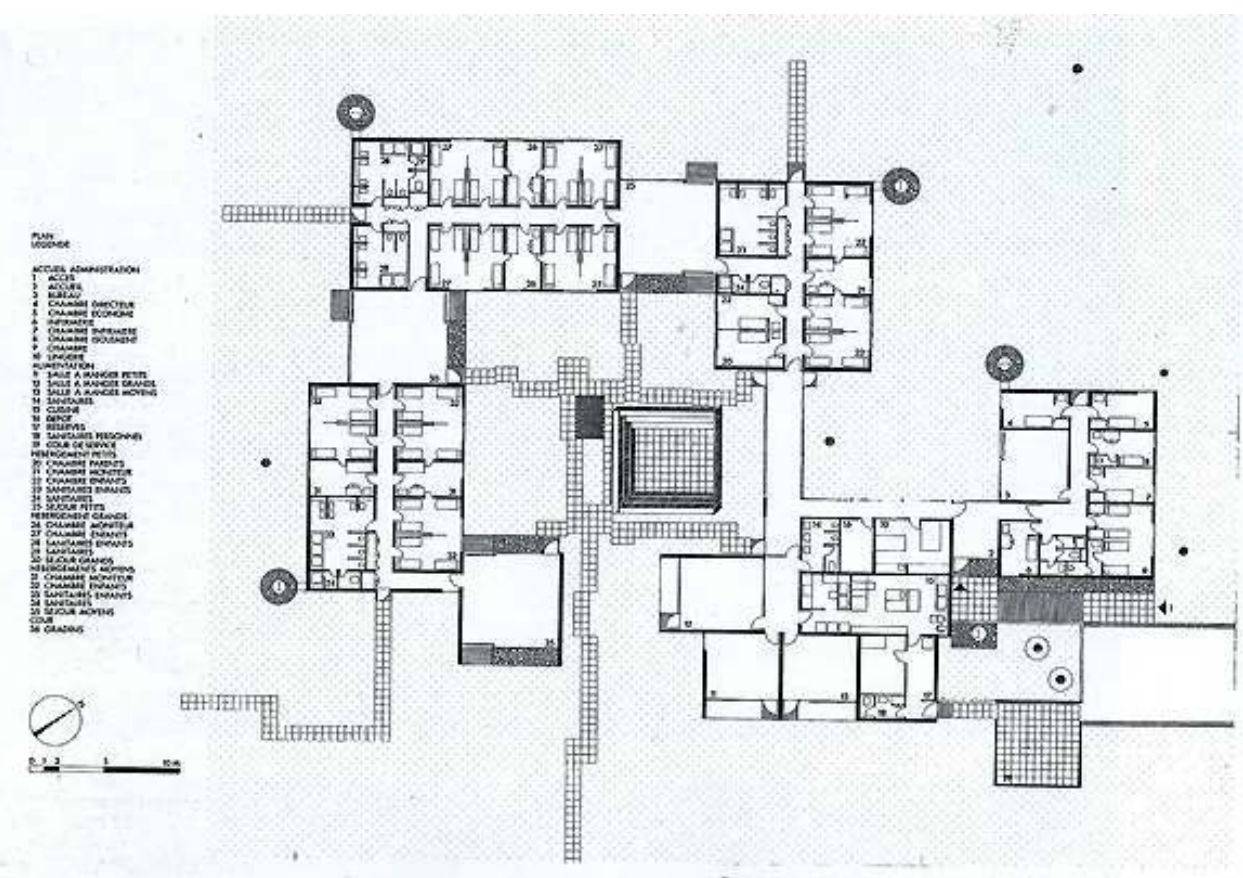

Ballan (Indre-et-Loire). Centre maternel du ministère de l'Économie et des Finances, projet réalisé par l'architecte Roland Schweitzer

Extrait de Les équipements sportifs et socio-éducatifs, $n^{\circ}$ spécial du Moniteur des travaux publics et du bâtiment, 9e édit. revue et augmentée, 1980

L'architecte Roland Schweitzer précise que «le contact avec la nature est essentiel pour l'éducation de l'enfant. Plus les liens avec la colonie de vacances et le site sont clairs et naturels, plus la création se fondra avec le cadre. Cette volonté d'intégration conduit à fragmenter les espaces construits et, par là même, à la création d'espaces ouverts qui sont autant de pénétrations du site dans la colonie » (fig. $\left.\mathbf{n}^{\circ} \mathbf{2 8}\right)$. 


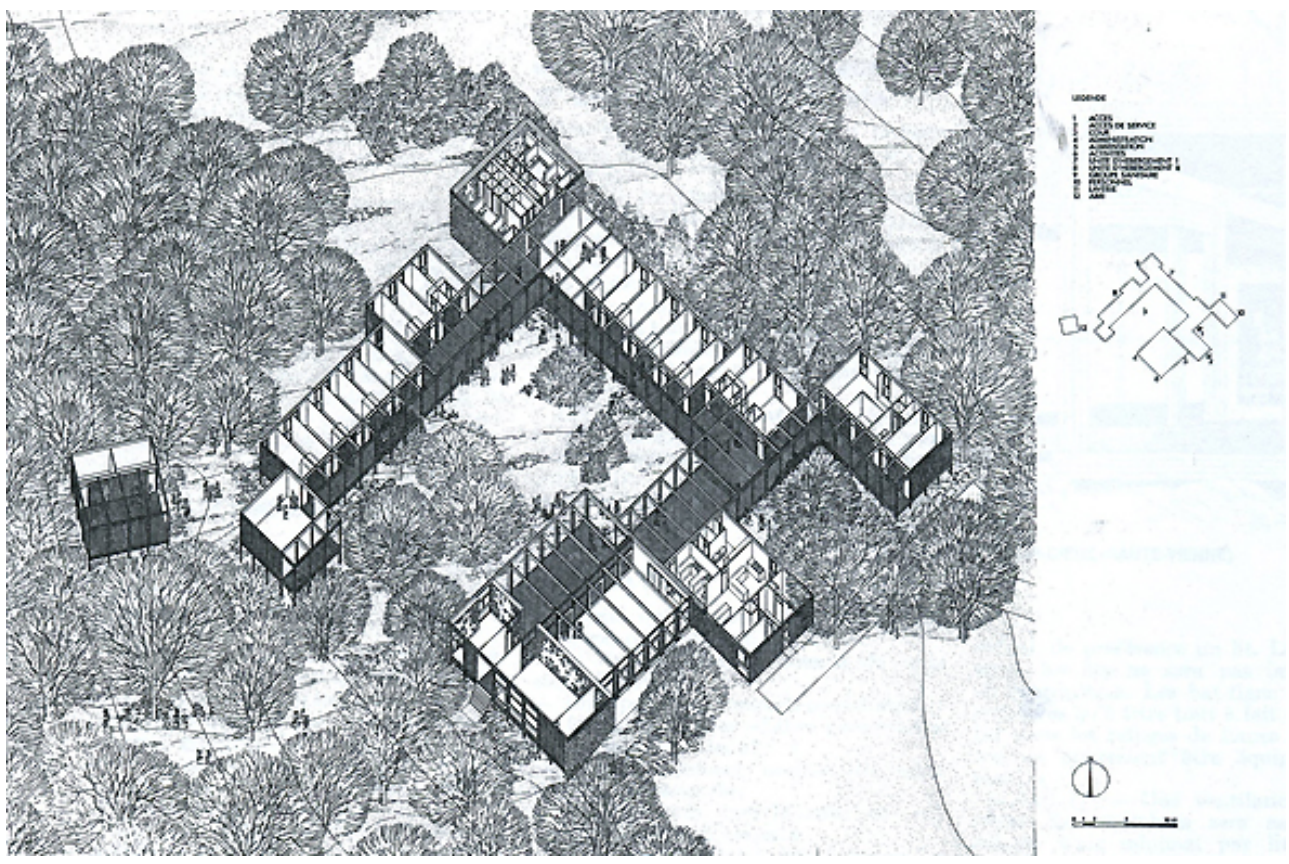

Four Cieux (Haute-Vienne). Centre de vacances pour préadolescents, projet réalisé par l'architecte Roland Schweitzer

Extrait de Les équipements sportifs et socio-éducatifs, $n^{\circ}$ spécial du Moniteur des travaux publics et du bâtiment, 9e édit. revue et augmentée, 1980

87 Une évolution très sensible apparaît entre les textes de 1949 et ceux de 1964. L'expression chambre remplace celle de dortoir : " elles sont à effectif limité, la meilleure capacité se situe entre 3 et 6 lits ». Les normes de distances et de surfaces ont été remplacées par des cubages d'air (8 mètres cube exigés par lit). L'évolution est identique pour les salles à manger qui ont remplacé les réfectoires : « elles seront bien éclairées, bien ventilées, bien équipées ». Les salles de réunion sont remplacées par des «lieux abrités d'activités : salles, préaux, abris qui seront adaptés aux conditions climatiques locales». La réglementation tient compte de la nature du centre de vacances en différenciant ceux installés dans des constructions en dur et ceux installés dans des camps sous toile, qui relèvent de la réglementation des campings. Dans ces centres de vacances temporaires où les activités se déroulent en majorité en plein air, le terrain est aménagé en jouant sur les modelés et les courbes de niveau ainsi que sur la végétation afin de caractériser des espaces pour les groupes et les activités.

\section{Des colonies fragmentées, humanisées et ouvertes sur la nature}

De nombreux architectes s'impliquent dans les constructions nouvelles qui ne représentent dans les années 1970 que moins de $10 \%$ du corpus recensé. On assiste à un dernier sursaut de constructions qui se termine dans les années 1970, largement inspiré des modèles issus des principes développés par les CEMEA et des villages de vacances, alors en pleine vogue. À partir de 1971, les architectes H. Chollet et J. Le Berre construisent pour les Postes et Télécommunications de Rennes au Bois de Pleuven à Saint-Yvi dans le Finistère, un centre de vacances. Le parti de plan s'inspire de l'architecture organique avec un soin particulier apporté aux espaces extérieurs liés aux 
rassemblements ludiques (jeux, théâtre, placettes, ...) ou aux espaces de transition pour relier les bâtiments dispersés sur le site. Les bâtiments aux larges toitures descendant parfois très bas, sont intégrés à l'environnement boisé : unités de sommeil disposées autour d'une place quadrangulaire, unités de services organisées en forme d'U, et diverses salles d'activités pour l'accueil de 115 enfants $^{114}$ (fig. $\mathbf{n}^{\circ}$ 29). La composition d'ensemble et le style de cette colonie du Bois de Pleuven sont à comparer avec une autre colonie contemporaine édifiée par l'architecte André Gomis pour le comité d'entreprise du comité de la Caisse d'allocations familiales de la région parisienne (CCAF) aux Roches Blanches à Douarnenez dans le Finistère ${ }^{115}$.

Figure 29

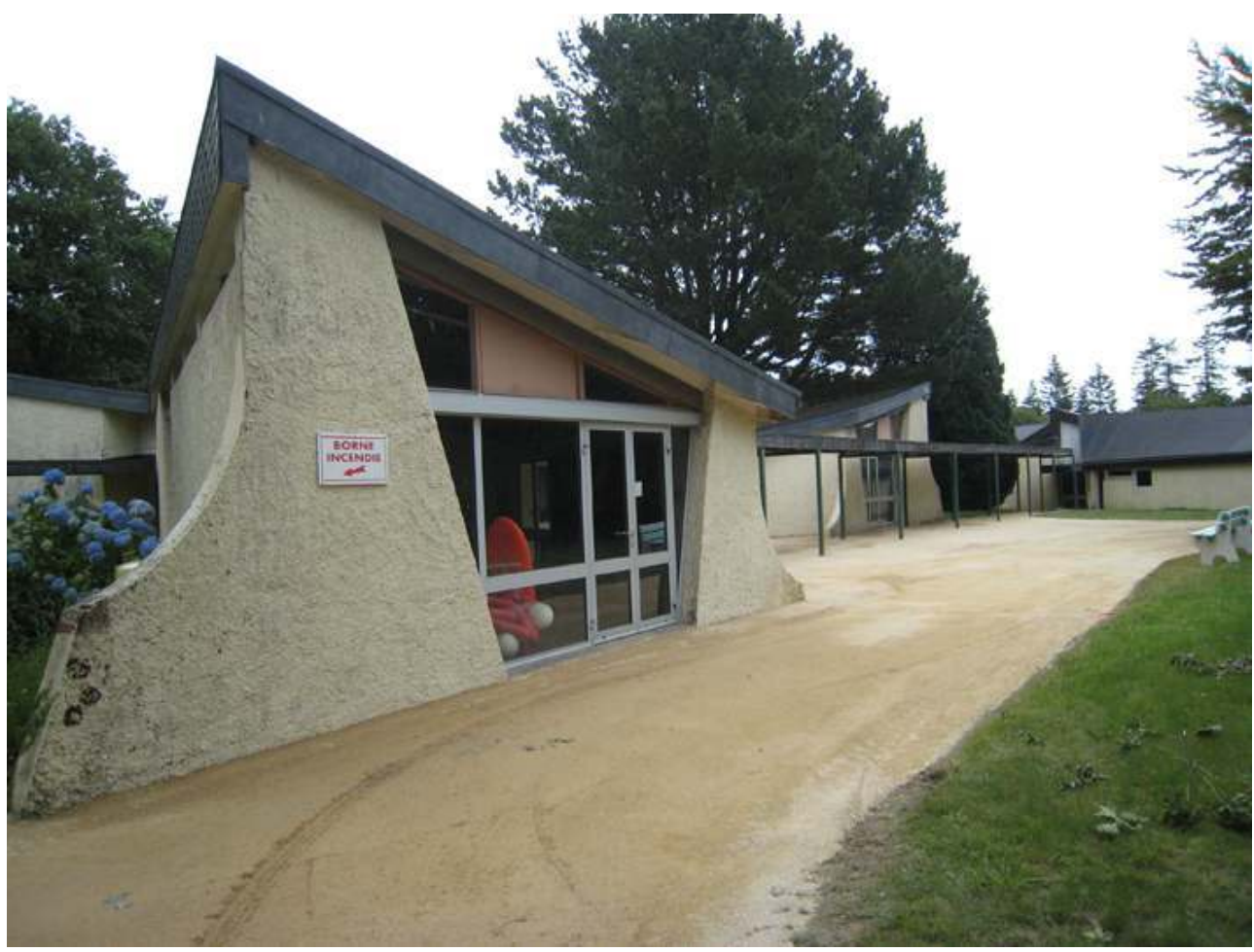

Saint-Yvi (Finistère). Centre de vacances du Bois de Pleuven de la Société nationale du chemin de fer français

Doutre, Maryline (c) SDAP Finistère, 2007

89 À travers ces deux exemples, on voit se dessiner la tendance à organiser les espaces construits en unités indépendantes, sous forme de pavillons à rez-de-chaussée, permettant le fractionnement de la collectivité en groupes autonomes, réparties selon les classes d'âge, dont les dimensions sont mieux adaptées à une vie sociale. Ce type d'organisation accroît également la souplesse nécessaire au bon fonctionnement en modulant la capacité d'accueil et en favorisant une appropriation aisée des espaces (volumes adaptés à l'échelle des enfants, qualité des liaisons, etc.).

\section{La création d'équipements standardisés pour le loisir de la jeunesse}

Au début des années 1960, la colonie traditionnelle ne répond plus aux attentes de la nouvelle société urbaine et ses possibilités d'accueil sont toujours insuffisantes. Il faut développer d'autres centres de loisirs pour les enfants comme les centres aérés et les 
camps de vacances. Le secrétariat d'État à la jeunesse et aux sports se tourne vers les " équipements de zone »: auberges de jeunesse, campings, bases de plein air, centres de montagne et de mer, centres aérés, et colonies de vacances. Comme en d'autres domaines (maisons de la culture, maisons de jeunes avec l'opération Mille clubs ou piscines type Tournesol, etc.), l'État met en place des équipements standardisés dont la répartition peut être homogène sur l'ensemble du territoire en raison de la nature des activités qu'ils sont destinés à satisfaire et qui sont entièrement liés à des conditions géographiques, climatiques ou touristiques. Le plan quinquennal 1960-1965 envisage la création de 255000 lits et une augmentation par cinq des crédits. Le plan suivant pour 1965-1970 annonce le développement de camps pour adolescents avec la construction de 1000 centres dont 700 sous toile.

91 La nouvelle colonie, transformée en "centre nautique », en "centre de mer » ${ }^{116}$ ou en "stage de ski», accorde une place prépondérante aux activités sportives. Les équipements sont conçus pour le plein emploi et destinés à l'accueil d'un centre de ski avec classes de neige en hiver et d'un centre de vacances en été.

\section{De nouvelles colonies sportives spécialisées : les centres de montagne}

Dans le département de Haute-Savoie, le pic des constructions neuves de colonies s'établit dans les années 1963-1966. De nombreux agrandissements s'échelonnent encore durant la période 1968-1972, et se prolongent jusqu'à la fin de la décennie ${ }^{117}$. Dès 1955 , Roland Macchi, fondateur de l'école de ski français, construit dans la nouvelle station de Châtel un premier bâtiment conçu pour l'accueil des colonies et des classes de neige. L'ouverture de la station d'Avoriaz en 1966, favorise la création d'un plus grand nombre de colonies associées à des classes de neige ${ }^{118}$.

Les instructions de 1949 mais surtout les recommandations du CEMEA de 1965 sont appliquées, en tenant compte des surfaces et des volumes demandés, mais aussi de la déclivité du terrain et de la protection contre les intempéries. On abandonne l'idée des pavillons pour des constructions monoblocs ou articulées en deux corps de bâtiment, exposés au sud. Les parties communes sont au rez-de-chaussée : cuisine et réfectoire, salles d'activités, salles de matériel pour le ski - et éventuellement salles de classe au rezde-chaussée inférieur ou dans une aile spécifique - et les chambres aux étages, avec un couloir central permettant une double orientation. Les chambres s'ouvrent sur un balcon ou une galerie (fig. $\mathbf{n}^{\circ} \mathbf{3 0}$ ). 


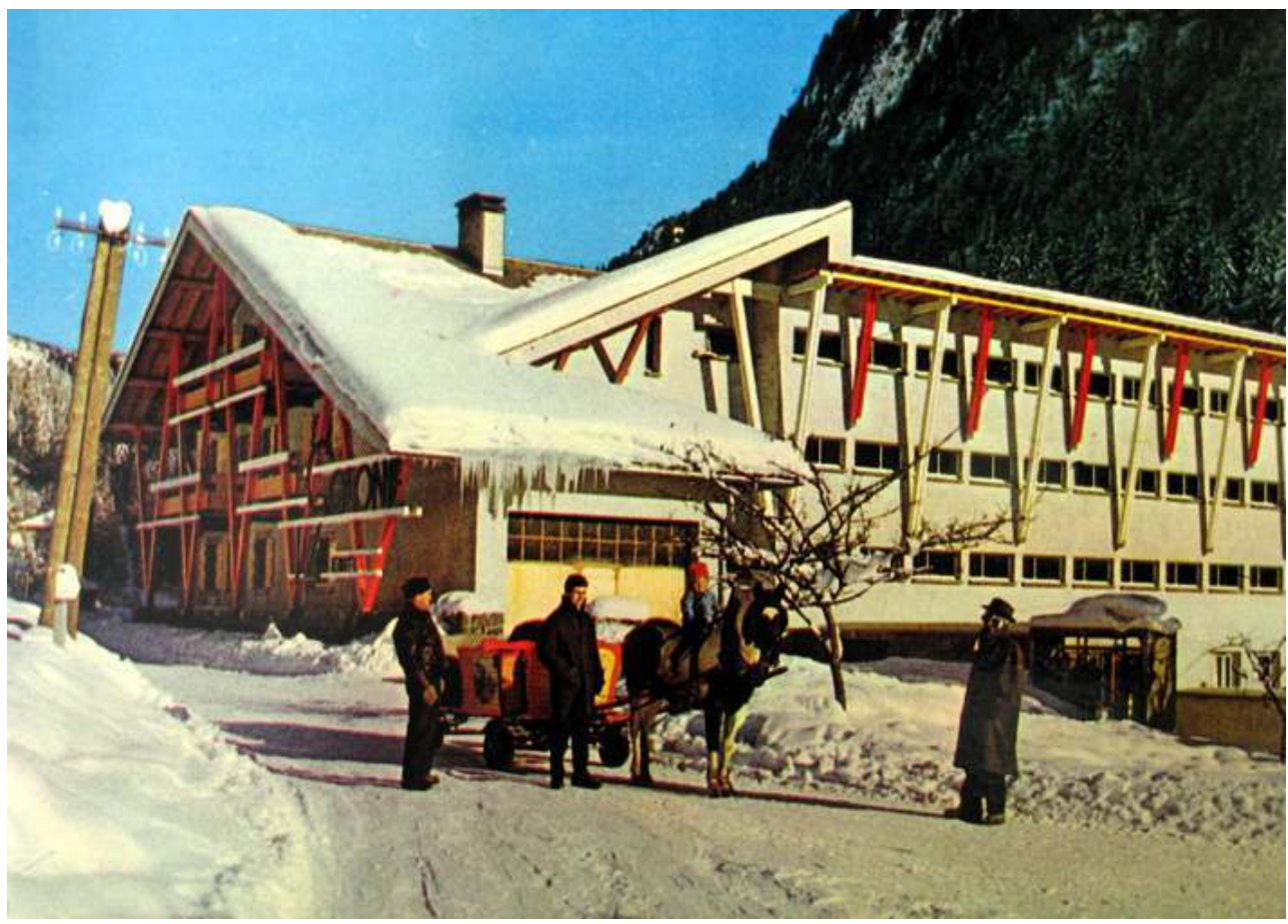

Montriond (Haute-Savoie). Hameau de Lavanchy, colonie de vacances et classes de neige du XIX arrondissement de Paris

Carte postale, coll. B. Toulier ( $)$ B. Toulier

De nombreuses collectivités construisent selon ce programme des centres de montagne autour des stations nouvelles et proches des domaines skiables ${ }^{119}$. En 1964, le département du Loiret construit à Chamrousse en Isère une " colonie » pour les stages de ski et les classes de découverte, gérée par l'Oeuvre universitaire des enfants du Loiret en vacances. En 1965-1968, la ville de Montreuil dans la région parisienne construit un « centre de vacances » pour 216 enfants (ou 6 classes) au Collet d'Allevard en Isère. Le programme est établi avec les instructeurs du CEMEA, en conformité avec les principes de l'association, et les architectes Pierre Andra et Paul Marme, architectes de la ville de Montreuil. Le centre s'élève en moyenne montagne, à la cote 1460. Il est composé de quatre bâtiments orientés au sud et s'ouvrant sur la montagne, reliés par des coursives semi-enterrées : un bâtiment abritant les services communs et administratifs, à l'une des extrémités ainsi que trois unités identiques orientées au sud, abritant chacune 60 enfants. Les unités de vie des enfants s'élèvent sur quatre niveaux, regroupant sous un même toit salles d'activités/ateliers au rez-de-chaussée éclairées par de larges baies vitrées et au premier étage, pour les salles de classe; les deux derniers niveaux sont à l'usage de « chambres » pour les enfants avec des baies fermées par des volets de bois. Chaque bloc reçoit 36 enfants et 4 adultes, soit l'effectif d'une classe. Les chambres donnant sur une coursive sont organisées en trois unités de deux chambres, avec sanitaire donnant sur la façade opposée. Les enfants sont dans des chambres de 6 et disposent chacun d'un placard et d'une table. La composition pavillonnaire s'articule avec un espace de plein air maitrisé pour les jeux, complément de l'espace ouvert du domaine skiable. 


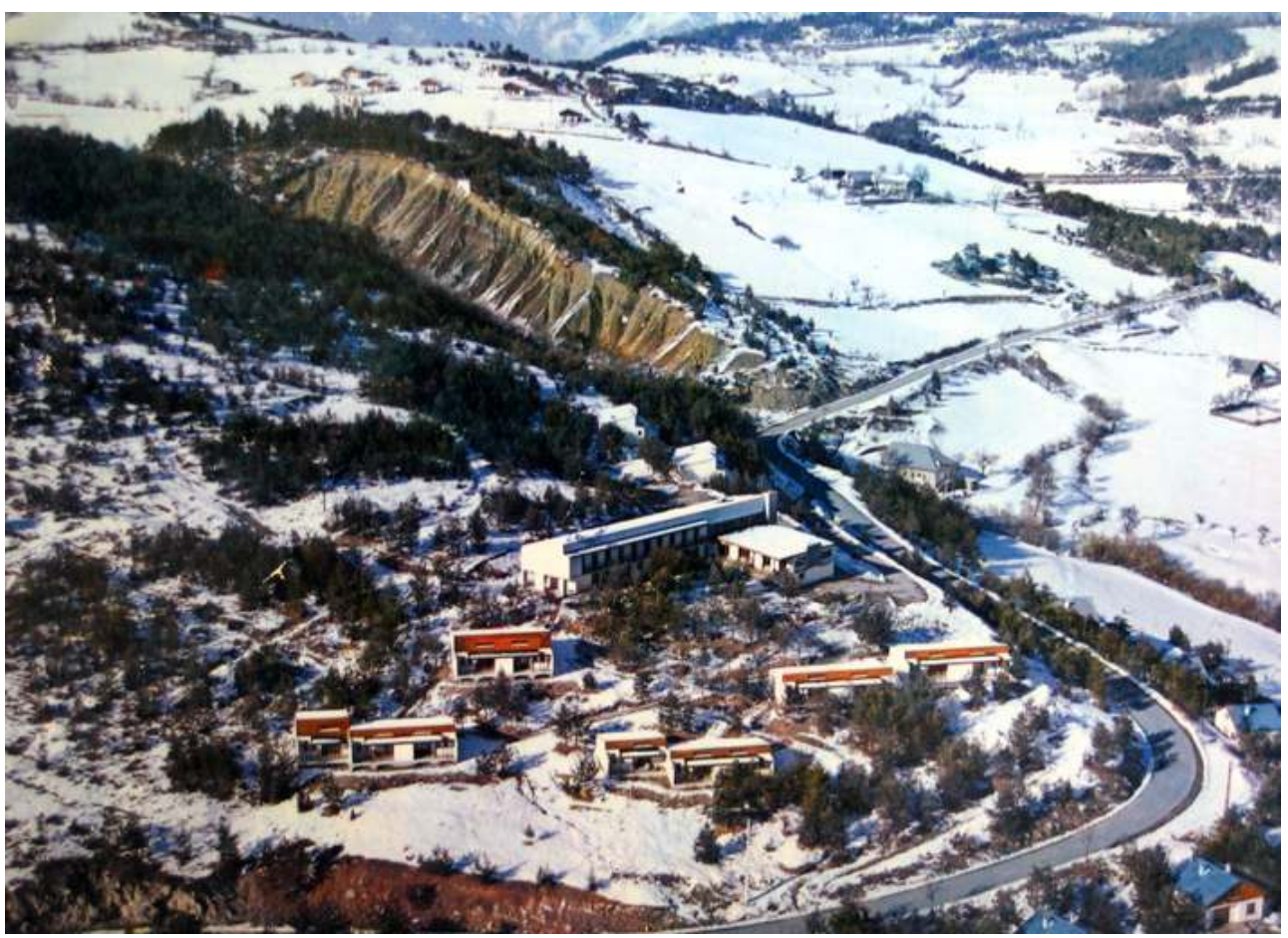

Seyne-les-Alpes (Alpes-de-Haute-Provence). Colonie de vacances «Azur et Neige »

Carte postale, coll. B. Toulier (C) B. Toulier

La rentabilité pousse les institutions et les organismes gestionnaires à multiplier, toute l'année, les classes vertes, classes de découvertes et, en milieu de montagne, classes de neige (fig. $\mathbf{n}^{\circ} \mathbf{3 1}$ ). Mais les colonies ont du mal à résister aux nouveaux centres aérés mis en place à partir de 1965.

\section{Le temps des reconversions}

Durant ces dernières décennies, l'État passe le relais, baisse ses subventions et accroît son contrôle sur le respect de la réglementation et particulièrement des règles de sécurité ${ }^{120}$. Les associations traditionnelles - qu'il faut distinguer des comités d'entreprises, caisses des écoles ou comités des œuvres sociales - et qui détiennent près de $40 \%$ des centres de vacances, s'essoufflent. Elles éprouvent de plus en plus de difficultés à entretenir les bâtiments souvent vétustes et à rénover les équipements hors normes. Les centres sont fermés, les bâtiments vendus ou des orientations nouvelles, plus rentables, sont mises en place, entraînant de larges transformations du bâti existant. Le désengagement des moyens de l'État et la décentralisation favorisent une coopération entre les collectivités publiques propriétaires, d'origine et d'accueil, et obligent les gestionnaires à une utilisation polyvalente des centres de vacances.

97 Le temps des reconversions entraîne de nombreux transferts de propriétaires et de gestionnaires. Comme l'État, les collectivités locales et les comités d'entreprise se désengagent; ils contractent avec des associations ou des sociétés qui ont pour objet de diversifier les équipements et les activités pour en garantir une meilleure rentabilité. Ainsi, le comité d'entreprise de l'Aérospatiale a cédé son centre de Saint-Jorioz à 
l'association Relais-Soleil dans les années 1990. Dans les mêmes années, les collectivités territoriales suivent la même voie. La mairie de Gravelines (Nord) cède la gestion de son centre d'Entremont en Haute-Savoie aux Pupilles de l'École Publique du Nord et la Fédération des Oeuvres Laïques de Haute-Savoie récupère la gestion du centre de Berneix qui appartenait à .la mairie de La Courneuve en Seine-Saint-Denis ainsi que le centre de Montmin qui relevait de la Caisse des écoles du $\mathrm{XV}^{\mathrm{e}}$ arrondissement de Paris. Comme les mairies, les caisses d'allocations familiales se désengagent ou sous-traitent avec des sociétés spécialisées : la colonie est devenue un produit de consommation à destination de certaines couches de population. Vers 1975, la fréquentation des Centres de loisirs sans hébergement (CLSV) (anciens centres aérés) est plus importante que celle des Centres de vacances (anciennes colonies de vacances) ${ }^{121}$. À cette date, le tiers des colons sont parisiens.

La situation est paradoxale. Si l'on observe que de nombreux centres de vacances ont été fermés - notamment des structures à fort effectif ou d'anciens établissements scolaires dont les normes de confort et de sécurité sont obsolètes ${ }^{122}$-, le nombre de structures a augmenté durant les décennies 1980-1990. Mais la vocation première n'est plus l'accueil des mineurs et des « colons ». Durant cette dernière décennie du XX ${ }^{e}$ siècle, l'appellation " centres de vacances" regroupe aussi des établissements scolaires comme des classes transplantées (classes de neige par exemple), des maisons familiales, des gîtes, des centres équestres comme des bases de plein air. Reconversion et diversification mêlent les anciennes « colonies » avec l'accueil de groupes de sportifs, l'ouverture d'un centre de loisirs communal sans hébergement (CLSH) pour les enfants du village ou d'un club du troisième âge ...

Un programme de rénovation est lancé en 1977 par le ministère chargé de la jeunesse et des sports $^{123}$, relayé par le programme d'action prioritaire $\mathrm{n}^{\circ} 14 \mathrm{du}$ VII $^{\mathrm{e}}$ Plan de développement économique social (1979-1981). Le programme concernait des centres de petite et de moyenne capacité, soit de 60 à 120 lits. "La rénovation doit s'interpréter comme une transformation et une modernisation tendant à améliorer en premier lieu : les possibilités d'activités à l'intérieur comme à l'extérieur des installations, tout en favorisant la création d'activités nouvelles; la qualité de l'hébergement des résidents; l'exploitation des installations par la recherche du plein emploi ; le caractère fonctionnel des installations». Les locaux s'ouvrent alors plus largement sur l'extérieur et l'hébergement laisse une plus large place à l'apprentissage de la vie en collectivité, en harmonisation avec une vie personnelle. Les dortoirs, encore largement en usage jusque dans les années 1950 sont " cloisonnés et remplacés par des chambres à effectif limité, dotées d'une bonne isolation, d'une bonne insonorisation et d'une bonne ventilation ». L'État, avec l'aide de la Caisse nationale d'allocations familiales et l'effort des collectivités propriétaires ou locataires, aurait participé à la rénovation d'une centaine de centres par an entre 1979 et 1982.

À partir de 1982, des prêts spéciaux sont mis en place pour favoriser « les hébergements de tourisme associatif à vocation sociale». Mais la réhabilitation aidée par l'État est irrégulière et atteint péniblement, malgré les «effets d'annonce » une moyenne d'une cinquantaine de projets annuels entre 1989 et 1995, ne permettant plus aux services de l'État d'élaborer de véritables politiques contractuelles avec les partenaires.

101 Les statistiques sur les ventes montrent que les centres de vacances cèdent à la pression immobilière, dans des milieux particulièrement recherchés pour les opérations immobilières comme le bord de mer. À La Prade près d'Hossegor, dans la commune de 
Messanges, la colonie de vacances du département des Landes, en fonction de 1930 à 1987, est vendue en 1999 et aménagée en hôtel par l'architecte Stephan Hallier ${ }^{124}$. Dans le département du Var par exemple, des locaux vétustes mais bien situés, au bord de la Méditerranée, n'ont eu aucune difficulté à trouver des acquéreurs. En Bretagne, près de $20 \%$ des établissements abritant des colonies de vacances ont disparu durant les trois dernières décennies ${ }^{125}$. En Haute-Savoie, le nombre des établissements est passé de 600 dans les années 1990 à 350 en 2007... ${ }^{126}$

Aujourd'hui, les enfants accueillis dans les « centres de vacances» atteignent un effectif de 850000 enfants hébergés dans des bâtiments « en dur ». En 2002, les départs en été ne représentent que moins de $74 \%$ des séjours, qui ont lieu aussi en hiver $(14,5 \%)$ et au printemps $(7,9 \%)$. Le milieu choisi est de préférence en bordure de l'Océan Atlantique et dans les Alpes, et avec une répartition dans les départements plus méridionaux, au sud d'une ligne partant de la Gironde au Jura ${ }^{127}$. En 1994, les départements les plus denses en centres de vacances sont la Haute-Savoie (525), l'Aveyron (456), la Haute-Loire (439), la Savoie (138), le Maine-et-Loire (375), le Lot (350), les Hautes-Alpes (339), l'Isère (301) et le Finistère (299), sur un total de 10429 centres de vacances ${ }^{128}$. La montagne, avec une très forte concentration dans les Alpes, représente $40 \%$ des destinations et un nombre de jours de fonctionnement le plus élevé. La mer, avec des équipements en général plus légers attire $35 \%$ des enfants et la campagne, avec $25 \%$, attire une bonne proportion d'enfants de maternelle ${ }^{129}$.

\section{Conclusions}

La colonie de vacances est née avec le mouvement de la villégiature moderne postindustrielle : elle apporte, loin de la ville, un dépaysement et un nouveau contact régénérateur avec la nature. La colonie de vacances n'est pas directement un programme d'architecture mais d'abord un mouvement migratoire et temporaire de "placement " des enfants hors des villes. La colonie est à la croisée de programmes à vocation hygiénique, pédagogique et sportive. Les constructions nouvelles n'ont jamais dépassé $10 \%$ du corpus des bâtiments employés à l'usage de colonie, mais constituent un vivier d'architectures remarquables et innovantes, dont quelques unités sont déjà protégées au titre des monuments historiques.

La diversification des offres de loisirs et la multiplication des temps de loisirs, le retour des vacances familiales et la baisse des aides financières pour ces vacances collectives, entrainent une accélération de la disparition des colonies. Depuis les années 1970, plus de $30 \%$ des colonies de vacances ont disparu. Aujourd'hui, l'évolution des formules de vacances est telle que le centre de vacances ne fait plus référence à un équipement ni à un bâtiment, mais plutôt à une prestation offerte à une famille par une institution sous le contrôle de l'État.

Il est urgent de porter un nouveau regard sur le patrimoine des centres de vacances, qui ont échappé jusqu'à ce jour au mouvement d'élargissement de la notion de patrimoine. Le patrimoine immobilier des colonies de vacances est étroitement lié au patrimoine éducatif, lieu d'expérimentation privilégié des méthodes pédagogiques. Le patrimoine des centres de vacances participe à la lutte contre l'exclusion et à l'offre diversifiée de loisirs et de vacances pour les jeunes. Le centre de vacances reste un facteur de développement économique, intégré à l'aménagement du territoire, notamment dans le secteur rural et les régions de montagne. 


\section{NOTES}

1. Cet article vient de faire l'objet d'une publication. Voir: Toulier, Bernard. Holiday camps, what architecture? In: Balducci, Valter, Bica, Smaranda. Architecture and society of the holiday camps. History and perspectives. Timisoara: Orizonturi Universitare; Mirton, 2007, p. 36-59.

2. Corbin, Alain (dir.). L'avènement des loisirs 1850-1960. Paris : Aubier, 1995, p. 110 et ss.

3. Pour une histoire des colonies de vacances, voir notamment: Plantet, Eugène, Delpy, Arthur. Colonies de vacances et œuvres du grand air en France et à l'étranger. Paris : Hachette, 1910, IX ; .Rey-Herme, Philippe-Alexandre. Colonies de vacances. Origines et premiers développements : 1881-1906. Paris : Librairie centrale d'éducation nouvelle, 1954 ; Rey-Herme, Philippe-Alexandre. Les colonies de vacances en France. 1906-1936. Paris : Fleurus, 3 t., 1961 ; Muller, Gérard. Les premières colonies de vacances. Eléments pour l'histoire de l'éducation populaire, Actes des journées d'études organisées par l'Institut national d'éducation populaire les 28, 29, 30 avril 1975, Marly-le-Roi, 1976; Houssaye, Jean. Le livre des colos. Histoire et évolution des centres de vacances pour enfants. Paris : La Documentation Française, 1989 ; Houssaye, Jean. Aujourd'hui, les centres de vacances. Vigneux-sur-Seine : Éditions Matrice, 1991 ; Vulbeau, Alain. Du gouvernement des enfants. Paris: Desclée de Brouwer, 1993 ; Houssaye, Jean. Et pourquoi que les colos, elles sont pas comme ça ? Vigneux-sur-Seine: Éditions Matrice, 1995; Downs, Laura Lee. Childhood in the promised land: working-class and pedagogical reform in the colonies de vacances in France, 1880-1960. Durham and London: Duke University Press, 2002 ; Lebon, Francis. Une politique de l'enfance, Du patronage au centre de loisirs. Paris : L'Harmattan, 2005 ; Houssaye, Jean (dir.). Colos et centres de loisirs : recherches. Paris : Matrice, 2007.

4. Bordelet, Brigitte. Vers une architecture de loisirs (colonie de vacances). Rouen : Ecole d'architecture de Normandie, 1987 ; GOUMY, Philippe. Les centres de vacances pour enfants des origines à nos jours. Paris : Ecole d'architecture de Belleville, mémoire TPFE, 1992. Pour une première approche sur l'histoire des bâtiments: Toulier, Bernard. Pour une histoire des «maisons» de colonies de vacances en France. Architetture per le colonie di vacanza. Esperienze europee. Firenze : Alinea Editrice, 2005, p. 30-36.

5. Au 17 octobre 2007, la base Mérimée recense seulement 71 colonies de vacances, dont moins de $10 \%$ sont des constructions ex-nihilo. http://www.culture.gouv.fr/public/mistral/merimee_fr : colonie de vacances. L'échantillonnage proposé semble représentatif de la réalité, bien que $90 \%$ des fiches ne mentionnent pas la date de la transformation des bâtiments en colonies de vacances. Il faudrait aussi étendre les investigations aux colonies et protectorats. Pour le Maroc, par exemple, dans les années 1920-1930, plusieurs colonies de vacances ont été construites dans la ville de villégiature de montagne d'Ifrane pour les enfants du personnel du Chemin de fer ou des Postes et Télégraphes (architecte Gaston Goupil). Voir dans la Base Archidoc: notice 00056634. Source A.P. SADG, Paris. Voir aussi dans la base Mémoire, les nombreux clichés sur les colonies de vacances des Alpes Maritimes provenant du fonds Jean Gilletta et celles sur la colonie du Boulay-Thierry (Aisne) provenant de la collection Anne Morgan (Aide aux régions dévastées, 1919-1924). Anne Morgan, dirige à partir de 1917 le Comité américain pour les régions dévastées (CARD) qui a en charge le sud de la Picardie. En 1920, le CARD installe un camp de vacances à Francfort (Oise) dans la forêt de Compiègne, avec du matériel et des tentes en provenance des Etats-Unis.

6. Ministère de la Santé Publique. Notice questionnaire à remplir par les œuvres organisant les camps, des colonies de vacances ou des garderies de plein air. Circulaire du 1er déc.1925. 
7. Centre de vacances: "Constituent un centre de vacances les accueils collectifs de mineurs avec hébergement, [...] pendant les périodes de vacances visées à l'article L.521-1 du code de l'éducation, dès lors que le nombre de mineurs accueillis est au moins égal à douze et que la durée de leur hébergement est supérieure à cinq nuits consécutives ». Décret $\mathrm{n}^{\circ}$ 2002-883 du 3 mai 2002 relatif à la protection des mineurs à l'occasion des vacances scolaires, des congés professionnels et des loisirs. JO 5 mai 2002. Centres de vacances : «La vocation des centres de vacances est d'offrir un accueil collectif " plein temps » à des enfants et des jeunes éloignés de leur famille pour une durée moyenne de 3 semaines l'été et d'environ 10 jours pendant les petites vacances scolaires, et ce sur la base d'un projet pédagogique. Le public auquel s'adressent les centres de vacances est scindé par la réglementation en trois tranches d'âge: les centres de vacances maternels ( 4 à 6 ans), les centres de vacances pour enfants ( 6 à 14 ans) et les centres de vacances pour adolescents (12 à 18 ans)». Equipements sportifs et socio-éducatifs, t. 1 . Le Moniteur des travaux publics et du bâtiment, hors-série, 1993, 11e éd., p. 360.

8. Les camps de vacances sont des colonies de vacances dont l'hébergement s'effectue sous toile. Une partie des bâtiments peut être en dur (sanitaires, cuisine, réfectoire). Le camp peut être fixe ou mobile.

9. Les historiens suisses contestent cette prééminence zurichoise. Pour Marianne Zutter, la première colonie aurait été organisée par la communauté suisse-allemande de Genève, avec le pasteur Otto Steiger, dès 1875. Zutter, Marianne. Colonies et camps de vacances: bref historique (2001). http://www.camps-vacances.ch

10. Lurieu, G. de, Romand, H. Etudes sur les colonies agricoles de mendiants, jeunes détenus, orphelins et enfants trouvés. Hollande, Suisse, Belgique, France. Paris : Librairie agricole de la Maison rustique, 1851, XIX.

11. Larousse universel en 2 volumes, 1922, vol. 1, p. 485.

12. Parmi les plus importantes, citons les colonies de Luc, Vailhauquès (Hérault), Combelles, Belle-Ile-en-Mer (Morbihan)... Pour mémoire : Mettray (Indre-et-Loire), créée en 1839. Voir dans la Base Mérimée : notice PA37000016; Chaptelat (Haute-Vienne), fondée par le chanoine Féret vers 1830-1840. Base Mérimée : notice IA00031429 ; Abbaye mauriste d'Aniane (Hérault), créée en 1845. Base Mérimée : notice IA34000005; Abbaye cistercienne dite Notre-Dame à Saint-Nicolaslès-Citeaux à Nuits-Saint-Georges (Côte-d'Or), créée en 1846. Base Mérimée : notice IA21000096; Nazareth à Angers (Maine-et-Loire), créée en 1853. Base Mérimée : notice IA49006817; SainteAnne dans l'Ile du Levant, à Hyères (Var), créée en 1861. Base Mérimée : notice IA83000192; Gaillon (Eure). Base Mérimée : notice IA00017636; Béguey (Gironde), pour les pensionnaires de l'hôpital de Cadillac (Gironde). Base Mérimée : notice IA33000019; Colonie agricole et industrielle d'Haguenau (Bas-Rhin), créée en 1875. Base Mérimée : notice IA00061923.

13. Par exemple, colonie pénitentiaire industrielle de la coutellerie Sommelet Dantan et Cie puis Fils et Neveu à Nogent (Haute-Marne) de 1867 à 1879 puis à Bologne (Haute-Marne) de 1879 à 1921. Voir dans la Base Mérimée : notice IA00070425; notice IA00070407.

14. Un concours public. Revue générale de l'architecture et des travaux publics, 1849-1850, col.39-42. Programme d'un concours pour la rédaction d'un avant-projet d'une "coloniehospice ", implantée dans les environs de Nantes (Loire-Atlantique).

15. Renseignement aimablement communiqué par Pierre-Louis Laget, Service de l'Inventaire général du patrimoine culturel, région Nord-Pas-de-Calais.

16. Toulier, Bernard. À l'origine des établissements climatologiques en bord de mer : hôpitaux marins et colonies de vacances (1847-1919). Les 15 glorieuses de l'architecture sanatoriale. Assy : CREHA, 2006.

17. Varrentrapp, Dct. Les colonies d'écoliers en vacances. Quatrième congrès international d'hygiène et de démographie à Genève (4-9 septembre 1882), t. 1. Genève : H. Georg libraire éditeur, 1883, p. 163.

18. Congrès national des colonies de vacances, 1906 (I) Bordeaux ; 1908 (II) Saint-Quentin ; 1909 (III) Toulouse ; 1910 (IV) Paris ; 1922 (V) Marseille ; 1923 (VI) Strasbourg ; 1925 (VII) Saint- 
Etienne ; 1927 (VIII) Reims ; 1929 (IX) Pau (ce IXe congrès national constitue le $1^{\text {er }}$ congrès international des colonies de vacances).

19. D'après Rey-Herme, les colonies s'implantent en Seine-et-Marne, dans la Nièvre, et le Loiret en plaçant les enfants chez l'habitant. L'association aurait construit deux édifices à Montmajoult (Oise), La Clef des champs (1891) pour les filles et La Sapinière (1896) pour les garçons. À partir de 1889, elle se tourne vers la Manche et achète deux villas à Ver-sur-Mer en 1894 et 1895., Brise de mer et Etoile de mer. En 1899, l'Oeuvre possède deux autres maisons près de Gisors (Eure). D'après Bompard, Raoul. Les colonies scolaires en France. La Presse médicale, n 66, 17 août 1901.

20. L'Oeuvre des colonies de vacances est une branche spéciale dérivée en 1889 de l'Oeuvre de la Chaussée du Maine, fondée en 1871. D'après Rey-Herme, le choix s se porte en 1889 sur Les Bézards, village du Loiret déjà investi précédemment par l'Oeuvre des trois semaines pour ensuite essaimer dans les villages alentours. À partir de 1889, elle se tourne vers les sites balnéaires de la Manche et réutilise des chalets de bord de mer à Onival (Somme) puis à Coutainville (Manche) et s'étend à la périphérie de la capitale à Jouy-en-Josas (Yvelines).

21. Voir dans la Base Mérimée : notice IA00028270. L'histoire de l'usage de ce bâtiment pour une colonie reste à préciser.

22. Née en 1907, l'Union parisienne des colonies de vacances devient deux ans plus tard l'Union nationale des colonies de vacances et œuvres du grand air, puis en 1934 Union française des colonies de vacances, actuellement Union française des centres de vacances (UFCV).

23. Jayle, L. Les colonies de vacances. La Presse médicale, nº 63, 7 août 1909, p. 619-626.

24. Loi du 10 mars 1867 instituant la Caisse des écoles (art.15). Loi du 23 mars 1882 tendant à l'obligation de créer, dans chaque commune, une Caisse des écoles (art.17).

25. Cottinet, Edmond. Instruction sur la formation et le fonctionnement des colonies de vacances. Paris : Imp. Chaix, 1887.

26. Renseignement aimablement communiqué par Jean-Marie Bataille.

27. Carte extraite de La Presse médicale, n 63, 7 août 1909, p. 621.

28. Hubert, Corinne. Demain on part en colo. Les premières colonies de vacances de l'actuel Valde-Marne sous la III ${ }^{e}$ République. Fédération des Soc. hist. et archéol. de Paris et Ile-deFrance, t. 42, 1991, p. 287-325.

29. Varrentrapp, Dct. Les colonies d'écoliers en vacances. Quatrième congrès international d'hygiène et de démographie à Genève (4-9 septembre 1882), t. 1. Genève : H. Georg libraire éditeur, 1883, p. 163.

30. Landouzy, L. La défense contre la tuberculose Armes préventives. Les colonies de vacances en France. La Presse médicale, $\mathbf{n}^{\circ}$ 86, 26 octobre 1901, p. 128.

31. À titre d'exemple, la « colonie rurale » est encore en usage à Suresnes (Hauts-de-Seine), entre les deux guerres.

32. Hubert, Corinne. Demain on part en colo. Les premières colonies de vacances de l'actuel Valde-Marne sous la $\mathrm{III}^{\mathrm{e}}$ République. Fédération des Soc. hist. et archéol. de Paris et Ile-deFrance, t. 42, 1991, p. 317.

33. Coutureau, Eric. Villégiature. Yeu et Noirmoutier. Iles de Vendée. Paris : Imp. Nationale, 1994, p. 421-422.

34. Voir dans la Base Mérimée : notice IA00122106.

35. Voir dans la Base Mérimée : notice IA39000487. Classé MH en 1994.

36. Voir dans la Base Mérimée: notice IA78000020, p.1-9. BUSSIÈRE, Roselyne. Le passé recomposé. Saint-Germain-en-Laye. 1800-1940. Paris : APIF, 1997, p. 9 (photo).

37. Colonie scolaire de Mers-les-Bains. La Construction moderne,1906-1907, p. 135-137, pl. 29-30, fig. [plans, coupes, élévations, détails]. Une carte postale du début du $\mathrm{XX}^{\mathrm{e}}$ siècle représentant cette colonie mentionne: «MERS.- Colonie Scolaire de Saint-Maur-les-Fossés en villégiature ». A.D. Val-de-Marne, 2Fi Saint-Maur 294, repro. Hubert, Corinne. Demain on part en colo. Les premières colonies de vacances de l'actuel Val-de-Marne sous la III République. 
Fédération des Soc. hist. et archéol. de Paris et Ile-de-France, t. 42, 1991, p. 323. Renseignement aimablement communiqué par Elisabeth Justome.

38. Renseignement aimablement communiqué par Pierre-Louis Laget, Service de l'Inventaire général du patrimoine culturel, région Nord-Pas-de-Calais.

39. Les colonies et camps de vacances sont des établissements à fonctionnement temporaire, ne recevant pas d'enfants malades, mais des enfants ayant besoin d'un changement de climat. Une variante de ces colonies, la colonie sanitaire, reçoit des enfants débiles ; le contrôle médical y est plus strict. En 1942, la définition de la colonie sanitaire est plus précise. Elle accueille les enfants ou convalescents non contagieux qui présentent soit une primo-infection tuberculeuse, soit une autre affection médicale ou chirurgicale entraînant une convalescence prolongée.

40. Vacances et loisirs. Architecture d'aujourd'hui, $\mathrm{n}^{\circ} 7$, juillet 1939. Numéro spécial paru à la suite de toutes ces nouvelles instructions administratives.

41. Cette réglementation est à comparer avec la recommandation donnée en 1924 par le docteur Dequidt et Mme Gévin Cassal. « ...les colonies de vacances sont installées loin des agglomérations, autant que possible sur un terrain pittoresque, à l'horizon étendu, bien exposé, abrité des vents et sur un sol en pente et perméable, susceptible de jolies excursions ». Ministère de l'Intérieur, ministère du Travail et de l'Hygiène. Rapport présenté par l'inspection générale des services administratifs. Melun : Imprimerie administrative, 1924, p. 87

42. Downs, Laura Lee. L'avenir de la jeune fille : les filles dans les colonies de vacances 1884-1860. In Bruit Zaidman, Louise, Houbre, Gabrielle, Klapisch-Zuber, Christiane, Schmitt Pantel, Pauline (dir.). Le corps des jeunes filles de l'Antiquité à nos jours. Paris : Perrin, p. 201.

43. Sur une centaine de colonies de vacances signalées dans la Base Mérimée du ministère de la Culture, près des $60 \%$ sont d'anciens châteaux.

44. Voir dans la Base Mérimée : notice IA91000178.

45. Voir dans la Base Mérimée : notice IA00123919.

46. Voir dans la Base Mérimée : notice IA00073820.

47. Le long de la côte est de l'Ile de Ré, le Fort de la Prée, à La Flotte a été déclassé en 1934 et remis aux domaines en 1948. Durant ces années, il a hébergé des colonies de vacances. Vendu en 1949 à une association du département de l'Eure (?), les colonies de vacances continuent à camper au pied du bâtiment jusque dans les années 1970.

48. Voir dans la Base Mérimée : notice IA00127665.

49. Zolty, Bernard. Les colonies de vacances de Juifs immigrés. Voir le site: http:// www.sdv.fr/judaisme/histoire/document/colos/ujre.htm

50. Cette initiative est soutenue par une association créée en mai 1943 par le pasteur J. Jousselin, le Comité protestant des colonies de vacances. Voir le site : http://cpcv.fc.free.fr/histoire.htm

51. Maison dite des Enfants d'Izieu. Inscription Monuments Historiques, 26/03/1991. Voir dans la Base Mérimée : notice PA00116609.

52. Hubert, Corinne. Demain on part en colo. Les premières colonies de vacances de l'actuel Valde-Marne sous la III ${ }^{e}$ République. Fédération des Soc. hist. et archéol. de Paris et Ile-deFrance, t. 42, 1991, p. 320.

53. Colonie de vacances de La Meilleraie. Architecte: Henri Pacon. Architecture d'aujourd'hui, $\mathrm{n}^{\circ} 7$, juillet 1939, p. 13.

54. Ministère de l'Intérieur, ministère du Travail et de l'Hygiène. Rapport présenté par l'inspection générale des services administratifs. Melun: Imprimerie administrative, 1924, p. 96.

55. Coutureau, Eric. Villégiature. Yeu et Noirmoutier. Iles de Vendée. Paris : Imp. Nationale, 1994, p. 422. Voir photo carte postale ancienne

56. L'établissement, ouvert de mai à septembre, est destiné à la convalescence des enfants parisiens et de sa banlieue. Dans le grenier, une pièce est aménagée pour que les enfants puissent recevoir des rayons ultra-violets. Voir dans la Base Mérimée : notice IA22000308. 
57. L'Enfance coopérative, créée en 1920 a pour objet la création et la gestion de colonies de vacances, orphelinats, maisons de convalescence, préventorium, camps de vacances et auberges de la Jeunesse.

58. L. Clément-Camus est l'architecte de l'association de l'Enfance coopérative. Il est aussi l'auteur de la colonie de vacances de La Maison-Joyeuse à Gérardmer dans les Vosges et de l'aérium de Montplaisir à Saint-Trojan-les-Bains sur l'île d'Oléron. Il participe avec d'autres architectes à la construction de la cité-jardin de Draveil (Essonne).

59. Voir dans la Base Mérimée : notice IA00073763 ; notice PA17000066. La colonie est inscrite au titre de la loi sur les monuments historiques par arrêté du 23 juillet 2004. Dossier aimablement communiqué par M. Dupuis, Centre régional de documentation du patrimoine, Poitiers.

60. Francis Jourdain (1876-1958) a été peintre, créateur de meubles et de décorations d'intérieurs, de céramiques, et d'autres objets d'arts décoratifs. Il invente un système de meubles interchangeables bon marché destiné à la clientèle populaire. En 1919, il ouvre une boutique de céramiques, tissus, luminaires et autres objets décoratifs d'un style résolument moderne.

61. Cartes postales A.P., aimablement mises à notre disposition par Quentin Joste.

62. Coutureau, Eric. Villégiature. Yeu et Noirmoutier. Iles de Vendée. Paris: Imp. Nationale, 1994, p. 422. Voir vue ancienne et vue actuelle.

63. Premier congrès international des écoles de plein air en la faculté de médecine de Paris 24-28 juin 1922. Paris : A. Maloine, 1925, p. 144.

64. JO 19 septembre 1923.

65. Châtelet, Anne-Marie. Des idées aux bâtiments : l'essor des écoles de plein air en France. Châtelet, Anne-Marie, Lerch, Dominique, Luc, Jean-Noël (dir.). L'école de plein air. Paris: Editions Recherches, 2003, p. 168-189.

66. Greber, Jacques. La lutte contre la tuberculose à Roubaix. Terrain de jeux, écoles en plein air, colonie de vacances. Le Monde illustré, 5 mars 1923, p. 40-41. Canneva-Tétu, Odile, Lefebvre, Anne. Roubaix, une ville née de l'industrie. Lille: La Voix du Nord, 2000, p. 58-59 (Coll. Itinéraires du patrimoine, $\left.\mathrm{n}^{\circ} 205\right)$.

67. Voir exemples édifiés entre 1922 et 1939 dans Architecture d'aujourd'hui, n 7, 1939.

68. Album-souvenir de Colleville-sur-Orne par Hermanville-sur-Mer (Calvados). Caen: ๔uvre des colonies scolaires parisiennes, s.d. [album de 20 cartes postales].

69. Jean Zay et la politique scolaire du Front populaire. Orléans : CDAL, 1982, p. 29.

70. Laroche, Claude. Hossegor, 1923-1939: Architecture et identité régionale. Bordeaux : APIA/Le festin, 1993, p. 62-65.

71. Les parcs landais pour la jeunesse française. Architecture d'aujourd'hui, nº 7 , juillet 1939, p. 11.

72. Dossier documentaire aimablement communiqué par Claude Laroche, disponible au Centre de documentation, service de l'Inventaire général du patrimoine culturel d'Aquitaine.

73. Colonie de vacances. Pierre Forestier, architecte. Architecture d'aujourd'hui, $\mathrm{n}^{\circ} 7$, juillet 1939, p. 17-19.

74. Le séjour dure cinq semaines, entre le 10 juillet et le 25 septembre.

75. Ministère de l'Education nationale, secrétariat d'état à l'enseignement technique, à la jeunesse et aux sports, direction générale de la jeunesse et des sports. Installation et aménagement des colonies de vacances. Paris: Imprimerie nationale, 1949. Document aimablement communiqué par Pascal Blum.

76. Ricardeau, M. Rapport du groupe de travail "équipement de zones» au premier ministre et au haut comité de la jeunesse, commission équipement et animation. Paris, juin 1963.

77. Archives direction départementale de la jeunesse et des sports, liste de déclaration des centres d'accueil pour les mineurs, 1966. Dépouillement Maryline Doutre. 
78. Voir concours d'architecture pour la conception de centres collectifs sportifs en altitude à usage hivernal. Architecture d'aujourd'hui, n 1, 1937.

79. Installation et aménagement des colonies de vacances, 1949, p. 8-10. D'après une étude de M. Romanet sur l'implantation des colonies de vacances. Vers l'Education nouvelle, n 29-30, 1948. 80. Installation et aménagement des colonies de vacances, 1949, p. 13-14. D'après une étude de M. Romanet sur l'implantation des colonies de vacances. Vers l'Education nouvelle, $n^{\circ} 29-30,1948$. 81. Vers 1948, à Ronce-les-Bains en Charente-Maritime, l'architecte Olivier Rabaud organise sa colonie autour du concept de «maisons ». Chaque maison comprend quatre dortoirs de 12 enfants construite selon les principes des Instructions de 1949. Colonie de vacances permanente à Ronce-les-Bains. Olivier Rabaud, architecte DPLG. L'architecture française, $\mathrm{n}^{\circ} 89-90,1949$, p. $22-26$.

82. Exemple du dortoir de la colonie de la Drôme, édifiée à Cavalière, Cap Nègre (Var) vers 1950.

83. Dans les années 1960-1970, la caisse centrale d'activités sociales (CCAS) du personnel des industries électrique et gazière édite une carte de France routière Michelin avec l'implantation des centres de vacances pour enfants et pour adultes, accessibles aux salariés de l'entreprise et à leur famille.

84. Exemple de la colonie des Trois Doms de la SNCF à Montdidier (Somme). Appartenant à la SNCF qui aujourd'hui en assure la gestion à travers le Comité Central d'Entreprise (CCE), le site des Trois Doms était à l'origine un ancien relais de locomotives à vapeur qui, après transformation, a accueilli la première "colonie de vacances" d'Europe. La SNCF convertit d'anciennes gares désaffectées en colonies de vacances comme celle de Ribérac (Dordogne).

85. Exemple de la colonie de Pontcharra-sur-Bréda (Isère). La colonie est logée dans la cité-jardin de la Viscamine, construite en style-néo-basque pour la compagnie des Houillères de La Loire.

86. Exemple de la colonie du comité d'entreprise Renault à Brignognan-Plages (Finistère).

87. Exemple de la Société française des Pétroles B.P. qui installe sa colonie au château de Lambertie (Haute-Vienne).

88. Voir dans la Base Mérimée : notice IA00024362.

89. Cartes postales et documentation aimablement communiquées par Christian Chénault.

90. Voir dans la Base Mérimée: notice IA67008944. Inscription Monuments Historiques 10/04/1996.

91. Installation et aménagement des colonies de vacances, 1949, p.6. D'après une étude de M. Romanet sur l'implantation des colonies de vacances. Vers l'Education nouvelle, $\mathrm{n}^{\circ} 29-30,1948$.

92. Peatrik, François, Brauner, Alfred. Camps de vacances pour enfants, jeunes, adultes, familles, L'architecture française, $\mathrm{n}^{\circ} 89-90,1949$, p. 13. L'article reprend les centres de vacances présentés à l'Exposition de l'Habitation et de l'Urbanisme de 1947 à Paris, avec l'aide du Bureau d'études de l'association Tourisme et travail.

93. Voir dans la Base Mérimée : notice IA00130578. Voir la vue extérieure d'un des bâtiments, dans la Base Mémoire: photographies IVR93_94831068ZA et l'intérieur du dortoir IVR93_94830613ZA.

94. Colonie de vacances de Montélimar. Le dortoir et les lavabos en arrière-plan. Vue intérieure. Base Mémoire IVR93_94831066ZA.

95. Voir dans la Base Mérimée : notice IA38000003.

96. Voir dans la Base Mérimée : notice IA65000315.

97. Voir dans la Base Patrimoine architectural et mobilier en Bretagne : notice IA22000454.

98. Voir dans la Base Mérimée : notice IA00067178.

99. Voir dans la Base Mérimée : notice IA04000118. Homps-Brousse, Hélène. Villas en Ubaye, retour du Mexique (Alpes-de-Haute-Provence)... Aix-en-Provence: Association pour le Patrimoine de Provence, 2002. Voir aussi son article : Les références culturelles des émigrants mexicains de la vallée de Barcelonnette: du grand magasin à la villa [document 
électronique]. Paris: Ministère de la Culture et de la Communication, revue In Situ, $\mathrm{n}^{\circ} 4$, mars 2004.

100. Voir dans la Base Mérimée : notice IA22000337.

101. Voir dans la Base Mérimée : notice IA00136070.

102. Voir dans la Base Mérimée : notice IA39000502.

103. Voir dans la Base Mérimée : notice IA39000377.

104. Voir dans la Base Mérimée : notice IA39000478.

105. Peatrick, François, Brauner, Alfred. Camps de vacances pour enfants, jeunes, adultes et familles, L'architecture française, $n^{\circ}$ 89-90, 1949, p. 11-13.

106. Dès 1928, le Père Fillière prend la direction de la colonie Ozanam de Jouy-sur-Morin en Seine-et-Marne et fonde la cité des jeunes Notre-Dame.

107. Joly, Pierre, Joly, Robert. L'architecte André Lurçat. Paris : Picard, 1995.

108. Colonie de plein air à Mériel. André Lurçat architecte. L'architecture d'aujourd'hui, $n^{\circ} 47$, avril-mai 1953, p. 70.

109. Colonie de vacances à Saint-Servan. Raymond Gravereaux et Raymond Lopez, architectes. L'architecture d'aujourd'hui, n 47, avril-mai 1953, p.71. Abram, Joseph. L'architecture moderne en France, tome 2... 1940-1960. Paris : Picard, 1999, p. 305.

110. Voir Archives de l'INA, Les actualités françaises, 31/08/1950 ; www.ina.fr.

111. Coll. Construction, installation, aménagement, équipement des centres de vacances d'enfants et d'adolescents. Paris : CEMEA, 1965. Ouvrage aimablement communiqué par Pascal Blum.

112. Prescriptions relatives aux installations et aux équipements des établissements de vacances. Arrêté ministériel du 20 novembre 1964.

113. L'architecte Roland Schweitzer, un des spécialistes de l'architecture en bois a construit de nombreux centres de vacances : au Pré Long à Murol, Puy-de-Dôme (1973) ou au château de La Carte à Ballan-Miré, Indre-et-Loire (1977) ; des villages de jeunes au domaine du Four à Cieux, Haute-Vienne (1972) ; des villages de vacances : au Lac du Gril à Egletons, Corrèze (1969); des auberges de jeunesse : Vénissieux, Rhône (1965-1973), Le Moulin Blanc à Brest, Finistère (1983) ; des centres internationaux pour les jeunes : à Choisy-le-Roi, Val-de-Marne (1961-1969)... et le centre de formation du CEMEA de Bénouville près de Caen, Calvados (1972); www.archiguide.com

114. Renseignement aimablement communiqué par Maryline Doutre.

115. Colonies de vacances d'enfants. Le Moniteur des travaux publics et du bâtiment, avril 1972, numéro hors-série, Les équipements sportifs et socio-éducatifs, 7e édit. revue et augmentée, p. 390.

116. Exemple du centre de mer de Saint-Philibert (Morbihan) construit par l'architecte J. Starkier dans les années 1970. Colonies de vacances d'enfants. Le Moniteur des travaux publics et du bâtiment, avril 1972, numéro hors-série, Les équipements sportifs et socio-éducatifs, 7e édit. revue et augmentée, p. 392-393.

117. Information aimablement fournie par Jean-Marie Bataille.

118. Les classes de neige sont officiellement reconnues par la circulaire du 27 novembre 1964, soit plus de dix ans après le lancement des premières expériences. BO de l'Education nationale du 10/12/1964.

119. Voir dans cet ouvrage Jean-François Lyon-Caen: Les installations pour colonies de vacances en montagne, une architecture de plein air ? et Jean-Marie Bataille : Le patrimoine des colonies de vacances, un objet peu connu.

120. Colonies de vacances d'enfants. Le Moniteur des travaux publics et du bâtiment, avril 1972, numéro hors-série, Les équipements sportifs et socio-éducatifs, 7e édit. revue et augmentée, p. 385-406. La première édition de ce numéro hors-série a été publiée en juin 1962 et la 11e édition en 1993. 
121. Depuis 1974, l'appellation « centre de vacances " remplace celle de «colonie de vacances ». Houssaye, Jean. De la colo. au centre aéré: l'enfermement. Autrement, nº 10, sept.1977, p. 182-190.

122. Dans le Finistère, les établissements scolaires hébergeant des colonies ont diminué de plus $50 \%$ en l'espace de 40 ans. En 1967, ils représentaient encore la majorité du corpus, avec plus de $60 \%$, alors qu'en 2007 ils chutent à près de $27 \%$ du corpus recensé. Renseignement aimablement communiqué par Maryline Doutre.

123. Circulaire du ministère de la Jeunesse et des Sports sur la rénovation des centres de vacances du 28 novembre 1977.

124. Daurel, Julie. La jolie colonie de vacances. Côté Ouest, $n^{\circ} 70$, juillet 2007, p. 156-157. Renseignement aimablement communiqué par Isabelle Balsamo.

125. Renseignement aimablement fourni par Marilyne Doutre.

126. Renseignement aimablement fourni par Jean-Marie Bataille.

127. Langeois, Cécile. Les centres de vacances. Données chiffrées 1994-2002. Note jeunesse et vie associative, $\mathrm{n}^{\circ} 04.01,2003$.

128. Ministère de la Jeunesse et des Sports, direction de l'administration générale. Recensement des centres de vacances. Paris, 1994.

129. Équipements sportifs et socio-éducatifs, t. 1 . Le Moniteur des travaux publics et du bâtiment, hors-série, 1993, 11e édit., p. 361-362.

\section{RÉSUMÉS}

Il est urgent de porter un nouveau regard sur le patrimoine des centres de vacances, qui ont échappé jusqu'à ce jour au mouvement d'élargissement de la notion de patrimoine. Le patrimoine immobilier des colonies de vacances est étroitement lié au patrimoine éducatif, lieu d'expérimentation privilégié des méthodes pédagogiques. Le patrimoine des centres de vacances participe à la lutte contre l'exclusion et à l'offre diversifiée de loisirs et de vacances pour les jeunes. Le centre de vacances reste un facteur de développement économique, intégré à l'aménagement du territoire, notamment dans le secteur rural et les régions de montagne.

It is urgent to bring a new approach to the heritage of the holiday centers, which have up to today escaped the movement of widening of the concept of cultural and architectural heritage. The real estate holding of the holiday camps is closely related to educational heritage, the privileged place of experimentation for pedagogical methods. The heritage of the holiday centers takes part in the struggle against exclusion and in the diversified offer of leisure and holidays for young people. The holiday centers remain an economic factor of development, integrated into regional planning, in particular in the rural sector and the mountain areas. 


\section{INDEX}

Mots-clés : hygiène, tuberculose, théories pédagogiques, inventaire, villégiature, Ministère de la jeunesse et des sports, centre de vacances, camp de vacances, Wilhelm Bion, Zurich, colonies d'écoliers en vacances, colonie pénitentiaire, asile, Charles Lucas, colonie agricole, colonie maritime, colonie industrielle, établissement pénitencier, Congrégation du Bon-Pasteur, NotreDame de Charité du Refuge, Sœurs des prisons, hospice, sociétés de charité, Coraly Hinsch, Maison Krüger, Hôpital marin, sanatorium, Lazaret de Sète, Asile Dollfus, Lord Brougham, Riviera méditerranéenne, caisse des écoles de Saint-Mandé, Sanatorium Parmentier, Sanatorium Bouville, Sanatorium de Zuydcoote, préventorium, école de plein air, Fédération nationale des colonies de vacances et œuvres de grand air, Edmond Cottinet, Pasteur Lorriaux, Æuvre des Trois semaines, CEuvre de la Chaussée du Maine, Elise de Préssenssé, CEuvre des colonies de vacances, Louis Comte, Æuvre des enfants à la montagne, Henri Leehnardt, Æuvre israélite des séjours à la campagne, patronage paroissial, colonies catholiques, Abbé Pitray, colonie Edouard, CEuvre fraternelle des Enfants de France, Alfred Brauner, François Peatrik, Françoise Riesel-Brauner, Porte A. architecte, village d'enfants, André Lurçat, Raymond Lopez, Raymond Gravereaux, Roland Schweitzer, H. Chollet architecte, J. Le Berre architecte, André Gomis architecte, Stephan Hallier, aménagement du territoire, E Euvre mutuelle des colonies de vacances, Euvres des comités de patronage des paroisses, Docteur Varrentrapp, Pasteur Bion, Rey-Herme, Chanoine Sobeaux, Villa Saint-Joseph, Château de Syam, Champonnois l'aîné, Schacre, villa de villégiature, Paul-Louis Renaud, villa Scolaire, Fernand Ratier, Alexandre Maistrasse, Charles Berger, CEuvre des vacances populaires enfantines, famille Oberkampf, Raoul Dautry, Henri Pacon, Paul Gélis architecte, Fondation May Lockwood, André Hellé dessinateur, Francis Jourdain, Couillaud architecte, Jacques Greber architecte, CEuvre universitaire des enfants du Loiret en vacances, Alfred Eluère, Marcel Le Gal architecte, Pierre Forestier architecte, cité ouvrière, parcs et jardins, Roland Macchi, Pierre Andra, Paul Marme, centre de loisir sans hébergement, centre de loisir communal sans hébergement

\section{AUTEUR}

\section{BERNARD TOULIER}

Conservateur du patrimoine. Sous-direction de l'archéologie, de l'ethnologie, de l'inventaire et du système d'information, direction de l'architecture et du patrimoine.

bernard.toulier@culture.gouv.fr 